THAIANA HELENA ROMA SANTIAGO

\title{
CULTURA ORGANIZACIONAL PARA SEGURANÇA DO PACIENTE EM TERAPIA INTENSIVA: COMPARAÇÃO DE DOIS INSTRUMENTOS HOSPITAL SURVEY ON PATIENT SAFETY CULTURE (HSOPSC) E SAFETY ATTITUDES QUESTIONNAIRE (SAQ)
}

\begin{abstract}
Dissertação apresentada ao Programa de Pós-Graduação em Enfermagem na Saúde do Adulto da Escola de Enfermagem da Universidade de São Paulo para obtenção do título de Mestre

Área de concentração: Enfermagem na Saúde do Adulto

Orientadora: Prof ${ }^{\mathrm{a}} \mathrm{Dr}^{\mathrm{a}}$ Ruth Natalia Teresa Turrini
\end{abstract}

Versão corrigida. A versão original encontra-se na Biblioteca da Escola da Enfermagem da Universidade de São Paulo

São Paulo 
AUTORIZO A REPRODUÇÃO E DIVULGAÇÃO TOTAL OU PARCIAL DESTE TRABALHO, POR QUALQUER MEIO CONVENCIONAL OU ELETRÔNICO, PARA FINS DE ESTUDO E PESQUISA, DESDE QUE CITADA A FONTE.

Assinatura:

Data:

Catalogação na Publicação (CIP)

Biblioteca "Wanda de Aguiar Horta"

Escola de Enfermagem da Universidade de São Paulo

Santiago, Thaiana Helena Roma

Cultura organizacional para segurança do paciente em terapia intensiva: comparação de dois instrumentos Hospital Survey on Patient Safety Culture (HSOPSC) e Safety Attitudes Questionnaire (SAQ)/ Thaiana Helena Roma Santiago. São Paulo, 2014.

$110 \mathrm{p}$.

Dissertação (Mestrado) - Escola de Enfermagem da Universidade de São Paulo.

Orientadora: Prof. ㅁ Dr. . Ruth Natalia Teresa Turrini

Área de concentração: Enfermagem na Saúde do Adulto 
Nome: Thaiana Helena Roma Santiago

Titulo: Cultura organizacional para segurança do paciente em terapia intensiva: comparação de dois instrumentos Hospital Survey on Patient Safety Culture (HSOPSC) e Safety Attitudes Questionnaire (SAQ)

Dissertação apresentada ao Programa de Pós-Graduação em Enfermagem em Saúde do Adulto da Escola de Enfermagem da Universidade de São Paulo para obtenção do título de Mestre em Ciências.

Aprovado em:

Banca Examinadora

Prof. Dr. Instituição:

Julgamento: Assinatura:

Prof. Dr. Instituição:

Julgamento: Assinatura:

Prof. Dr. Instituição:

Julgamento: Assinatura: 


\section{DEDICATÓRIA}

A Deus, a minha família e ao Neto, pelo companheirismo, amor, carinho e compreensão. 


\section{AGRADECIMENTOS}

À minha orientadora, Prof ${ }^{\underline{a}} \mathrm{Dr}^{\mathrm{a}}$ Ruth Natalia Turrini, pelos ensinamentos, paciência e disponibilidade, fundamentais para o meu desenvolvimento e para a finalização deste trabalho.

A Ana Paula Terra Miethke, por todo o suporte, carinho e incentivo.

Às professoras Drª Marta Maria Melleiro e Dra Elena Bohomol, pelas valiosas contribuições no exame de qualificação.

À professora $\mathrm{Dr}^{\mathrm{a}}$ Rubia Aparecida Lacerda pela contribuição neste trabalho.

Aos preciosos amigos, Murilo, Audrey, Leilane, Flavia, o apoio de vocês foi imprescindível nesta empreitada.

A equipe do Hospital Estadual Sumaré, em especial a Dra. Dulce e a Joyce.

Muitas pessoas não mencionadas tiveram papel importante na construção deste trabalho, serei eternamente grata a todos. 
SANTIAGO THR. Cultura organizacional para segurança do paciente em terapia intensiva: comparação de dois instrumentos Hospital Survey On Patient Safety Culture (HSOPSC) e Safety Attitudes Questionnaire (SAQ) [dissertação]. São Paulo: Escola de Enfermagem, Universidade de São Paulo: 2014

\section{RESUMO}

Introdução: A segurança do paciente tornou-se uma preocupação formal em diversos sistemas de saúde no mundo nas últimas décadas. Em 2004 a Organização Mundial da Saúde (OMS) propõe a Aliança para segurança do paciente e aponta a avaliação da cultura de segurança nas instituições de saúde como um dos aspectos chave para esse processo. Método: pesquisa transversal de abordagem quantitativa, realizada em um hospital de ensino no interior do estado de são Paulo entre os meses de março e abril de 2014. A população de estudo foi composta por todos os profissionais que faziam parte da escala de trabalho das unidades de terapia intensiva (UTI) adulto, pediátrica e neonatal e não se enquadravam no critério de exclusão (menos de 6 meses na unidade). Foram aplicados dois instrumentos para avaliação da cultura e clima de segurança do paciente, o Hospital Survey on Patient Safety (HSOPSC) e o Safety Attitudes Questionnaire (SAQ), e um instrumento para levantamento das informações sociodemográficas e profissionais. Para a análise de dados utilizou-se o teste de confiabilidade das escalas pelo Alfa de Cronbach. Foi verificada a presença de associações das escalas com variáveis de estudo pelo quiquadrado de Pearson ou teste exato de Fischer nas variáveis qualitativas, a ANOVA para as variáveis quantitativas. A presença de correlação entre os instrumentos SAQ e HPSOPSC foi verificada pelo teste de correlação de Pearson. Resultado: os dados sociodemográficos quanto a sexo e idade e cargo foram homogêneos nas três UTI. A UTI Neonatal possuía profissionais com mais tempo de trabalho na unidade e na especialidade quando comparada as demais unidades. Ambas as escalas apresentaram boa confiabilidade pelo alfa de Cronbach, 0,853 para o SAQ e 0,889 para o HSPOSC. $\mathrm{Na}$ análise dos domínios do SAQ, observou-se pontuação $\leq 62$ para as "Condições de Trabalho e para "Percepções da Gerência, enquanto para o HSPOSC a dimensão "Resposta não punitiva aos erros" obteve o menor percentual de repostas positivas $(29,6 \%)$, e as dimensões "Abertura da comunicação" e "Retorno da comunicação e das informações sobre o erro" uma proporção de neutros maior de 30\%. A nota total de segurança do paciente pelo HSPOSC foi de $85 \%$ (somados ótima e muito boa). Analisando-se o comportamento das UTIs através de cada escala, a UTI Neonatal apresentou maior satisfação no trabalho do que as demais UTIs. A UTI Adulto apresentou menores pontuações em cada domínio quando comparada com as demais e para os domínios do HSPOSC somente o domínio "Abertura de comunicação" obteve uma proporção de respostas positivas discretamente superior às demais UTIs. A correlação entre as escalas através da correlação de Pearson foi de força moderada (coeficiente de Pearson de 0,656). As respostas abertas evidenciaram que as mudanças ocorridas no hospital em decorrência dos processos de acreditação, contribuíram para a melhor percepção dos profissionais sobre a segurança do paciente. Conclusões: há diferenças de percepções quanto a segurança do paciente entre as UTIs dentro de um mesmo hospital, o que corrobora com a existência de microculturas locais. As escalas de avaliação de clima/ cultura de segurança do paciente parecem medir fenômenos semelhantes.

PALAVRAS-CHAVE: Segurança do Paciente. Cultura de Segurança. Clima de Segurança. Terapia Intensiva. Enfermagem. 
SANTIAGO THR. Patient Safety Culture in intensive care: comparison of two instruments Hospital Survey on Patient Safety Culture (HSOPSC) and Safety Attitudes Questionnaire (SAQ) [dissertation]. São Paulo: Nursing School, University of São Paulo.

\begin{abstract}
Introduction: Patient safety has become a formal concern in several health systems in the world, in the last decades. In 2004 the World Health Organization (WHO) proposes the Alliance for patient safety and aims safety culture evaluation in healthcare institutions as one of the key aspects to this process. Method: Crosssectional quantitative research approach, performed in a teaching hospital in São Paulo State between the months of March and April 2014. The study population was composed of all the professional who were part of the work schedule of intensive care unit (ICU) adult, pediatric and neonatal and did not fit the exclusion criteria (less than six months in the unit). Two instruments for assessing the culture environment and patient safety, the Hospital Survey on Patient Safety (HSOPSC) the Safety Attitudes Questionnaire (SAQ), and an instrument for survey of demographic and professional information were applied. For data analysis, the test of reliability of the scales by Cronbach's alpha was used. The presence of associations of scales with study variables was checked by Pearson's chi-square test or Fisher's exact test in the qualitative variables, the ANOVA for quantitative variables. The presence of correlation between the SAQ and the HPSOPSC instruments was tested by Pearson correlation test. Result: sociodemographic data regarding gender and age and position were homogenous in the three ICUs. Professional of the Neonatal ICU had worked longer time in this unit and specialty when compared to other units. Both scales showed good reliability by Cronbach's alpha, 0.853 for SAQ and 0.889 for HSPOSC. In the analysis of the SAQ domains, it was observed score $\leq 62$ for "Working Conditions and Perceptions of Management", while for HSPOSC dimension "Non-punitive Response to Error" had the lowest percentage of positive responses (29.6\%), the dimension "Open Communication" and "Return of Communication and Information on the Error" a proportion of neutral responses more than $30 \%$. The total score of patient safety by HSPOSC was $85 \%$ (summed up great and very good). Analyzing the behavior of ICUs through each scale, Neonatal ICU had higher job satisfaction than the other ICUs. Adult ICU had lower scores in each domain compared to other domains and for HSPOSC only the area "Open Communication" obtained the proportion of positive responses slightly superior to the other ICUs. The correlation between the scales through Pearson correlation was of moderate strength (Pearson correlation coefficient of 0.656 ). The open responses showed that changes in hospital as a result of accreditation processes, contributed to a better perception of professionals about patient safety. Conclusions: There are differences in perceptions of patient safety among ICUs within the same hospital, which corroborates the existence of local microcultures. Rating scales of climate/culture of patient safety seems to measure similar phenomena.
\end{abstract}

KEYWORDS: Patient Safety. Safety culture. Safety climate. Intensive care. Nursing. 


\section{Lista de Quadros}

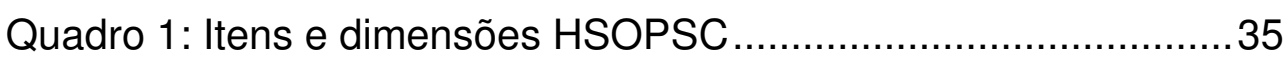

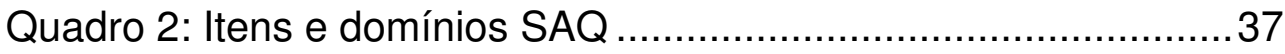




\section{LISTA DE FIGURAS}

Figura 1: Modelo de Acidente Organizacional ...............................21

Figura 2: Modelo de Cultura de Segurança do Paciente .................26

Figura 3: Relação entre as Dimensões do HSOPSC ........................34

Figura 4: Pontuação média do SAQ por Domínios nas UTIs. Sumaré,

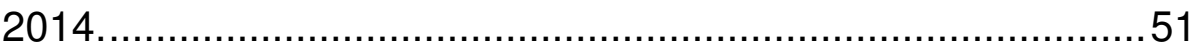

Figura 5: Percentual de respostas positivas por dimensão do HSOPSC nas UTIs. Sumaré, 2014 ....................................... 52

Figura 6 Frequência de respostas sobre a nota de segurança do paciente. Sumaré, 2014........................................................53

Figura 7: Pontuação do SAQ por domínios nas UTIs Adulto, Pediátrica e Neonatal. Sumaré, 2014........................................54

Figura 8: Percentual de respostas positivas, neutras e negativas para as dimensões 1 e 2 da Unidade HSOPSC nas UTIs Adulto, Pediátrica e Neonatal. 56

Figura 9: Percentual de respostas positivas, neutras e negativas para as dimensões 3 e 4 da Unidade HSOPSC nas UTIs Adulto, Pediátrica e Neonatal. 57

Figura 10: Percentual de respostas positivas, neutras e negativas para as dimensões 5 e 6 da Unidade HSOPSC nas UTIs Adulto, Pediátrica e Neonatal. 59

Figura 11: Percentual de respostas positivas, neutras e negativas para as dimensões 7 e 8 da Unidade HSOPSC nas UTIs Adulto, Pediátrica e Neonatal. 60

Figura 12: Percentual de respostas positivas, neutras e negativas para as dimensões 9 e 10 da Unidade HSOPSC nas UTIs Adulto, Pediátrica e Neonatal. 62

Figura 13: Percentual de respostas positivas, neutras e negativas para as dimensões 11 e 12 da Unidade HSOPSC nas UTIs Adulto, Pediátrica e Neonatal. 63

Figura 14: Nota de segurança do paciente por UTI, Sumaré 2014..64 
Figura 15: Número de eventos modificados nos últimos 12 meses

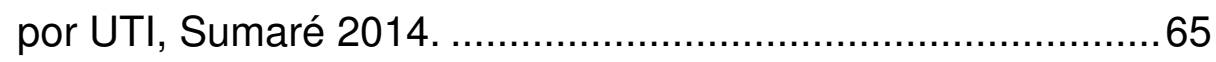

Figura 16: Comparação do Alfa Cronbach- SAQ .............................72

Figura 17: Comparação do Alfa Cronbach-HSOPSC .....................73

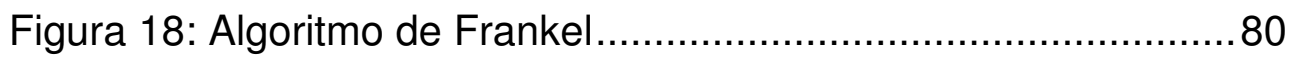




\section{LISTA DE TABELAS}

Tabela 1: Distribuição das variáveis qualitativas relativas aos profissionais de terapia intensiva, por tipo de unidade. Sumaré, 2014. 44

Tabela 2: Distribuição das variáveis relacionadas ao tempo de trabalho e idade dos profissionais de saúde das UTIs. Sumaré, 2014. 45

Tabela 3: Distribuição das variáveis relacionadas ao tempo de trabalho e idade dos profissionais de saúde da UTI Adulto. Sumaré, 2014. 46

Tabela 4: Distribuição das variáveis relacionadas ao tempo de trabalho e idade dos profissionais de saúde da UTI Pediátrica. Sumaré, 2014. 46

Tabela 5: Distribuição das variáveis relacionadas ao tempo de trabalho e idade dos profissionais de saúde da UTI Neonatal. Sumaré, 2014. 47

Tabela 6: Teste de diferença de médias para as variáveis quantitativas e tipo de UTIs. Sumaré, 2014 47

Tabela 7: Teste de diferença de médias para as variáveis quantitativas e categoria profissional. Sumaré, 2014 ............... 48

Tabela 8: Valores de alfa de Cronbach para a escala SAQ e seus domínios. Sumaré, 2014

Tabela 9: Valores de alfa de Cronbach para a escala HSOPSC e suas dimensões. Sumaré, 2014. 50 


\section{LISTA DE SIGLAS}

ANVISA - Agência Nacional de Vigilância Sanitária

CNES - Cadastro Nacional de Estabelecimentos de Saúde

CSS - Culture of Safety Survey

HSOPSC - Hospital Survey on Patient Safety Culture

HTSSCS - Hospital Transfusion Service Safety Culture Survey

IHI - Institute for Healthcare Improvement

IOM - Institute of Medicine

MSS - Medication Safety Self Assessment

NPSF - National Patient Safety Foundation

PSCHO - Patient Safety Culture in Healthcare Organizations

SAQ - Safety Attitudes Questionnarie

SCS - Safety Climate Survey

SLOAPS - Strategies for Leadership: An Organizational Approach to Patient Safety

SUS - Sistema Único de Saúde

UNICAMP - Universidade de Campinas

USP - Universidade de São Paulo

UTI - Unidade de Terapia Intensiva

VHA PSCQ - Veterans Administration Patient Safety Culture Questionnaire

WHO - World Health Organization 


\section{Sumário}

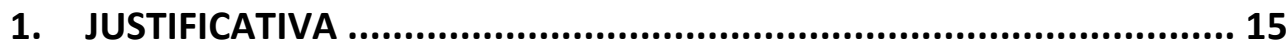

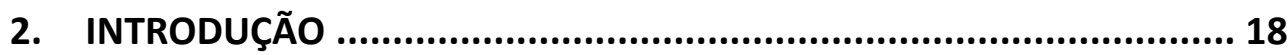

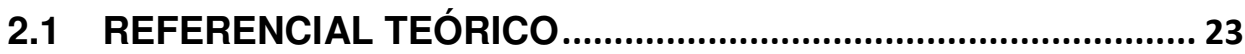

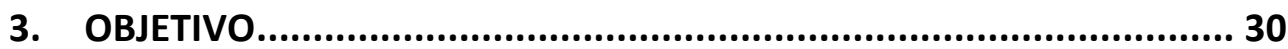

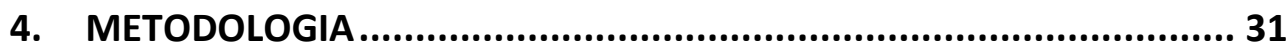

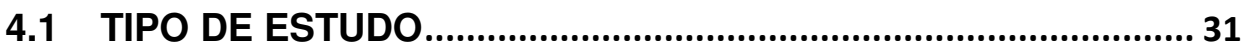

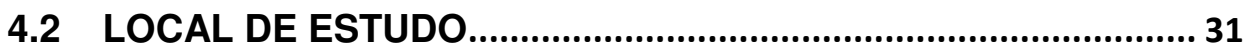

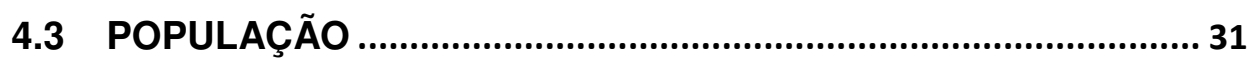

4.4 PROCEDIMENTO DE COLETA DE DADOS ............................... 32

4.5 INSTRUMENTOS DE COLETA ...................................................... 32

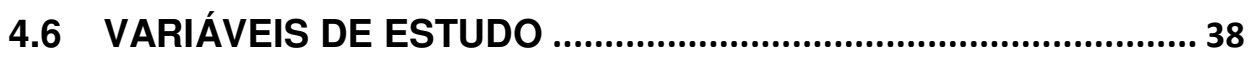

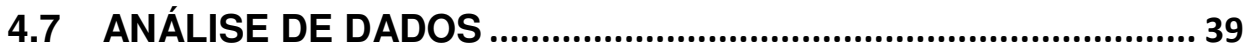

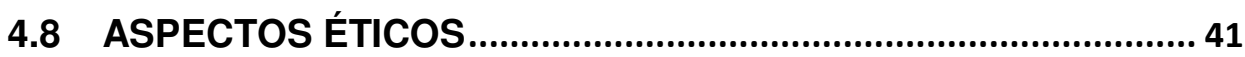

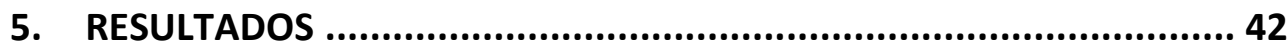

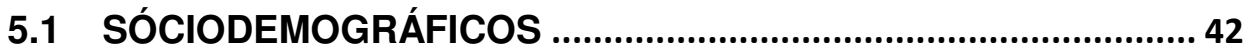

5.2 AVALIAÇÃO DA PERCEPÇÃO DA SEGURANÇA DO PACIENTE SEGUNDO OS INSTRUMENTOS SAQ E HSOPSC............................. 48

5.2.1 Análise das propriedades psicométricas ..................................... 48

5.2.2 Unidades de terapia intensiva agrupadas ....................................50

5.2.3 Comparativo entre as Unidades de Terapia Intensiva Adulto,

Pediátrica e Neonatal utilizando o instrumento SAQ .............................54

5.2.4 Comparativo entre as Unidades de Terapia Intensiva Adulto,

Pediátrica e Neonatal utilizando o instrumento HSOPSC .....................55

5.2.5 Associação entre as escalas e as variáveis sóciodemográfica

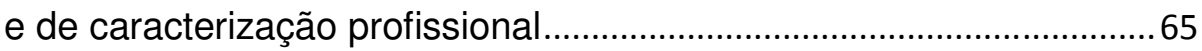

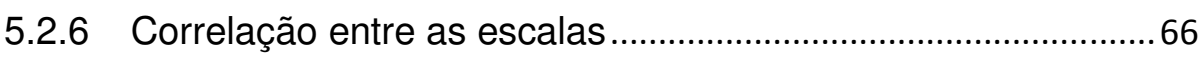

5.2.7 Análise de conteúdo da questão aberta ................................67

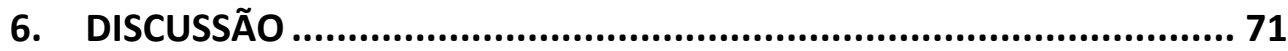

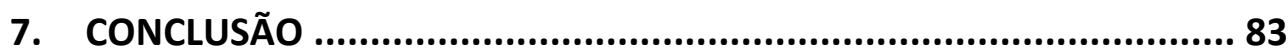

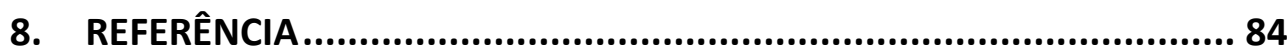

APÊNDICE A - Termo de Consentimento Livre e Esclarecido ................... 90

APÊNDICE B - Informações Sócio-Demográficas .................................. 91

APÊNDICE C - HSOPSC layout alterado ......................................... 92

APÊNDICE D - Dimesnsões HSOPSC e categorias profissionais....................96

ANEXO 1 - SAQ Short Form Validado Brasil ....................................... 97

ANEXO 2 - HSOPSC Validado Brasil .................................................... 98 
ANEXO 3 - CAAE Parecer consubstanciado CEP UNICAMP ................. 105

ANEXO 4 - CAAE Parecer CEP USP ................................................. 108

ANEXO 5 - Carta de autorização hospital ......................................... 109 


\section{JUSTIFICATIVA}

Em minha experiência profissional, na avaliação de práticas de qualidade e segurança em diversas instituições de saúde pelo país, percebo grande diferença entre as organizações.

O impacto dos incidentes assistenciais reflete-se tanto na esfera pessoal, por pacientes e familiares, quanto no âmbito coletivo; oneram o sistema saúde, elevam o tempo de internação e causam prejuízos sociais, entre outros. Como exemplo, citam-se as sequelas permanentes, muitas delas ocorridas em pessoas em idade economicamente ativa, e o aumento do tempo de permanência hospitalar.

A avaliação do desfecho em saúde é pouco utilizada de forma plena. Avaliar os resultados de serviços de saúde, para a maioria das instituições, é de difícil concepção e o mesmo acontece quando se questiona a segurança dentro de um serviço de saúde.

Historicamente, a ideia de primeiro não causar dano, Primun non nocere, marca a formação dos profissionais de saúde. Entretanto, há uma visão bastante pautada na culpa e na responsabilização individual, e uma noção frágil sobre a saúde como sistema.

O comportamento frente à avaliação dos incidentes da assistência, dos erros e eventos adversos variam muito entre instituições e mesmo dentro de uma mesma instituição de saúde.

A preocupação com a segurança do paciente ganhou espaço no cenário mundial, com o lançamento nos Estados Unidos da América há pouco mais de dez anos do polêmico relatório sobre o assunto, nomeado To err is human. Em 2004, a Organização Mundial de Saúde criou a Aliança Mundial para Segurança do Paciente. 
Os reflexos da assistência insegura a saúde estão sendo percebidos, com mais nitidez do que em outras épocas, seja pelo maior acesso a informação por parte da população e pelo aumento populacional, seja pelo sistema de saúde predominantemente hospitalocêntrico.

É importante ressaltar que há uma percepção coletiva de que a assistência à saúde segura e de qualidade é cara, e, portanto, seria difícil conciliar essas características à rentabilidade e sustentabilidade financeiras dos serviços de saúde.

Compreender o sistema de saúde de um modo mais abrangente nos mostra que diversas situações estão presentes quando um evento adverso acontece, e nos faz reconhecer que a saúde é, de fato, um sistema complexo, que precisa ser olhado de modo sistêmico para que as falhas sejam identificadas e as barreiras de segurança sejam estabelecidas.

Em qualquer instituição, inclusive nos serviços de saúde, as pessoas nos mais diferentes cargos e níveis hierárquicos, individual ou coletivamente, notam o "modo de funcionar" do ambiente organizacional onde estão inseridas. Ainda, em um sistema organizacional, o perfil da liderança das equipes também interfere no comportamento dos profissionais, e mostra o que é ou não importante e valorizado naquele espaço.

$\mathrm{Na}$ vida profissional as características do contexto organizacional se associam frequentemente à pressão por produção, grande demanda de pacientes e estilos de gestão com diferentes focos.

Os serviços de saúde, em especial os hospitais, possuem modelo de funcionamento pautado por relações de poder entre categorias profissionais e entre profissionais e pacientes, configurando um ambiente que pouco favorece o questionamento e a discussão franca de problemas. 
Assim, intervir no funcionamento das organizações e, portanto, na cultura organizacional de serviços de saúde, tornando-os mais seguros para os pacientes e trabalhadores, demonstra-se como uma tarefa bastante complexa, que envolve esforços da sociedade, do governo, dos profissionais de saúde e engajamento dos pacientes. E esse parece ser um caminho mandatório nos dias atuais.

Conhecer o clima de segurança do paciente na instituição hospitalar fornece informações importantes e também orienta esforços para que a segurança seja ampliada e melhores práticas de assistência e gestão em saúde sejam adotadas.

Os profissionais de saúde no Brasil passam um período do tempo de sua formação dentro de Serviços de Saúde, sob a forma de estágios curriculares, programas de residência ou especialização. Considerando que os profissionais em formação são um caminho para a mudança do cenário dos serviços de saúde a médio e longo prazo, surge a questão: Como a cultura e o clima de segurança são percebidos pelos profissionais de saúde que trabalham em um hospital de ensino?

Este trabalho tem a proposta de avaliar a percepção dos profissionais de saúde a respeito deste fenômeno em unidades de terapia intensiva adulto, pediátrica e neonatal de um hospital de ensino do município de Sumaré, interior do estado de São Paulo. 


\section{INTRODUÇÃO}

Nas últimas décadas a questão da segurança do paciente se tornou uma preocupação formal em diversos sistemas de saúde no mundo (Carneiro, 2010).

Apesar de discussões recentes, que separam a segurança do paciente da qualidade em saúde, há uma tendência predominante em considerar a primeira como uma dimensão da qualidade em saúde. A qualidade em saúde é definida pelo Institute of Medicine (IOM), como o aumento da probabilidade de desfechos desejados conforme o conhecimento científico vigente (ANVISA, 2013).

Reis (2013) apresenta segurança do paciente como uma dimensão do cuidado em saúde. Para isso, a autora retoma personagens importantes da história da saúde como Florence Nightingale, que relatou a redução na mortalidade dos soldados após intervenções a partir da padronização do cuidado e melhora na higienização.

A National Patient Safety Foundation (NPSF), em seu dicionário de segurança do paciente, destaca o fato de a qualidade hospitalar tradicional não tratar completamente do erro ou da lesão, e este é um aspecto que marca a diferença entre as definições de qualidade e de segurança do paciente. Para a NPSF, a segurança do paciente reside no sistema e também nas pessoas, e deve ser ativamente procurada e estimulada (NPSF, 2013).

O termo segurança do paciente vem sendo frequentemente utilizado nos dias atuais e sua definição tem focado principalmente os danos decorrentes da assistência prestada.

Segundo a Organização Mundial de Saúde (OMS), a segurança do paciente é definida como a redução de danos preveníveis ao paciente durante o processo de assistência a saúde a um mínimo aceitável (WHO, 2009). 
Para Vincent (2009), a segurança do paciente pode ser definida, em sua forma mais simples, como o ato de evitar, prevenir e melhorar os resultados adversos e as lesões originadas no processo de atendimento médico hospitalar. Ainda segundo o autor, o que diferencia a segurança do paciente dos aspectos mais gerais ligados a qualidade do atendimento médico é que a primeira foca o lado negro da qualidade, no atendimento que é realmente prejudicial, e não aquele em que o padrão apenas não seja bom.

O erro médico e os danos causados aos pacientes vêm sendo estudados há séculos, mas, com raras exceções, na área médica e de enfermagem, poucos parecem ter percebido a extensão e a gravidade do problema, ou, se têm conhecimento, não estão preparados para darem a devida atenção à questão (Vincent, 2009).

Avedis Donabedian traz a tríade estrutura, processo e resultado, para contextualizar a qualidade em serviços de saúde, mas naquela época a linguagem do erro não havia sido adotada como nos dias atuais.

O autor cita que talvez a dimensão mais importante da qualidade em saúde seja a segurança. Parte relevante do interesse em estudar as variações na qualidade do atendimento vieram mais do impacto econômico que elas representavam do que do interesse pelas lesões dela ocorrido. (Vincent, 2009)

Após a publicação do relatório do Institute of Medicine (IOM), em 1999, To err is human, relatando que 44.000 a 94.000 mortes ao ano seriam evitáveis e provenientes de erros médicos, o assunto tomou um representatividade ainda maior. A idéia da queda diária de aviões, representando a mortalidade envolvida nos eventos relacionados à assistência a saúde, deu um enfoque mais concreto ao alarmante problema.

Eventos adversos causados pela assistência à saúde têm sido importantes causas de morbimortalidade no mundo e possuem 
impacto considerável sobre o consumo de recursos (Carneiro, 2010; Jha et al, 2013). A fim de que se soubesse de maneira fidedigna qual a incidência desses eventos, uma série de estratégias tem sido utilizadas para ampliar sua detecção, como a adoção de ferramentas gatilho - ferramentas gatilho se referem a situações onde potencial evento adverso pode estar presente e deve ser investigado - propostas pelo Institute of Healthcare Improvement (IHI) e o acompanhamento de indicadores da qualidade (Griffin, Resar, 2009).

As discussões sobre a responsabilização e a maneira de lidar com os erros dentro do sistema de saúde são complexas e polêmicas.

Em organizações complexas o erro raramente é isolado, falhas ativas e condições latentes contribuem para causar o dano. Falhas ativas são, por exemplo, violações a normas e condições latentes que podem ser exemplificadas por decisões gerenciais, pressão por produção, entre outras. Portanto, a idéia é tornar o sistema mais seguro, através do aumento do número de barreiras, dificultando o alinhamento dos furos do "queijo suíço", ao invés de aperfeiçoar o treinamento humano individual, unicamente (Reason, 2000).

De modo geral, reportar erros e eventos é um grande desafio, principalmente em serviços de saúde, onde a "cultura da culpa" tem grande representatividade.

É de fundamental importância a compreensão dos erros nos serviços de saúde, em especial o fato de que a maioria deles não é intencional, e sim cometida por profissionais comprometidos e bem intencionados. Tratá-los, através da responsabilização individual sumária, pode impedir o desenvolvimento de uma visão mais ampla sobre o sistema e dificultar a criação de um modelo de antecipação de erros (Carneiro,2010).

Estudos das últimas décadas (Reason, 2000) trazem a noção de serviços de saúde como um sistema complexo, passível de falhas, e, 
onde inúmeras variáveis colaboram com o desfecho. Lidar com a segurança do paciente de modo mais transparente requer habilidades dos profissionais e das organizações de saúde e também da sociedade.

Na Figura 1, observa-se o Modelo de Acidente Organizacional de Reason adaptado por Vincent, Adams e Stanhope (1998), onde os fatores contribuintes para o dano podem ser identificados.

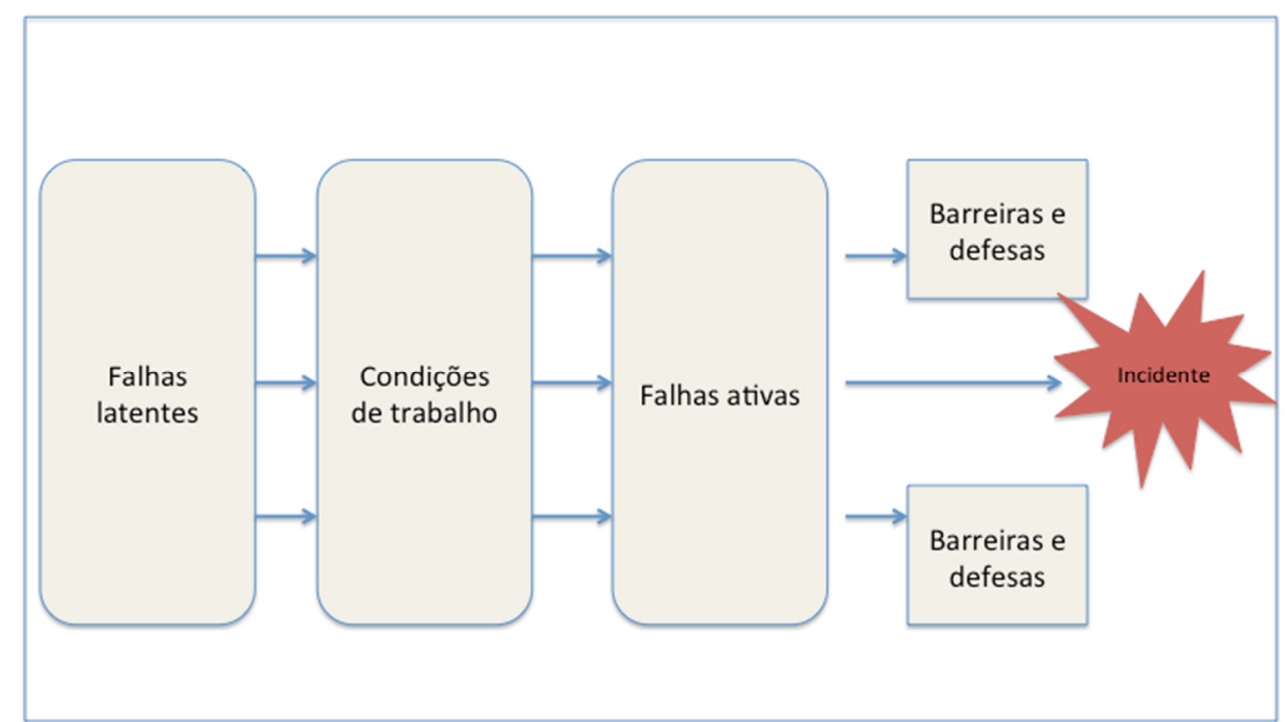

Fonte: Adaptado de Vincent, Adams, Stanhope (1998)

Figura 1- Modelo de Acidente Organizacional

O esquema representado na figura 1 monstra uma relação entre incidente, falhas ativas e latentes, mostrando que os incidentes ocorrem também por consequências de decisões gerenciais e processos organizacionais e não só através de falhas ativas dos últimos sujeitos relacionados ao cuidado em saúde. Conceitualmente, as falhas latentes são transmitidas adiante nos ambientes de trabalho onde há a criação de condições locais que favoreçam erros ou violações. Habitualmente, foca-se nas pessoas que estão mais diretamente envolvidas no erro, nos últimos profissionais que tiveram contato antes do incidente. Culpá-los 
somente é uma simplificação equivocada da análise de todo o incidente.

Há influências organizacionais, formadas por decisões da alta administração, que têm impacto sobre a segurança de todo o sistema. Indústrias químicas, petrolíferas e nucleares têm desenvolvido ferramentas para analisar sistematicamente 0 desempenho da organização quanto aos aspectos da segurança.

Condições de trabalho como supervisão, comunicação, equipamentos, conhecimento e habilidade são fatores relevantes a segurança do sistema e são afetados pelos processos organizacionais e decisões gerenciais anteriormente esquematizados. Além disso, somam-se as características pessoais dos profissionais de saúde e o próprio paciente, que também é determinante da variabilidade da prática clínica. Por exemplo, limitações de linguagem e personalidade na comunicação com a equipe.

Esse tipo de interpretação levou a alguns questionamentos importantes para delineamento dos conceitos a respeito da segurança do paciente.

Desse modo um grande desafio para a segurança do paciente nos serviços de saúde é criar uma cultura de segurança, que permeie todas as ações da prática assistencial.

Para Vincent (2009), a cultura de segurança está contida dentro da cultura organizacional e um comprometimento com a mesma é esperado iniciando-se pelo executivo chefe da organização.

Entretanto, há variações importantes em como a cultura de segurança é percebida dentro da mesma organização, em diferentes unidades. Isso transposto para a área médico-hospitalar, envolve outros fatores dificultadores, como por exemplo, os diferentes profissionais envolvidos na assistência e as diferentes 
formas de lidar com os erros dentro das diferentes classes profissionais (Vincent, 2009).

\subsection{REFERENCIAL TEÓRICO}

A cultura em um âmbito mais geral, como a cultura da nação de um povo, também interfere na maneira de lidar com o erro. Por definição, cultura é entendida como um padrão de suposições básicas compartilhadas, por este grupo. Percebem-se com maior facilidade as diferenças culturais no contexto étnico e nacional do que no contexto organizacional (Schein, 2009).

Os fenômenos organizacionais transitam pela cultura da organização - valores e crenças intrínsecos, muitas vezes não percebidos - pelo clima manifestado em dado período de tempo, e recebe a influências das lideranças e dos processos de mudança, internos e externos experimentados.

Fleury e Sampaio (2002, p. 293) definem cultura organizacional como:

"conjunto de valores e pressupostos básicos
expresso em elementos simbólicos que em sua
capacidade de ordenar, atribuir significações e
construir a identidade organizacional, tanto agem
como elemento de comunicação e consenso como
ocultam e instrumentalizam as relações de
dominação."

Investir na redução do erro implica em uma avaliação mais ampla do fenômeno, observando características do trabalho em grupo, do modelo de gestão e da cultura da organização. Portanto, discutir a cultura e o clima organizacional, os aspectos relacionados a comunicação e ao trabalho em grupo dentro das instituições de saúde se faz necessário. 
Colla et al (2005) destacam que apesar de constantemente utilizadas como sinônimos, cultura organizacional e clima organizacional possuem conceitos diferentes.

Clima organizacional pode ser definido como um agrupamento de percepções compartilhadas pelos indivíduos sobre o ambiente organizacional onde estão inseridos (Menezes, Gomes, 2010).

O clima organizacional também pode ser definido como os significados que as pessoas atribuem às experiências que têm no trabalho. Por outro lado, a cultura organizacional representa as premissas básicas sobre o mundo e os valores que norteiam a vida na organização. Clima e cultura organizacional oferecem perspectivas sobrepostas para a compreensão de experiências que as pessoas vivenciam em ambientes organizacionais. (Schneider, Ehrhart, Macey, 2013).

A cultura aponta fenômenos que estão abaixo da superfície, mas que são poderosos em seu impacto. A expressão externa desses fenômenos pode ser percebida no clima organizacional (Schein, 2009). Portanto, clima é a parte perceptível, mensurável da cultura organizacional. A cultura está mais no cerne, retrata um aspecto mais profundo e difícil de ser mensurado.

Fleury e Sampaio (2002) também diferenciam cultura e clima organizacional. Para os autores o clima é mais volátil e menos estrutural do que a cultura, pode ser entendido como um conjunto de satisfações e insatisfações de membros de uma organização em um determinado período de tempo.

A cultura de segurança é definida como o produto de valores e padrões de comportamento individuais e de grupo, que determinam o compromisso e estilo de gestão de uma organização. As organizações reconhecidas como detentoras de cultura de segurança positiva parecem possuir uma estrutura de comunicação franca e de confiança entre os indivíduos, mediadas pelo 
reconhecimento da importância da segurança e da adoção de medidas preventivas no contexto organizacional. A avaliação da cultura de segurança do paciente pode ser adotada tanto para reconhecimento da situação organizacional como para averiguar o impacto de intervenções realizadas (Reis, Laguardia e Martins, 2012; Helth and Safety Executive, 2013).

Clima de segurança do paciente é definido como características mensuráveis da cultura organizacional, por meio de percepções e atitudes dos indivíduos, em determinado tempo (Colla et all, 2005).

Halligan e Zecevic (2011), em um estudo de revisão dos conceitos de cultura de segurança em saúde apontaram divergências sobre a conceituação de cultura de segurança e sobre a diferença entre os conceitos de clima de segurança e cultura de segurança do paciente.

Morello et al. (2013) estruturam a relação entre clima e cultura de segurança do paciente (Figura 2). Os autores ressaltam que a cultura se refere a valores e crenças compartilhados e que o clima é um aspecto mais superficial da cultura, que pode ser mensurado por meio de questionários, e que, atualmente, dada a pressão por baixos custos e agilidade na averiguação, muitas instituições tem utilizado instrumentos para a avaliação do clima de segurança do paciente. 


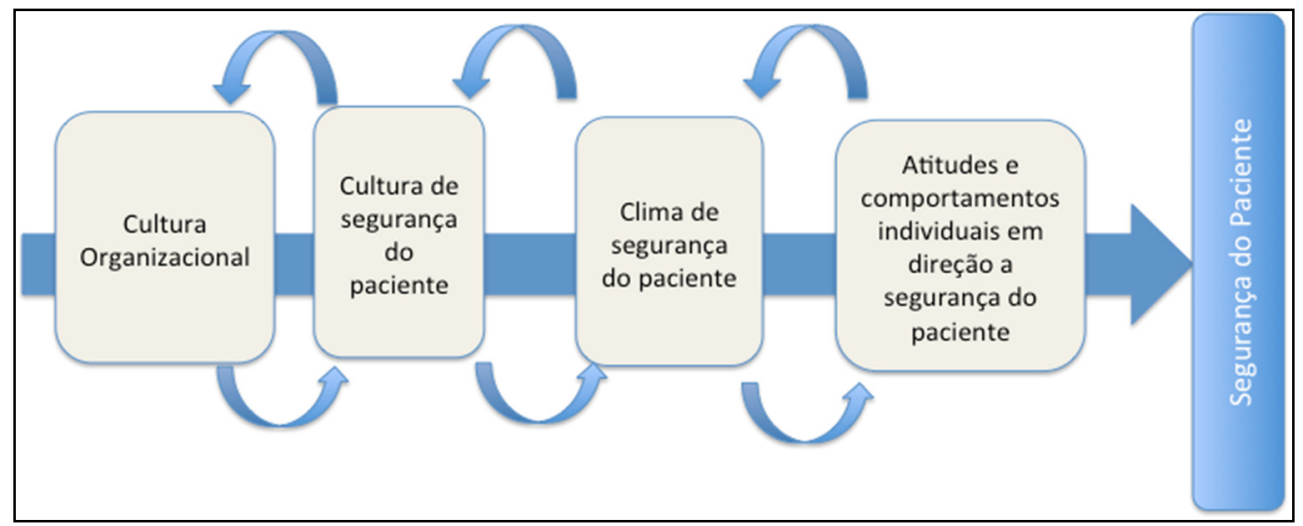

Fonte: Adaptado de Morello et al, 2013, p 12

Figura 2 - Modelo de Cultura de Segurança do Paciente

Desse modo, cultura de segurança e clima de segurança tem suas diferenças.

Reis (2013),reconhece a distinção entre os dois conceitos, optando em seu estudo de validação do instrumento Hospital Survey on Patient Safety Culture (HSOPSC) para o português no Brasil pelo uso de clima e cultura como sinônimos, uma vez que são usados como tal na literatura sobre segurança do paciente em organizações de saúde.

Sexton (2006) ressalta em seu estudo sobre as propriedades psicométricas do Safety Attitudes Questionnaire (SAQ), que, onde muitos esperariam ler "cultura de segurança do paciente", está empregado o termo "clima de segurança", pois, segundo o autor é mais facilmente mensurável que a cultura. As percepções fazem parte de ambas as definições - clima e cultura - e pesquisas, no geral, não são capazes de mensurar todos os aspectos ligados a cultura como valores e comportamento.

Segundo Puente-Palacios (2002), a semelhança entre os conceitos pode ser justificada, pois ambos os elementos estão no mesmo cenário e organização. A cultura, mais interna, é mais estável que o clima organizacional, este compreendido como as percepções dos 
membros sobre o agir da organização, alicerçadas na cultura, porém com menor estabilidade.

Nos últimos anos tem sido frequente a utilização de questionários para avaliação da cultura ou clima organizacional para segurança do paciente. Colla et al. (2005) em uma revisão sobre mensuração de clima de segurança do paciente compara nove instrumentos, todos utilizando escala Likert de 5 pontos e a força psicométrica das pesquisas variava consideravelmente. Sete delas foram desenhadas para serem preenchidas individualmente (Patient Safety Cultures in Healthcare Organizations - PSCHO; Veterans Administration Patient Safety Culture Questionnaire - VHA PSCQ; Hospital Survey on Patient Safety - HSOPS; Culture of Safety Survey - CSS; Safety Attitudes Questionnaire - SAQ; Safety Climate Survey - SCS; Hospital Transfusion Service Safety Culture SurveyHTSSCS e duas para serem respondidas em equipe (Strategies for Leadership: Organizational Approch to Patient Safety - SLOAPS e Medication Safety Self Assessment-MSSA).

Nesse estudo de revisão de literatura de Colla et al (2005),os instrumentos Safety Attitudes Questionnaire (SAQ) e Hospital Survey on Patient Safety (HSOPSC) foram avaliados e apresentavam alfa de Cronbach variando entre 0,68 a 0,81 e 0,63 a 0,83 , respectivamente.

O SAQ e o HSOPSC são, atualmente, instrumentos de avaliação de clima e cultura de segurança do paciente bastante utilizados mundialmente e ambos foram validados para a realidade brasileira $\mathrm{e}$ disponibilizados para utilização nos serviços de saúde. Estes fatores levaram a escolha destes dois instrumentos para aplicação nesta pesquisa.

O SAQ foi desenvolvido no Texas, Estados Unidos da América, a partir de duas escalas o Intensive Care Unit Managent Attitudes Questionarie e o Flight Managent Attitudes Questionarie. Na 
Validação da escala no modelo Short Form para o português no Brasil, o instrumento apresentou boas propriedades psicométricas com alfa de 0,89. A aplicação deste instrumento pode ajudar as organizações de saúde na avaliação de sua evolução ao longo do tempo e também na comparação com outras organizações (Sexton, 2006; Lima, 2011).

No estudo de validação e adaptação transcultural da SAQ para o Brasil os pesquisadores preservaram o layoute original e obtiveram um instrumento com tempo de preenchimento em torno de quinze minutos, com questões de múltipla escolha dispostas em 41 itens, distribuídos em seis domínios, a saber: "Clima de Trabalho em Equipe", "Satisfação no Trabalho", "Percepção da Gerência da Unidade e do Hospital", "Clima de Segurança", "Condições de Trabalho", "Percepção do Estresse". Cada item tem como resposta uma escala de cinco pontos de Likert, variando de "discorda totalmente" a "concorda totalmente" (Lima, 2011).

A validação do SAQ - Short Form para o português se deu com população constituida por profissionais de saúde de unidades de internação de cinco instituições hospitalares brasileiras de três regiões do país. A autora destaca que o SAQ pode ser adaptado a qualquer área hospitalar, o conteúdo dos itens de cada versão do instrumento é o mesmo e que o pesquisador pode particularizar o instrumento colocando o nome da unidade onde o mesmo será aplicado (Lima, 2011).

O Hospital Survey on Patient Safety Culture (HSOPSC), na versão original, foi lançado em 2004 pela Agency for Health Care Research and Quality (AHRQ), agência norte americana de qualidade em saúde. A versão final de Reis (2013), obtida após o trabalho de tradução, adaptação transcultural e validação, teve confiabilidade mensurada através do Alfa de Crombach de 0,91. São 42 itens distribuídos em 12 dimensões: "Trabalho em equipe dentro das unidades"; "Expectativas sobre seu supervisor/chefe e ações 
promotoras da segurança do paciente"; "Aprendizado organizacional- melhoria contínua"; "Apoio da gestão para segurança do paciente"; "Percepção geral da segurança do paciente"; "Retorno da informação e comunicação sobre o erro"; "Abertura da comunicação"; "Frequência de relato de eventos"; "Trabalho em equipe entre as unidades"; "Adequação de profissionais"; "Passagem de plantão ou de turno/transferências"; "Respostas não punitivas aos erros". A população para a validação do instrumento foi constituída por profissionais de unidades de internação de dois hospitais do Rio de Janeiro, incluindo funcionários de serviços de apoio diagnóstico e terapêutico que atendiam os pacientes destas unidades.

Um estudo conduzido em unidades de terapia intensiva de doze hospitais nos Estados Unidos avaliou a confiabilidade e validade preditiva do Safety Attitudes Questionnaire (SAQ) e do Hospital Survey on Patient Safety Culture (HSOPSC). Os pesquisadores concluíram que a confiabilidade era semelhante em ambos os instrumentos, deixando a decisão sobre a escolha entre um ou outro instrumento a cargo do pesquisador ou líder de segurança do paciente das organizações (Etchegaray, Thomas, 2012).

A maioria das instituições brasileiras não conhece qual seu clima ou cultura para segurança do paciente, quais são suas maiores fragilidades e suas fortalezas neste aspecto. A fim de investigar qual o retrato do clima/ cultura de segurança utilizar-se-á neste trabalho os dois instrumentos mais frequentemente utilizados para este fim no mundo - SAQ e HSOPSC, recentemente, validados e adaptados para o português no Brasil.

Este trabalho tratará da percepção dos colaboradores das unidades de terapia intensiva acerca do clima/cultura de segurança do paciente. Também pretende testar a hipótese de que o SAQ e o HSOPSC têm forte correlação. 


\section{OBJETIVO}

\section{Geral}

Avaliar a percepção dos profissionais de saúde sobre o clima e cultura de segurança do paciente em unidades de terapia intensiva em hospital de ensino do município de Sumaré, estado de São Paulo, por meio do Hospital Survey on Patient Safety Culture (HSOPSC) e Safety Attitudes Questionnaire (SAQ).

\section{Específicos}

Identificar a percepção de cultura de segurança dos profissionais que atuam em unidades de terapia intensiva adulto, pediátrica e neonatal.

Identificar a percepção sobre clima e atitudes de segurança dos profissionais que atuam em unidades de terapia intensiva adulto, pediátrica e neonatal.

Verificar a correlação entre cultura de segurança do paciente e atitudes de segurança. 


\section{METODOLOGIA}

\subsection{TIPO DE ESTUDO}

Estudo exploratório transversal descritivo, que tem por característica refletir o estado do fenômeno em um determinado momento.

\subsection{LOCAL DE ESTUDO}

Unidades de Terapia Intensiva de Hospital de ensino do município de Sumaré, totalizando 36 leitos, sendo 18 de terapia intensiva adulto, 12 neonatal e 6 pediátricos, conforme consulta realizada no Cadastro Nacional de Estabelecimento de Saúde (CNES) em novembro de 2013. O hospital atende pacientes pelo Sistema Único de Saúde (SUS). Este hospital trata-se de uma organização social de saúde, ligada a UNICAMP - Universidade Estadual de Campinas.

A instituição é hospital de ensino e oferece campo de estágio a graduandos e residentes da área da saúde da UNICAMP.

\subsection{POPULAÇÃO}

Profissionais que atuam nas unidades de terapia intensiva tanto na área assistencial (enfermeiros, técnicos de enfermagem, fisioterapeutas, médicos, nutricionistas, psicólogos, entre outros) como na área administrativa (gestores da unidade, auxiliares administrativos) e profissionais de apoio (auxiliares de serviços gerais). Critério de inclusão: estar na escala de trabalho da unidade de terapia intensiva. Considerou-se critério de exclusão: trabalhar há menos de seis meses na unidade. 
A relação dos profissionais que atuam nas unidades de terapia intensiva foi obtida através de contato com as coordenações dessas unidades.

O convite para participação no estudo foi feito a todos os profissionais da lista obtida.

A lista inicial de possíveis participantes compreendeu 197 profissionais, sendo, 25 enfermeiros, 124 técnicos de enfermagem, 30 médicos, 10 fisioterapeutas, um psicólogo, três auxiliares administrativos e quatro auxiliares de serviços gerais.

\subsection{PROCEDIMENTO DE COLETA DE DADOS}

A partir da lista de profissionais que atuam nas unidades de terapia intensiva, foi oferecido aos participantes da pesquisa um envelope contendo uma carta convite para participação na pesquisa, com o termo de consentimento livre e esclarecido em duas vias (APÊNDICE A), instrumento sobre dados sócio-demográficos e profissionais (APÊNDICE B), os instrumentos de avaliação sobre clima (ANEXO 1) e cultura de segurança do paciente (APÊNDICE C), respectivamente. Os profissionais foram orientados a devolver 0 envelope, caso não desejassem participar do estudo. A coleta ocorreu nos meses de março e abril de 2014.

Profissionais com menos de seis meses na unidade, que preencheram 0 instrumento, foram excluídos posteriormente da amostra para a análise dos dados.

\subsection{INSTRUMENTOS DE COLETA}

Foram utilizados três instrumentos nesta pesquisa. 
O instrumento Informações Sociodemográficas (APÊNDICE B), que condensou as informações sociodeográficas que constavam na versão validada para o Brasil dos instrumentos (HSOPSC) e (SAQ).

A fim de preservar o layout do instrumento $S A Q$, não foram retiradas as questões caracterizadoras da amostra, mesmo quando presentes no instrumento informações sociodemográficas (APÊNDICE B).

O instrumento HSOPSC validado por Reis (2013) (ANEXO 2) sofreu duas alterações nesta pesquisa: foram suprimidas as questões relacionadas a caracterização sociodemográfica da amostra e essas foram adicionadas ao instrumento Informações Sociodemográficas (APÊNDICE B) e o campo de resposta da pergunta "número de eventos que você notificou nos últimos 12 meses", ao invés de oferecer a variável categorizada em intervalos de tempo apresentou campo aberto para a resposta. Essas alterações resultaram no instrumento HSOPSC layout alterado (APÊNDICE C).

O instrumento SAQ (ANEXO 1), como utilizado por Lima (2011) está dividido em duas partes, a primeira possui 41 itens, divididos em seis domínios, a saber: clima de trabalho em equipe, satisfação no trabalho, percepção da gerência da unidade e do hospital, clima de segurança, condições de trabalho, percepção do estresse. Cada item tem como resposta uma escala de cinco pontos de Likert, variando de "discorda totalmente" a "concorda totalmente". O escore varia de zero a 100 , onde zero é a pior percepção e 100 a melhor percepção. São considerados valores positivos quando o escore é maior ou igual a setenta e cinco pontos.

O instrumento HSOPSC layout alterado (APÊNDICE C), também utiliza escala Likert de 5 pontos variando de "concordo totalmente" a "discordo totalmente", além de outros itens respondidos por uma escala de frequência de 5 pontos, variando entre "sempre" e "nunca". A variável de resultado relacionada ao grau de segurança do paciente, também possui resposta em escala de 5 pontos, 
oscilando de "excelente" a "muito ruim". A variável de resultado "número de eventos que você notificou nos últimos 12 meses" possui campo aberto de resposta.

A relação entre as dimensões avaliadas - dimensões da unidade, dimensões do hospital e variáveis de resultado, estão estabelecidas na figura 3 :

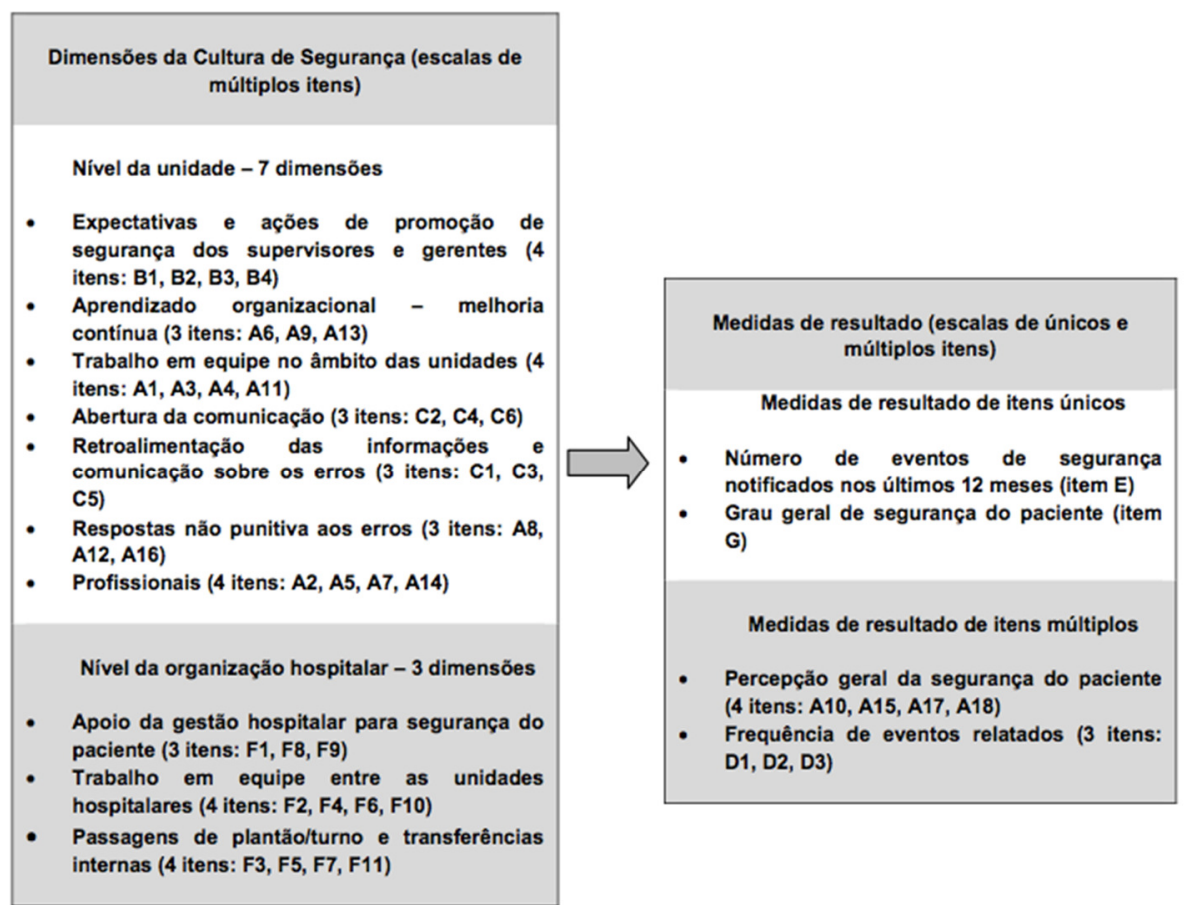

Fonte: Reis, 2013. p. 27

Figura 3 - Relação entre as Dimensões do HSOPSC

Os itens que compões cada dimensão do HSOPSC e domínio do SAQ estão descritos nos quadros 1 e 2 , respectivamente. 


\section{Quadro 1- Itens e dimensões do instrumento HSOPSC}

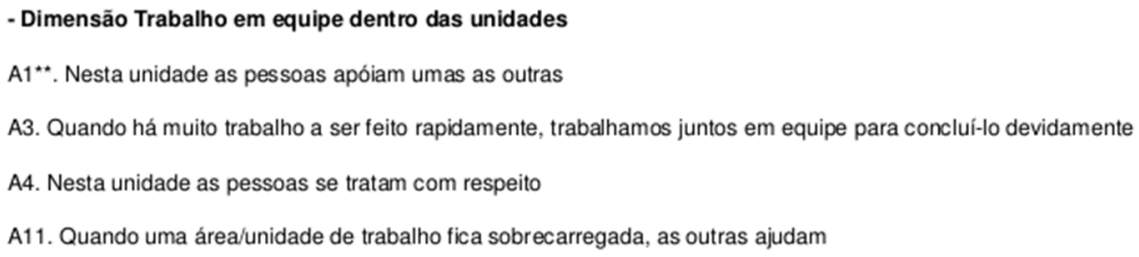

B2. O meu supervisor/chefe realmente leva em consideração as sugestões dos profissionais (independente do vínculo empregatício) para a melhoria da segurança do paciente

$\mathrm{B}^{2} \mathrm{R}^{* * *}$. Sempre que a pressão aumenta, o meu supervisor/chefe quer que trabalhemos mais rápido, mesmo que isso signifique "pular etapas"

B4R. O meu supervisor/chefe não dá atenção suficiente aos problemas de segurança do paciente que acontecem repetidamente

- Dimensão Aprendizado organizacional - melhoria contínua

A6. Estamos ativamente fazendo coisas para melhorar a segurança do paciente

A9. Erros, enganos ou falhas têm levado a mudanças positivas por aqui

A13. Após implementarmos mudanças para melhorar a segurança do paciente, avaliamos a efetividade

- Dimensão Apoio da gestão para a segurança do paciente

F1. A direção do hospital propicia um clima de trabalho que promove a segurança do paciente.

F8. As açōes da direção do hospital demonstram que a segurança do paciente é a principal prioridade

F9R. A direção do hospital só parece interessada na segurança do paciente quando ocorre algum evento adverso

- Dimensão Percepção geral da segurança do paciente

A10R. É apenas por acaso que erros, enganos ou falhas não acontecem por aqui

A15. A segurança do paciente jamais é comprometida em função de maior quantidade de trabalho a ser concluída

A17R. Nesta unidade temos problemas de segurança do paciente

A18. Os nossos procedimentos e sistemas são adequados para prevenir a ocorrência de erros

- Dimensão Retomo da informação e comunicação sobre erro

C1. Nós recebemos informação sobre mudanças implementadas a partir de relatórios de eventos

C3. Nós somos informados sobre os erros que acontecem nesta unidade

C5. Nesta unidade, discutimos meios de prevenir erros para que eles não aconteçam novamente

$R$ indica itens reversos

** indica posição no questionário

(continua)

*** indica sentença escrita negativamente 


\section{- Dimensão Abertura da comunicação}

C2. Os profissionais (independente do vínculo empregatício) têm liberdade para dizer ao ver algo que pode afetar negativamente o cuidado do paciente

C4. Os profissionais (independente do vínculo empregatício) sentem-se à vontade para questionar as decisōes ou açōes de seus superiores

C6R. Os profissionais (independente do vínculo empregatício) têm receio de perguntar, quando algo parece não estar certo

\section{- Dimensão Frequência de relato de eventos}

D1. Quando ocorre erro, engano ou falha, mas ele é percebido e corrigido antes de afetar o paciente, com que frequência ele é relatado?

D2. Quando ocorre erro, engano ou falha, mas não há risco de dano ao paciente, com que frequêencia ele é relatado?

D3. Quando ocorre erro, engano ou falha, que poderia causar danos ao paciente, mas não causa, com que frequência ele é relatado?

\section{- Dimensão Trabalho em equipe entre as unidades}

F2R. As unidades do hospital não estão bem coordenadas entre si

F4. Há uma boa cooperação entre as unidades do hospital que precisam trabalhar em conjunto

F6R. Muitas vezes é desagradável trabalhar com profissionais (independente do vínculo empregatício) de outras unidades do hospital

F10. As unidades do hospital trabalham bem em conjunto para prestar o melhor cuidado aos pacientes

- Dimensão Adequação de profissionais

A2. Temos profissionais (independente do vínculo empregatício) suficientes para dar conta da carga de trabalho

A5R. Nesta unidade, os profissionais (independente do vínculo empregatício) trabalham mais horas do que seria o melhor para o cuidado do paciente

A7R. Utilizamos mais profissionais temporários/terceirizados do que seria desejável para o cuidado do paciente

A14R. Nós trabalhamos em "situação de crise", tentando fazer muito e muito rápido

- Dimensão Passagem de plantão ou de turno/ transferências

F3R. O processo de cuidado é comprometido quando um paciente é transferido de uma unidade para outra

F5R. É comum a perda de informaçōes importantes sobre o cuidado do paciente durante as mudanças de plantāo ou de turno

F7R. Com frequência ocorrem problemas na troca de informaçōes entre as unidades do hospital

F11R. Neste hospital, as mudanças de plantão ou de turno são problemáticas para os pacientes

- Dimensão Respostas não punitivas aos erros

A8R. Os profissionais consideram que seus erros, enganos ou falhas podem ser usados contra eles

A12R. Quando um evento é relatado, parece que o foco recai sobre a pessoa e não sobre o problema

A16R. Os profissionais (independente do vínculo empregatício) se preocupam que seus erros, enganos ou falhas sejam registrados em suas fichas funcionais

$\mathrm{R}$ indica itens reversos

** indica posição no questionário

*** indica sentença escrita negativamente 


\section{Quadro 2 - Itens e domínios do instrumento SAQ}

\section{- Domínio Clima de Trabalho em Equipe}

1. As sugestōes do (a) enfermeiro (a) são bem recebidas nesta área

2. (R) Nesta área, é difícil falar abertamente se eu percebo um problema com o cuidado ao paciente.

3. Nesta área, as discordâncias são resolvidas de modo apropriado (ex: não quem está certo, mas o que é melhor para o paciente)

4. Eu tenho o apoio que necessito de outros membros da equipe para cuidar dos pacientes

5. É fácil para os profissionais que atuam nesta área fazerem perguntas quando existe algo que eles não entendem

6. Os (as) médicos (as) e enfermeiros (as) daqui trabalham juntos como uma equipe bem coordenada

- Domínio Clima de Segurança

7. Eu me sentiria seguro (a) se fosse tratado (a) aqui como paciente

8. Erros são tratados de modo apropriado nesta área

9. Eu conheço os meios adequados para encaminhar as questōes relacionadas à segurança do paciente nesta área

10. Eu recebo retorno apropriado sobre meu desempenho

11. (R) Nesta área, é difícil discutir sobre erros

12. Sou encorajado (a) por meus colegas a informar qualquer preocupação que eu possa ter quanto à segurança do paciente

13. A cultura nesta área torna fácil aprender com os erros dos outros

- Domínio Satisfação no Trabalho

15. Eu gosto do meu trabalho

16. Trabalhar aqui é como fazer parte de uma grande família.

17. Este é um bom lugar para trabalhar.

18. Eu me orgulho de trabalhar nesta área.

19. O moral nesta área é alto.

\section{- Domínio Percepção do Estresse}

20. Quando minha carga de trabalho é excessiva, meu desempenho é prejudica do.

21. Eu sou menos eficiente no trabalho quando estou cansado (a).

22. Eu tenho maior probabilidade de cometer erros em situaçōes tensas ou hostis.

23. O cansaço prejudica meu desempenho durante situaçōes de emergência (ex: reanimação cardiorrespiratória, convulsōes).

Os itens com $\mathrm{R}$ são reversos

Os itens com * não possuem domínios 
(continuação)

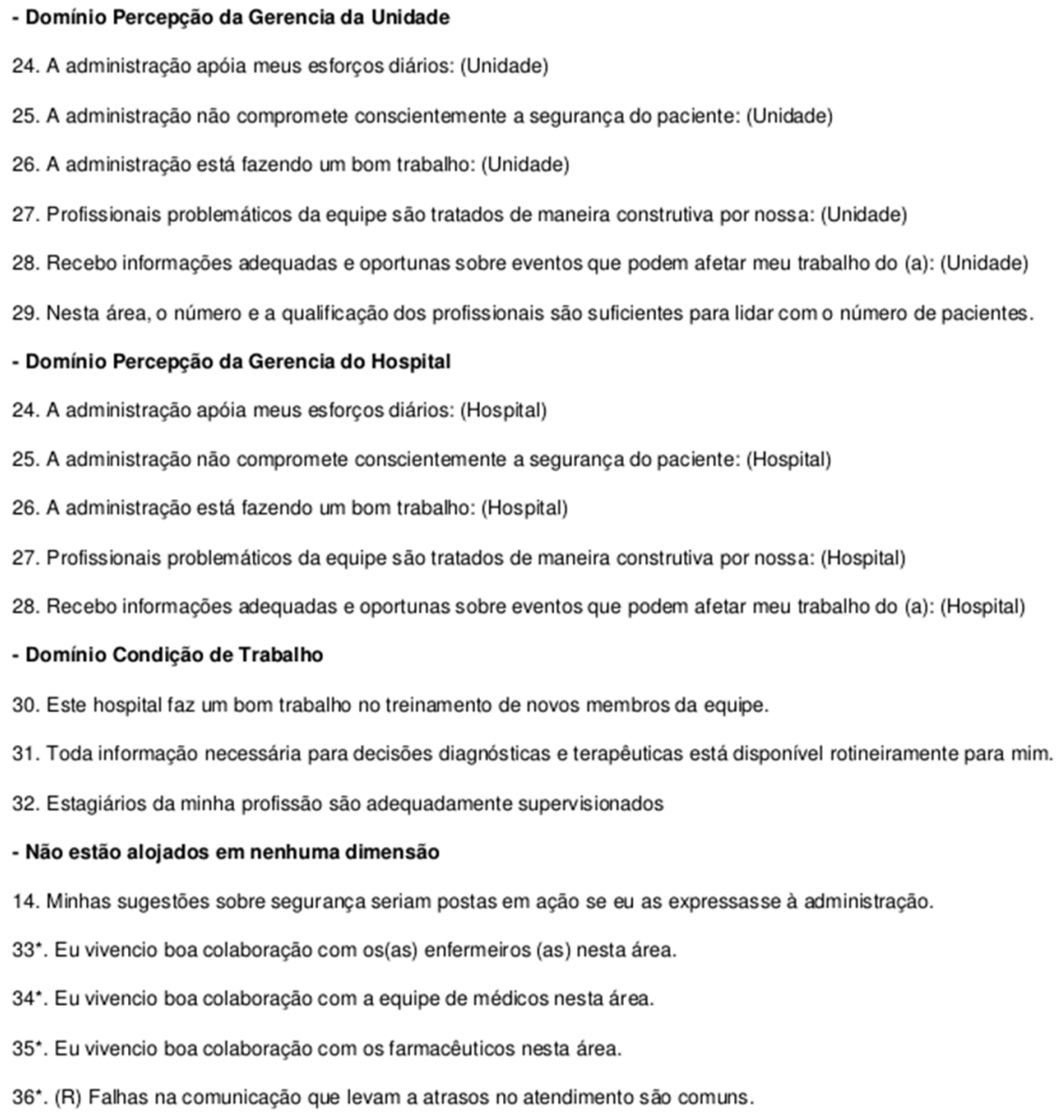

\subsection{VARIÁVEIS DE ESTUDO}

Cultura de segurança: medido por meio do instrumento Hospital Survey on Patient Safety Culture (HSOPSC). Após a inversão dos itens reversos, percentuais superiores a 75 de respostas positivas representam resultados satisfatórios quanto a cultura de segurança do paciente e quando iguais ou inferiores a 50 demonstram dimensões frágeis para o fenômeno. 
Atitudes de segurança: medido por meio do instrumento "Safety Attitudes Questionnaire" (SAQ), com pontuação máxima de 100. Pontuações acima de 75 sugerem área fortalecida com relação a segurança do paciente e pontuações abaixo de 50 representam áreas frágeis com relação a segurança do paciente (Sexton et al, 2006).

Tipo de UTI: Adulto, Neonatal e Pediátrica

Categorias profissionais: Profissional médico (médico), Profissional enfermagem (enfermeiro, técnico de enfermagem e auxiliar de enfermagem), Outros profissionais (nutricionista, fisioterapeuta, auxiliar de serviços gerais, auxiliar administrativo)

Idade: em anos

Sexo: masculino e feminino

Escolaridade: primeiro grau completo, segundo grau completo, ensino superior, pós-graduação

Contato com o paciente: sim e não

Tempo de trabalho no hospital: em meses

Tempo de atuação na unidade: em meses

Tempo na profissão: em meses

Carga horária semanal: em horas

Tipo de unidade intensiva: neonatal, pediátrica e adulto

\subsection{ANÁLISE DE DADOS}

Após a aplicação do critério de exclusão: trabalhar ao menos 6 meses na unidade, foram excluídos ainda 20 questionários da análise de dados por possuírem uma seção do HSOPSC não preenchida por completo, conforme efetuado no estudo de validação 
do instrumento por Reis (2013). Assim, foram incluídos na análise de dados 88 participantes.

Foi verificada a confiabilidade de ambos os instrumentos através da do Alfa de Cronbach. Os itens dos instrumentos foram analisados por domínio/dimensão e como escala completa por meio de médias ou medianas de acordo com a distribuição da população (normal ou não). Realizou-se também a análise dos instrumentos de cultura e clima de segurança por unidade de terapia intensiva, conforme cálculo proposto pelos autores dos instrumentos.

SAQ: Primeiramente faz-se a inversão dos itens reversos. Então, a ordem da pontuação é: discordo totalmente $(A)$ equivale a 0 pontos, discordo parcialmente (B) equivale a 25 pontos, neutro (C) equivale a 50 pontos, concorda parcialmente (D) equivale a 75 pontos e concordo totalmente (E) equivale a 100 pontos. Desta forma se em um domínio de quatro itens o indivíduo responder para cada questão neutro, concorda parcialmente, neutro e discordo parcialmente, temos: $(50+75+50+25) / 4=50$. Assim, a pontuação desse domínio seria 50 .

Outra maneira para calcular o SAQ é através da analise descritiva do questionário. Após a inversão dos itens reversos, o cálculo de cada item é feito com base na formula $(m-1) \times 25$, onde $m$ é a média dos itens do domínio em questão e variam de 0 a 100. (Lima, 2011 e Sexton, 2006)

A contagem dos escores foi realizada conforme os passos a seguir: itens reversos foram recodificados, itens foram agrupados por domínios, calculou-se a soma das respostas por domínio e dividiuse pelo número de itens do domínio.

HSOPSC: Após a inversão dos itens reversos, o percentual de respostas positivas para cada dimensão foi calculado utilizando a fórmula abaixo (Sorra e Nieva, 2004): 
$\%$ de respostas positivas da dimensão $X=$

[número de respostas positivas da dimensão $X$ / número total de respostas válidas aos itens da dimensão $X$ (positivas, neutras $e$ negativas, excluindo-se os dados ausentes)] $\times 100$

A pontuação do HSOPSC varia de 1 a 5 , sendo 1 discordo totalmente/ nunca, 2 equivale a raramente ou discordo, 3 equivale a não concordo nem discordo ou às vezes, 4 equivale a concordo ou quase sempre e 5 equivale a concordo totalmente ou sempre.

Foi verificada a presença de associações das escalas com variáveis como tipo de profissional, tempo de atuação na unidade, idade do participante. Para as variáveis qualitativas utilizou-se o teste de quiquadrado de Pearson ou teste exato de Fischer; para as variáveis quantitativas utilizou-se o teste de diferença de médias, a ANOVA, pela distribuição normal dos dados.

A presença de correlação entre os instrumentos SAQ e HSOPSC. foi verificada pelo teste de correlação de Pearson.

O nível de significância estatística considerado foi de 5\% para todos os testes estatísticos.

Para a questão aberta do instrumento HSOPSC foi realizada análise de conteúdo utilizando o referencial de Bardin (2007) e foram estabelecidas categorias para a análise.

\subsection{ASPECTOS ÉtICOS}

O estudo foi submetido à Comissão de Ética da Escola de Enfermagem da USP e à instituição co-participante pela Plataforma Brasil - CAAE: 24166713.0.3001.5404 (ANEXO 3) e CAAE: 24166713.0.0000.5392 (ANEXO 4). Enviou-se uma solicitação para 
a autorização ao hospital para coleta de dados (ANEXO 5). Após estas etapas, e o aceite de todos os envolvidos a pesquisadora visitou as unidades para realização da coleta de dados. Os participantes que concordaram em participar da pesquisa assinaram o Termo de Consentimento Livre e Esclarecido em duas vias (APÊNDICE A).

\section{RESULTADOS}

\subsection{SÓCIODEMOGRÁFICOS}

A amostra total de participantes (88) ficou assim distribuída nas três Unidades de Terapia Intensiva, Adulto ( $n=27 ; 30,7 \%)$, Pediátrica (26; $29,5 \%)$ e Neonatal $(n=35 ; 39,8 \%)$.

O sexo predominante foi o feminino $(94,3 \%)$ em todas as unidades de terapia intensiva (Tabela1). Não houve diferença estatisticamente significativa entre sexo e tipo de UTI $(p=1,00)$

A idade dos participantes variou de 21 a 58 anos, com média de 37,3 anos (DP \pm 9 ) e mediana de 36,5 anos (Tabela 2). Não houve diferença de média de idade entre os tipos de UTI $(p=0,174)$

Quanto a escolaridade, todos tinham curso de segundo grau completo ou superior, a exceção de um $(3,7 \%)$ respondente da UTI pediátrica que tinha apenas o primeiro grau completo. Houve maior proporção de profissionais com ensino superior na UTI adulto $(74,1 \%)$ (Tabela 1$)$ e diferença estatística $(p=0,029)$ entre as UTIs. Dos profissionais de ensino superior, $32(36,4 \%)$ tinham curso de pós-graduação, sendo 27 pós-graduação sensu lato (especialização) e cinco pós-graduação sensu stricto(mestrado ou doutorado). As UTIs pediátrica e adulto tinham profissionais com pós-graduação sensu stricto. 
Os questionários foram respondidos por profissionais de diversas categorias: fisioterapeutas, enfermeiros, técnicos de enfermagem, médicos, psicólogo, nutricionistas, auxiliares de serviços gerais e assistentes administrativos. No entanto, como o número de profissionais por cada categoria foi bastante distinto, optou-se por categorizá-los em três grupos: Profissionais Médicos, Profissionais de Enfermagem e Outros Profissionais. O maior grupo profissional foi de Profissionais de Enfermagem (71,6\%), sendo maior na UTI Neonatal $(82,9 \%)$ e menor na UTI Adulto (55,6\%), por consequência, o número de Outros Profissionais foi maior na UTI Adulto (Tabela 1). A nutricionista trabalhava nas UTIs Adulto e Pediátrica, e para a análise seu questionário foi replicado para cada uma das unidades. Não houve diferença estatística significativa entre as categorias profissionais e o tipo de UTI $(p=0,309)$.

A maioria dos respondentes tinha contato direto com o paciente nas suas funções no trabalho, 96,5\% (percentual válido), e não houve diferença em relação ao tipo de UTI $(p=0,478)$. 
Tabela 1 - Distribuição das variáveis sóciodemográficas e de contato do paciente relativas aos profissionais de terapia intensiva, por tipo de unidade. Sumaré, 2014.

\begin{tabular}{|c|c|c|c|c|c|c|c|c|c|c|}
\hline \multirow{2}{*}{\multicolumn{2}{|c|}{ Variáveis Qualitativas }} & \multicolumn{2}{|c|}{ UTI Neonatal } & \multicolumn{2}{|c|}{ UTI Pediátrica } & \multicolumn{2}{|c|}{ UTI Adulto } & \multicolumn{2}{|c|}{ Total } & \multirow[t]{2}{*}{$\mathrm{p}$} \\
\hline & & $\mathrm{N}$ & $\%$ & $\mathrm{~N}$ & $\%$ & $\mathrm{~N}$ & $\%$ & $\mathrm{~N}$ & $\%$ & \\
\hline \multirow[t]{2}{*}{ Sexo } & Masculino & 2 & 5,7 & 1 & 3,8 & 2 & 7,4 & 5 & 5,7 & 1,000 \\
\hline & Feminino & 33 & 94,3 & 25 & 96,2 & 25 & 92,6 & 83 & 94,3 & \\
\hline \multirow[t]{3}{*}{ Cargo } & Médico & 4 & 11,4 & 3 & 11,5 & 4 & 14,8 & 11 & 12,5 & 0,309 \\
\hline & Profissionais de Enfermagem & 29 & 82,9 & 19 & 73,1 & 15 & 55,6 & 63 & 71,6 & \\
\hline & Outros & 2 & 5,7 & 4 & 15,4 & 8 & 29,6 & 14 & 15,9 & \\
\hline \multirow[t]{3}{*}{ Grau de instrução } & Até ensino médio completo & 17 & 48,6 & 13 & 50,0 & 6 & 22,2 & 36 & 40,9 & 0,029 \\
\hline & Ensino superior incompleto & 2 & 5,7 & 3 & 11,5 & 1 & 3,7 & 6 & 6,8 & \\
\hline & Ensino superior completo & 16 & 45,7 & 10 & 38,5 & 20 & 74,1 & 46 & 52,3 & \\
\hline \multirow[t]{2}{*}{$\begin{array}{l}\text { Contato com } \\
\text { Paciente }\end{array}$} & Sim & 34 & 97,1 & 25 & 100,0 & 24 & 92,3 & 83 & $96,5 \%$ & 0,478 \\
\hline & Não & 1 & 2,9 & - & - & 2 & 7,7 & 3 & $3,5 \%$ & \\
\hline \multicolumn{2}{|c|}{ Total } & 35 & 39,8 & 26 & 29,5 & 27 & 30,7 & 88 & $100,0 \%$ & \\
\hline
\end{tabular}


O tempo de trabalho no hospital foi variável com uma média de 80,8 meses $(D P \pm 53,1)$ e o de trabalho na unidade, embora com uma média um pouco menor (69,5 meses), também mostrou uma ampla variabilidade. Com relação ao tempo de formado, a média mostrouse bastante elevada (130,4 meses) e a amplitude de variação foi de menos de 1 ano a 35 anos de profissão (Tabela 2). A carga horária semanal de trabalho teve uma média de 36 horas, provavelmente dado o maior número de profissionais de enfermagem.

Tabela 2 - Frequência e medidas de tendência central e de variabilidade das variáveis relacionadas ao tempo de trabalho e idade dos profissionais de saúde das UTIs. Sumaré, 2014.

\begin{tabular}{|c|c|c|c|c|c|c|}
\hline \multirow{2}{*}{ Quantitativa } & \multicolumn{6}{|c|}{ Total } \\
\hline & $\mathrm{N}$ & Média & DP & Mediana & Mínimo & Máximo \\
\hline Idade (anos) & 64 & 37,8 & 9,0 & 36,5 & 21 & 58 \\
\hline $\begin{array}{l}\text { Tempo de trabalho hospital } \\
\text { (meses) }\end{array}$ & 88 & 80,8 & 53,2 & 72,0 & 6 & 180 \\
\hline Tempo na unidade (meses) & 88 & 69,5 & 51,4 & 60,0 & 6 & 168 \\
\hline $\begin{array}{l}\text { Tempo na profissão } \\
\text { (meses) }\end{array}$ & 87 & 130,4 & 92,2 & 120,0 & 9 & 420 \\
\hline $\begin{array}{l}\text { Carga horária semanal } \\
\text { (horas) }\end{array}$ & 86 & 36,0 & 7,6 & 36,0 & 12 & 48 \\
\hline
\end{tabular}

A idade média dos respondentes da UTI Adulto, não diferiu da média geral (Tabela 3). Com relação ao tempo de profissão e local de atuação, as médias também se mostraram elevadas e a variação mínima no tempo de profissão foi de 18 meses (1 ano e meio). 
Tabela 3 - Frequência e medidas de tendência central e de variabilidade das variáveis relacionadas ao tempo de trabalho e idade dos profissionais de saúde da UTI Adulto. Sumaré, 2014.

\begin{tabular}{|c|c|c|c|c|c|c|}
\hline \multirow{2}{*}{ Quantitativa } & \multicolumn{6}{|c|}{ Adulto } \\
\hline & $\mathrm{N}$ & Média & $\mathrm{DP}$ & Mediana & Mínimo & Máximo \\
\hline Idade (anos) & 20 & 36,2 & 8,1 & 36,0 & 25 & 51 \\
\hline $\begin{array}{l}\text { Tempo de trabalho } \\
\text { hospital (meses) }\end{array}$ & 27 & 66,7 & 45,7 & 60,0 & 6 & 168 \\
\hline $\begin{array}{l}\text { Tempo na unidade } \\
\text { (meses) }\end{array}$ & 27 & 52,6 & 46,4 & 36,0 & 6 & 168 \\
\hline $\begin{array}{l}\text { Tempo na profissão } \\
\text { (meses) }\end{array}$ & 27 & 108,2 & 70,1 & 108,0 & 18 & 300 \\
\hline $\begin{array}{l}\text { Carga horária semanal } \\
\text { (horas) }\end{array}$ & 27 & 35,7 & 7,3 & 36,0 & 12 & 48 \\
\hline
\end{tabular}

Na UTI Pediátrica, as médias e variabilidades também foram elevadas e para o tempo de profissão, o tempo mínimo foi superior (2 anos), um pouco maior que na UTI adulto (Tabela 4). A mediana de carga horária nesta unidade foi superior à das demais UTIs.

Tabela 4 - Frequência e medidas de tendência central e de variabilidade das variáveis relacionadas ao tempo de trabalho e idade dos profissionais de saúde da UTI Pediátrica. Sumaré, 2014.

\begin{tabular}{lcccccc}
\hline \multirow{2}{*}{ Quantitativa } & \multicolumn{6}{c}{ Pediátrica } \\
\cline { 2 - 7 } & $\mathrm{N}$ & Média & DP & Mediana & Mínimo & Máximo \\
\hline $\begin{array}{l}\text { Idade (anos) } \\
\begin{array}{l}\text { Tempo de trabalho hospital } \\
\text { (meses) }\end{array}\end{array}$ & 21 & 34,9 & 8,6 & 34,0 & 21 & 54 \\
$\begin{array}{l}\text { Tempo na unidade (meses) } \\
\text { Tempo na profissão (meses) }\end{array}$ & 26 & 75,5 & 51,8 & 70,5 & 11 & 168 \\
$\begin{array}{l}\text { Carga horária semanal } \\
\text { (horas) }\end{array}$ & 25 & 138,0 & 97,8 & 96,0 & 24 & 360 \\
\hline
\end{tabular}

Na UTI Neonatal, os dados das variáveis de tempo de profissão e de local de trabalho também apresentaram grande amplitude, principalmente no tempo de profissão dada a presença de recémformados e de um funcionário com 35 anos de profissão. (Tabela 5) 
Tabela 5 - Frequência e medidas de tendência central e de variabilidade das variáveis relacionadas ao tempo de trabalho e idade dos profissionais de saúde da UTI Neonatal. Sumaré, 2014.

\begin{tabular}{lcccccc}
\hline \multirow{2}{*}{ Quantitativa } & \multicolumn{6}{c}{ Neonatal } \\
\cline { 2 - 7 } & $\mathrm{N}$ & Média & DP & Mediana & Mínimo & Máximo \\
\hline $\begin{array}{l}\text { Idade (anos) } \\
\begin{array}{l}\text { Tempo de trabalho hospital } \\
\text { (meses) }\end{array}\end{array}$ & 23 & 40,2 & 9,4 & 39,0 & 25 & 58 \\
$\begin{array}{l}\text { Tempo na unidade (meses) } \\
\text { Tempo na profissão (meses) }\end{array}$ & 35 & 95,5 & 55,8 & 120,0 & 9 & 180 \\
$\begin{array}{l}\text { Carga horária semanal } \\
\text { (horas) }\end{array}$ & 34 & $35,8,7$ & 8,37 & 96,0 & 6 & 168 \\
\hline
\end{tabular}

Observa-se pela tabela 6 que não houve diferença estatística significativa entre as UTIs para idade, tempo de trabalho no hospital, tempo de trabalho na profissão e carga horária. No entanto, houve diferença estatística significativa para a variável tempo de trabalho na unidade e o maior tempo de trabalho na unidade foi observado na UTI Neonatal.

Tabela 6 - Teste de diferença de médias para as variáveis quantitativas e tipo de UTIs. Sumaré, 2014

\begin{tabular}{lcccc}
\hline & \multicolumn{4}{c}{ Tipo de UTI } \\
\cline { 2 - 5 } \multicolumn{1}{c}{ Variáveis } & $\begin{array}{c}\text { Neonatal } \\
\text { média (DP) }\end{array}$ & $\begin{array}{c}\text { Pediatria } \\
\text { média (DP) }\end{array}$ & $\begin{array}{c}\text { Adulto } \\
\text { média (DP) }\end{array}$ & $\mathrm{p}$ \\
\hline Idade (anos) & $40,2(9,6)$ & $34,9(8,8)$ & $36,2(8,3)$ & 0,2019 \\
Tempo de trabalho no hospital (meses) & $95,5(56,6)$ & $75,5(52,9)$ & $66,7(46,6)$ & 0,1235 \\
Tempo de trabalho na unidade (meses) & $87,8(53,5)$ & $62,5(47,4)$ & $52,6(47,2)$ & 0,0272 \\
Carga horária semanal (horas) & $35,8(8,5)$ & $36,7(6,8)$ & $35,7(7,5)$ & 0,7147 \\
Tempo de trabalho na profissão (meses) & $142,1(101,2)$ & $138,0(99,8)$ & $108,2(71,5)$ & 0,4947 \\
\hline
\end{tabular}

Em meses, os profissionais da UTI Neonatal têm em média 87,5 meses de trabalho na unidade, enquanto os da UTI Pediátrica e Adulto têm, respectivamente, 62,5 meses e 52,6 meses. 
Pode se verificar na Tabela 7 que ao se considerar a categoria profissional houve diferença estatística significativa somente para a carga horária semanal, em que os médicos tem uma menor carga horária quando comparados aos demais profissionais da unidade.

Tabela 7 - Teste de diferença de médias para as variáveis quantitativas e categoria profissional. Sumaré, 2014

\begin{tabular}{lcccc}
\hline & \multicolumn{4}{c}{ Categoria profissional } \\
\cline { 2 - 5 } Variáveis & $\begin{array}{c}\text { profissional enfermagem } \\
\text { média (DP) }\end{array}$ & $\begin{array}{c}\text { médico } \\
\text { média (DP) }\end{array}$ & $\begin{array}{c}\text { outros média (DP) } \\
\text { mény }\end{array}$ & $\mathrm{p}$ \\
\hline Tempo de trabalho no hospital (meses) & $77,6(54,2)$ & $107,2(53,8)$ & $74,3(47,2)$ & 0,1888 \\
Tempo de trabalho na unidade (meses) & $64,9(51,2)$ & $101,7(51,3)$ & $65,2(48,1)$ & 0,0811 \\
Carga horária semanal (horas) & $38,3(6,0)$ & $25,6(99,6)$ & $34,0(4,7)$ & $<0,0000$ \\
Tempo de trabalho na profissão (meses) & $123,5(96,0)$ & $179,5(99,0)$ & $122,6(61,0)$ & 0,1363 \\
\hline
\end{tabular}

\subsection{AVALIAÇÃO DA PERCEPÇÃO DA SEGURANÇA DO PACIENTE SEGUNDO OS INSTRUMENTOS SAQ E HSOPSC}

\subsubsection{Análise das propriedades psicométricas}

A escala SAQ obteve boa confiabilidade pelo alfa de Cronbach $(0,853)$. No entanto, na avaliação da confiabilidade por domínio da escala, apenas os domínios "Satisfação no trabalho", "Percepção de estresse" e "Percepção da gerência" obtiveram valores de alfa acima de 0,700 (Tabela 8 ). 
Tabela 8 - Valores de alfa de Cronbach para a escala SAQ e seus domínios. Sumaré, 2014

\begin{tabular}{ll}
\hline \multicolumn{1}{c}{ Confiabilidade - SAQ } & Alfa \\
\hline Global & 0,853 \\
Clima de trabalho da equipe SAQ & 0,669 \\
Clima de segurança SAQ & 0,604 \\
Satisfação no trabalho SAQ & 0,729 \\
Condição de trabalho SAQ & 0,688 \\
Percepção de estresse - SAQ & 0,743 \\
Percepção da gerência SAQ & 0,775 \\
\multicolumn{1}{c}{ Percepção da gerência de unidade } & 0,629 \\
Percepção da gerência do hospital & 0,727 \\
\hline
\end{tabular}

Ao se decompor os itens da dimensão "percepção da gerência", observou-se melhor alfa de Cronbach para a sub-dimensão "percepção da gerência do hospital".

A escala HSOPSC obteve boa confiabilidade pelo alfa de Cronbach $(0,889)$ no conjunto dos itens. No entanto, na avaliação da confiabilidade por dimensão da escala, apenas as dimensões "Aprendizado organizacional-melhoria contínua", "Apoio da gestão para a segurança do paciente", "Trabalho de equipe entre as unidades do hospital", "Frequência de notificação de eventos" e "Transferências e passagem de informações entre turnos" obtiveram valores de alfa acima de 0,700 (Tabela 9). 
Tabela 9 - Valores de alfa de Cronbach para a escala HSOPSC e suas dimensões. Sumaré, 2014.

\begin{tabular}{lc}
\hline Confiabilidade - HSOPSC & Alfa \\
\hline Global & 0,899 \\
Trabalho em equipe dentro das unidades & 0,668 \\
Ações e expectativas sobre seu supervisor/chefe e & \\
ações promotoras da segurança do paciente & 0,550 \\
Aprendizado organizacional - melhoria contínua & 0,712 \\
Apoio da gestão para segurança do paciente & 0,710 \\
Percepção geral da segurança do paciente & 0,437 \\
Retroalimentação da informação e comunicação sobre erro & 0,674 \\
Abertura da comunicação & 0,487 \\
Frequência de notificação de eventos & 0,823 \\
Trabalho em equipe entre as unidades & 0,789 \\
Adequação de profissionais & 0,304 \\
Passagem de plantão ou turno/transferências & 0,742 \\
Resposta não punitiva aos erros & 0,468 \\
\hline
\end{tabular}

"Nota da segurança do paciente" e "Número de eventos relatados nos últimos 12 meses" embora componham a escala, são dimensões compostas por apenas um item cada e, portanto, não há valores de confiabilidade.

\subsubsection{Unidades de terapia intensiva agrupadas}

$\mathrm{Na}$ avaliação do SAQ nas UTIs, apenas o domínio "Satisfação no Trabalho" teve pontuação igual ou superior a 75 e nenhum domínio obteve 50 pontos ou menos (Figura 4).

Os domínios "Satisfação no Trabalho" e o "Clima de Trabalho em Equipe" apresentaram as maiores pontuações, 81,2 e 74,9, respectivamente. 
A pontuação mais baixa foi observada no domínio "Percepção da Gerência - Administração do Hospital” $(55,3)$.

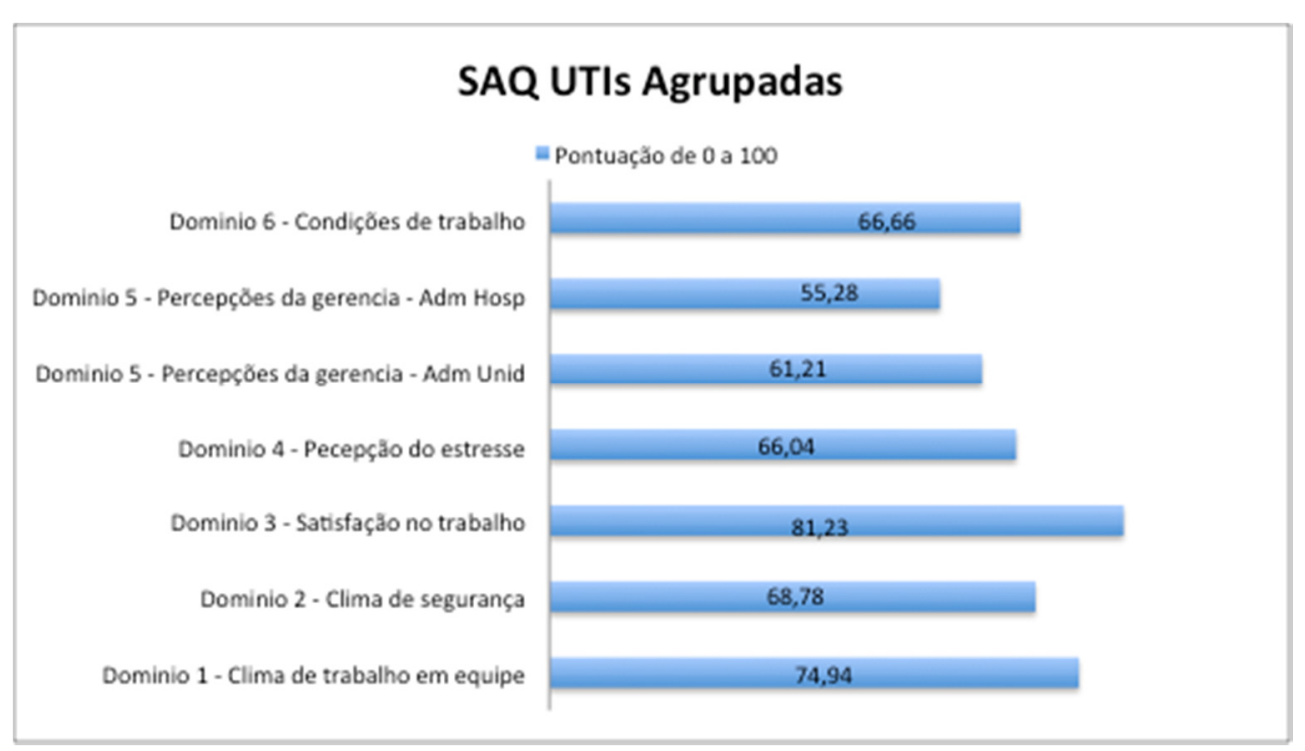

Figura 4 - Pontuação média do SAQ por Domínios nas UTIs. Sumaré, 2014.

A análise do HSOPSC nas UTIs evidenciou que as dimensões "Expectativas do supervisor/chefe" e "Ações de promoção da segurança" obteve $75,4 \%$, de respostas positivas sendo consideradas fortes, pela categorização proposta pelos autores do instrumento. A dimensão "Resposta não punitiva aos erros" obteve 0 menor percentual de repostas positivas (29,6\%) (Figura 5).

As dimensões com proporção de neutros maior de 30\% foram "Abertura da comunicação" e "Retorno da comunicação e das "Informações sobre o erro". 

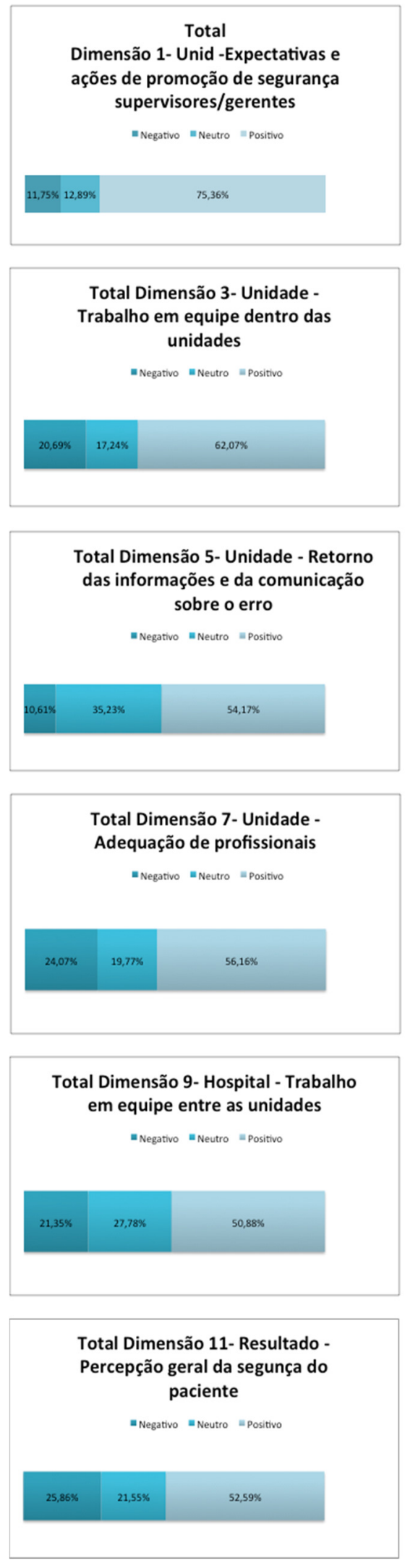

Figura 5 - Percentual de respostas positivas por dimensão do HSOPSC nas UTIs. Sumaré, 2014.
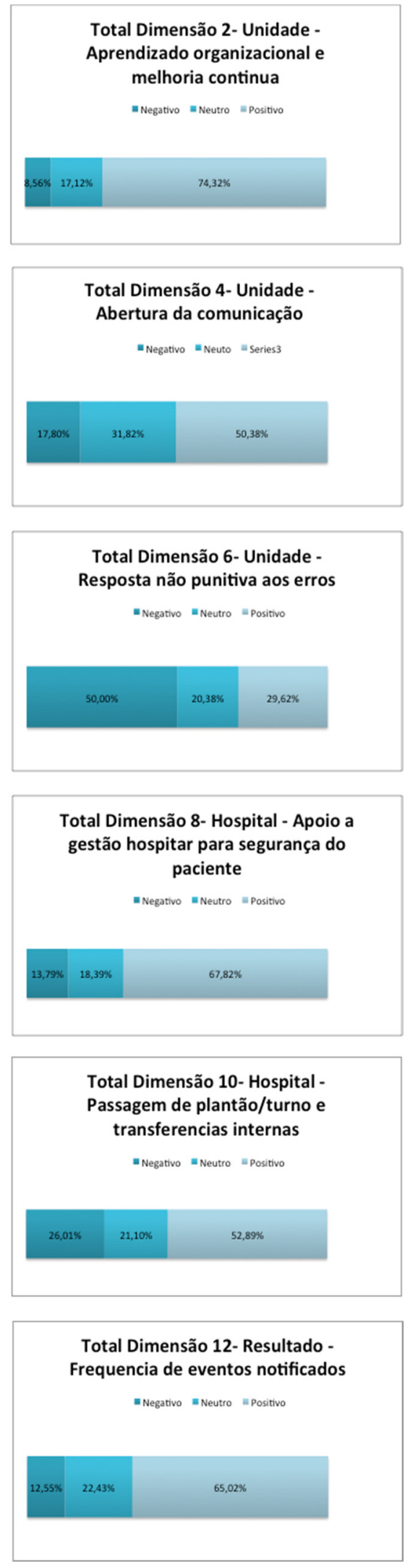
Na figura 6 observa-se que a maioria dos profissionais avaliou a nota de segurança do paciente como muito bom (69,3\%) e não houve nenhuma avaliação ruim ou muito ruim.

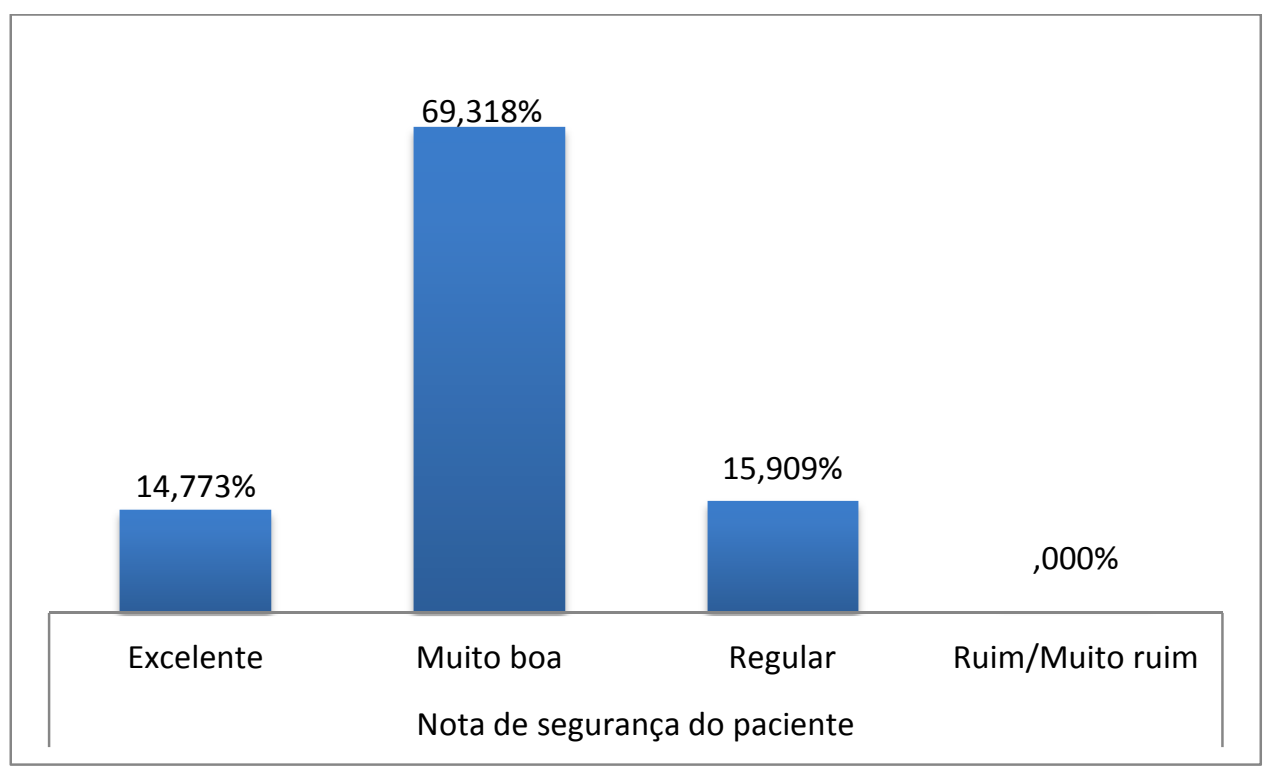

Figura 6 - Frequência de respostas sobre a nota de segurança do paciente. Sumaré, 2014.

Em ambos os instrumentos, seja na avaliação da cultura pelo HSOPSC, seja na de atitudes de segurança do paciente através do $S A Q$, menos da metade das dimensões e domínios obtiveram valores considerados "fortes" para a segurança do paciente - mais de $75 \%$ de respostas positivas no HSOPSC ou mais de 75 pontos no SAQ

Apesar da maior parte dos domínios ou dimensões terem obtido uma pontuação intermediária entre áreas fortes e frágeis para segurança do paciente, a nota dada pelos profissionais para segurança do paciente na unidade foi considerada em $84,1 \%$ "Muito boa" ou "Excelente". 


\subsubsection{Comparativo entre as Unidades de Terapia Intensiva Adulto, Pediátrica e Neonatal utilizando o instrumento SAQ}

Ao se comparar os domínios do SAQ entre as UTls (Figura 7), observou-se que a UTI adulto (UTI-A) apresentou apenas o domínio "Satisfação no trabalho" com pontuação superior a 75 ( 77,7 pontos).

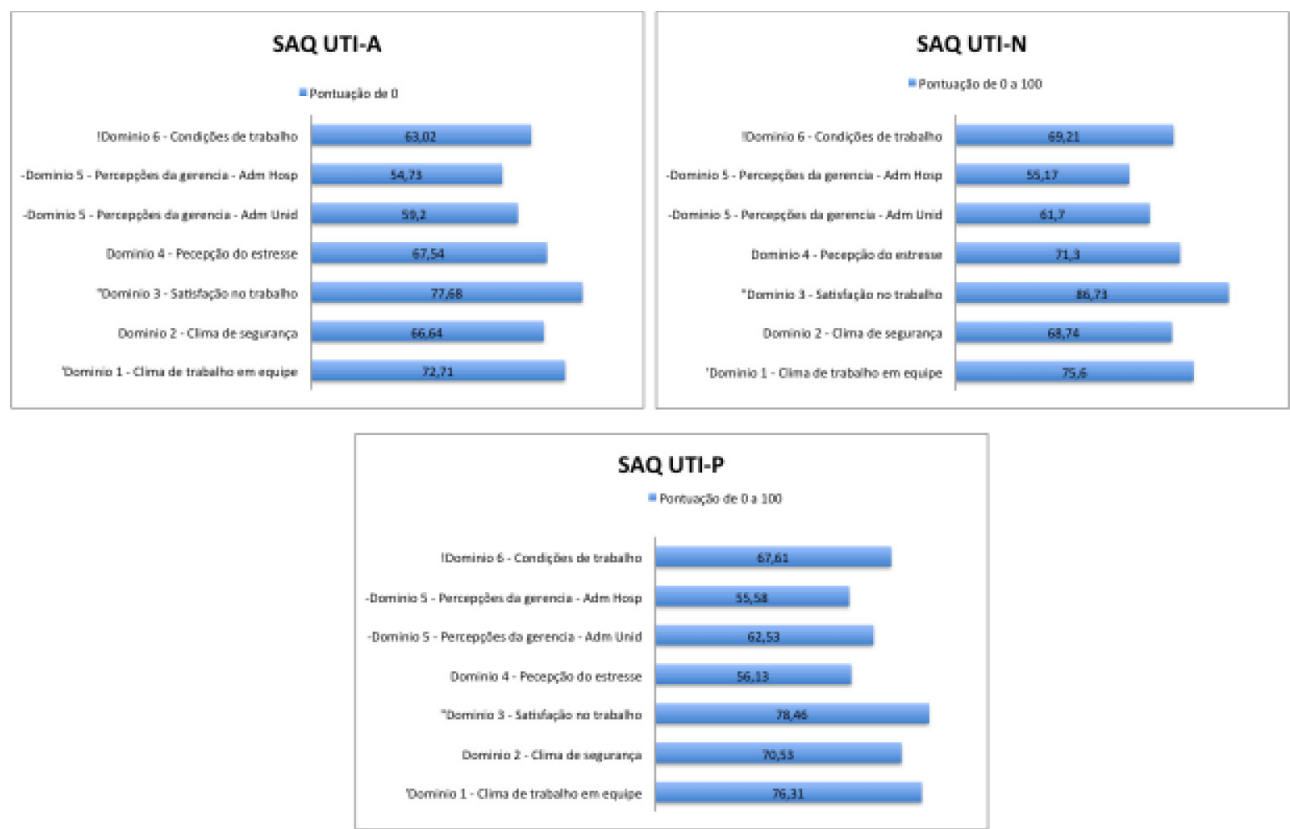

Figura 7 - Pontuação do SAQ por domínios nas UTIs Adulto, Pediátrica e Neonatal. Sumaré, 2014.

A UTI Pediátrica (UTI-P) e Neonatal (UTI-N) apresentaram dois domínios com pontuação superior a 75: "Clima de trabalho em equipe" (76,3 pontos na UTI Pediátrica e 75,6 na UTI Neonatal) e "Satisfação no trabalho" (78,5 pontos na UTI Pediátrica e 86,7 pontos na UTI Neonatal).

O domínio satisfação no trabalho foi expressivamente maior na UTI Neonatal (pontuação de 86,7) do que na UTI Adulto e Pediátrica, 77,7 e 78,5 pontos, respectivamente. 
O domínio percepção do estresse também apresentou-se mais elevado na UTI - Neonatal $(71,3)$ do que na UTI Adulto $(67,5)$ e Pediátrica $(56,1)$.

Nenhuma das unidades separadamente apresentou domínio com pontuação inferior a 50. As pontuações mais baixas na UTI Adulto e Neonatal foram no domínio 5 - Percepção da Gerência da Unidade e do Hospital. Na UTI Pediátrica as pontuações mais baixas foram nos domínios Percepção da Gerência - Administração do hospital $(55,6)$ e Percepção do Estresse $(56,2)$.

\subsubsection{Comparativo entre as Unidades de Terapia Intensiva Adulto, Pediátrica e Neonatal utilizando o instrumento HSOPSC}

Com relação às dimensões relacionadas a Unidade (dimensões de 1 a 7) observou-se que:

"Ações e expectativas sobre o seu supervisor/ chefe e ações promotoras da segurança do paciente" e "Aprendizado Organizacional e melhoria contínua" obtiveram percentuais elevados de respostas positivas, próximos ou superiores a $75 \%$ de respostas positivas (Figura 8).

A dimensão "Trabalho em equipe dentro das unidades" obteve elevado percentual de respostas positivas na UTI Pediátrica (82,5\%). $\mathrm{Na}$ UTI - Adulto e Neonatal este percentual ficou em torno de 67,0\% (Figura 9).

"Abertura da comunicação" obteve percentuais de respostas positivas inferiores a 50\% nas UTIs Pediátrica e Neonatal, 48,7\% e $46,7 \%$, respectivamente. Na UTI - Adulto o percentual de respostas positivas para esta dimensão foi de 56,8\%. (Figura 9). 

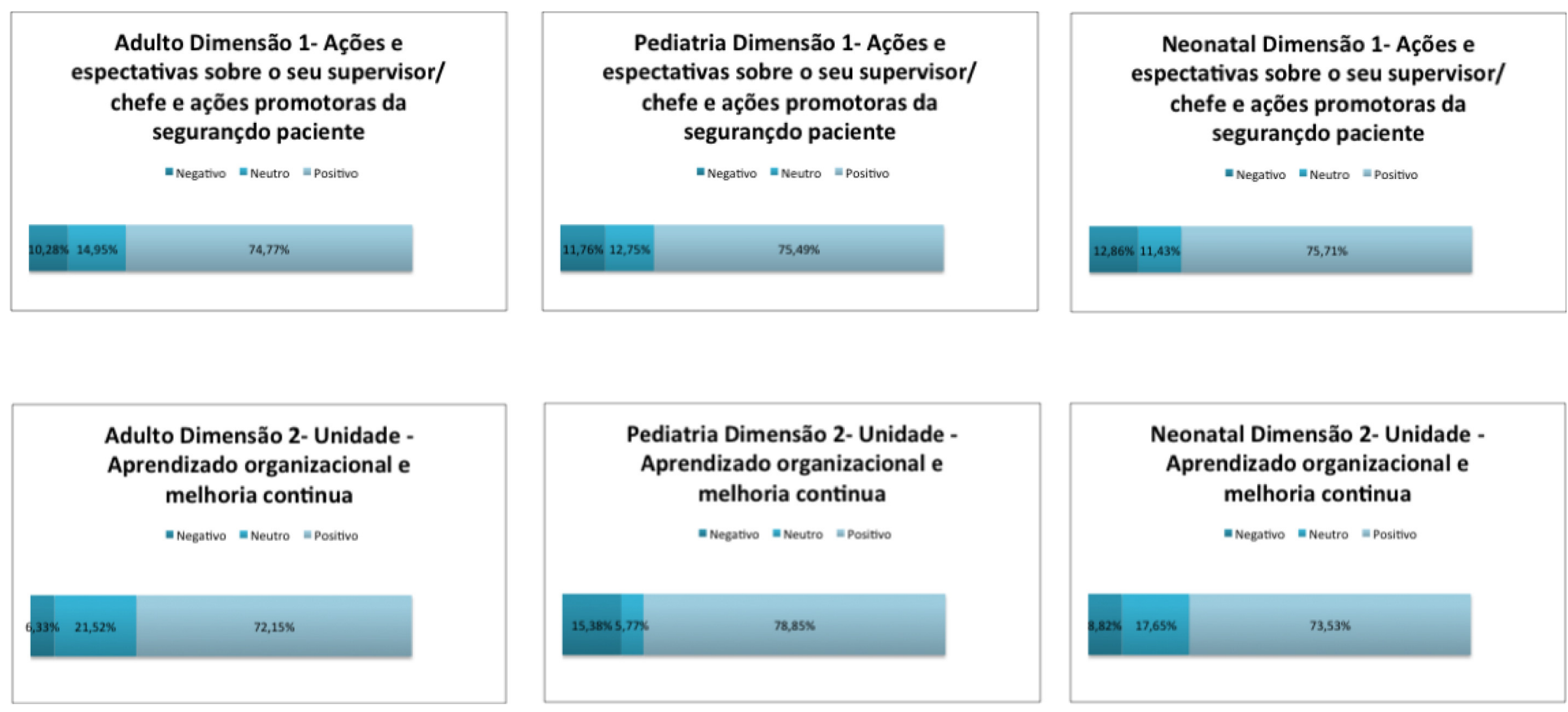

Figura 8 - Percentual de respostas positivas, neutras e negativas para as dimensões 1 e 2 da Unidade HSOPSC nas UTIs Adulto, Pediátrica e Neonatal. Sumaré, 2014. 

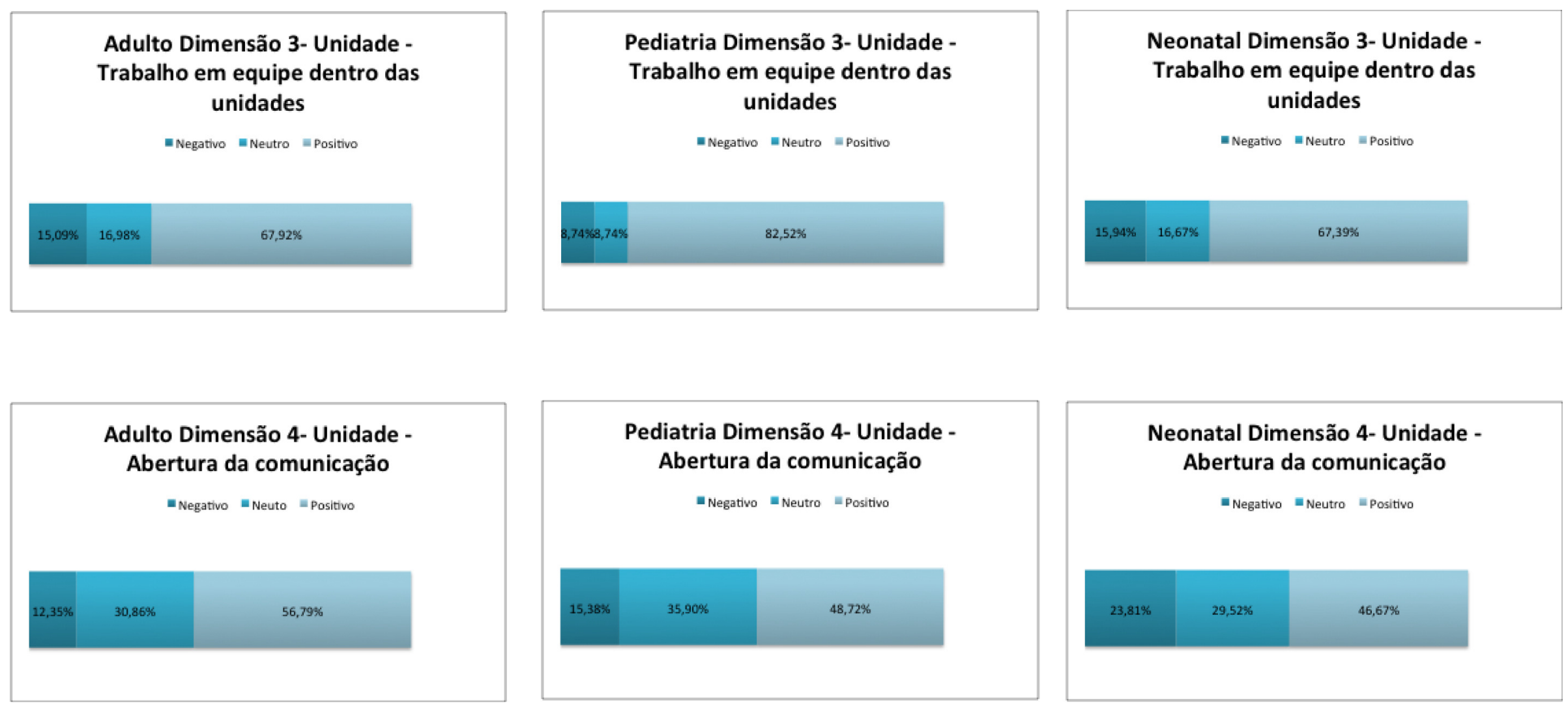

Figura 9 - Percentual de respostas positivas, neutras e negativas para as dimensões 3 e 4 da Unidade HSOPSC nas UTIs Adulto, Pediátrica e Neonatal. Sumaré, 2014. 
A dimensão "Retorno das informações e da comunicação sobre o erro" obteve percentuais de respostas próximas a $50 \%$, sendo $53,1 \%$ na UTI - Adulto 55,1\% na UTI Pediátrica e 55,3\% na UTI Neonatal. O percentual de respostas "neutro" variou entre 30,0 e 40,0\%.(Figura $10)$.

"Respostas não punitivas aos erros" foi a dimensão do HSOPSC com mais baixo percentual de respostas positivas, variando de $25 \%$ na UTI - Adulto a 32,5\% na UTI Pediátrica (Figura 10).

A dimensão 7 - Adequação de profissionais obteve percentual de respostas positivas inferior a $50 \%$ na UTI - Adulto. (Figura 11). Nesta dimensão são abordadas questões referentes a carga de trabalho na unidade e o número de profissionais, bem como o emprego de profissionais temporários. Nas UTIs Pediátrica e Neonatal o percentual de respostas positivas foi semelhante, $61,2 \%$ e $61,9 \%$, respectivamente. (Figura 11 ).

As dimensões de 8 a 10 referem-se ao hospital. Para a dimensão 8 - "Apoio da gestão para segurança", a UTI - Adulto apresentou um percentual de respostas positivas de $65,43 \%$ e obteve o maior percentual de respostas neutras comparada com as demais UTIs, totalizando $24,7 \%$, enquanto as demais mantiveram respostas neutras em torno de 15,0\%. (Figura 11). 

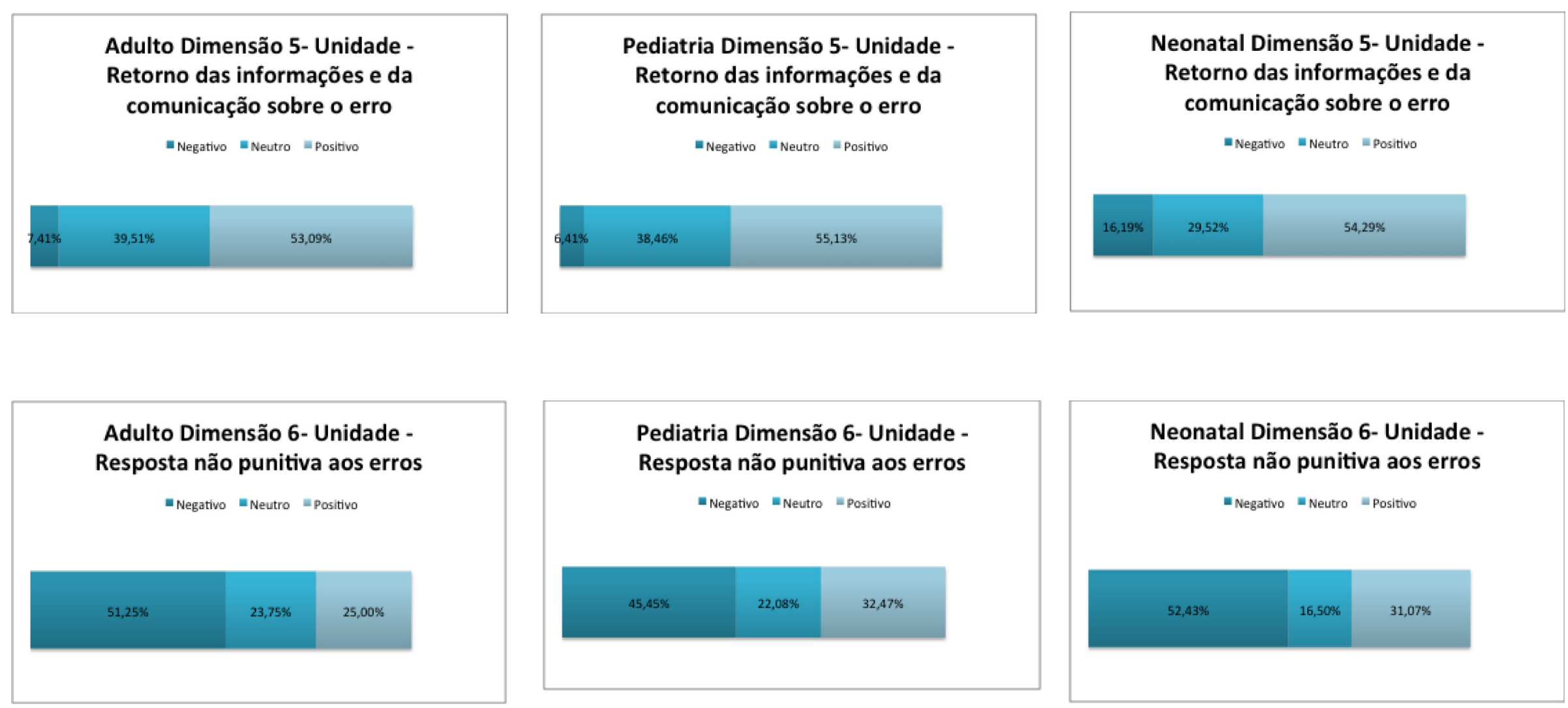

Figura 10 - Percentual de respostas positivas, neutras e negativas para as dimensões 5 e 6 da Unidade HSOPSC nas UTIs Adulto, Pediátrica e Neonatal. Sumaré, 2014. 

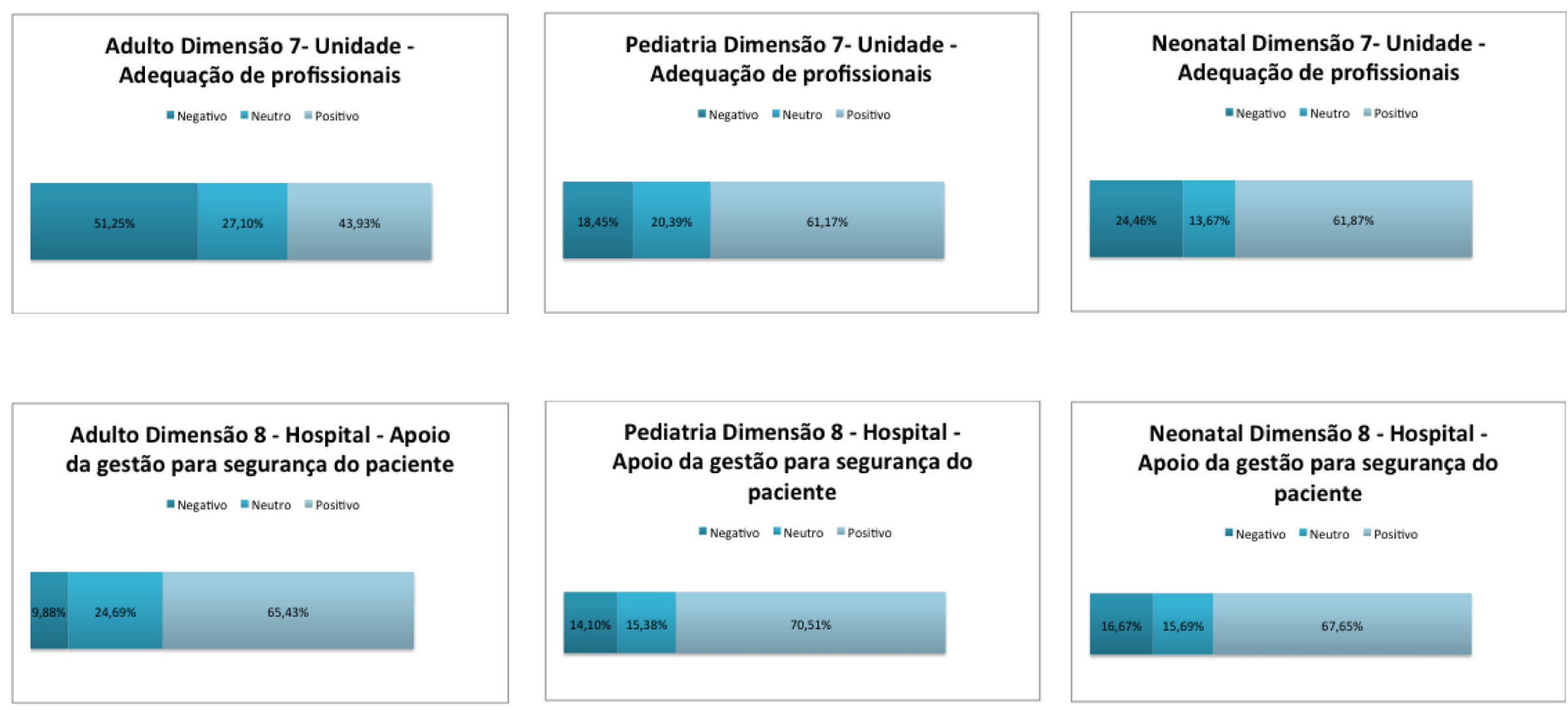

Figura 11 - Percentual de respostas positivas, neutras e negativas para as dimensões 7 e 8 da Unidade HSOPSC nas UTIs Adulto, Pediátrica e Neonatal. Sumaré, 2014. 
A dimensão "Trabalho em equipe entre as unidades" apresentou, nas três unidades de terapia intensiva baixos percentuais de respostas positivas, entre $48,5 \%$ na UTI - Adulto e $53,5 \%$ na UTI Pediátrica. Esta dimensão trata das relações entre as unidades do hospital, abordando a cooperação e a coordenação de atividades entre elas. (Figura 12).

A dimensão "Passagem de plantão ou de turno" aborda a transferência de informações entre turnos e entre unidades, apresentou percentual de respostas positivas abaixa de $50 \%$ na UTI - Adulto (41,7\%). Na UTI Neonatal o percentual de respostas positivas totalizou $52,6 \%$. (Figura 12 ).

Diferentemente destas unidades, a UTI Pediátrica apresentou valores intermediários de respostas positivas $65,05 \%$. (Figura 12).

$\mathrm{Na}$ dimensão 11 de resultado "Percepção geral da segurança do paciente" as UTIs Adulto e Neonatal apresentaram comportamento diferente da UTI Pediátrica. A UTI - Pediátrica apresentou 61,8\%, novamente um valor intermediário entre 50 e $75 \%$ de respostas positivas. A UTI - Adulto apresentou menos de $50 \%$ nesta dimensão e na UTI - Pediátrica 50,4\% de respostas positivas. (Figura 13).

A "Frequência de eventos notificados", também está relacionada como dimensão de resultado (Figura 13). O percentual de respostas positivas da UTI - Pediátrica se aproximou de 75,0\%, alcançando 72,7\%. A UTI - Neonatal obteve, entre as UTIs o mais baixo percentual de respostas positivas nesta dimensão, 59,1\%. 

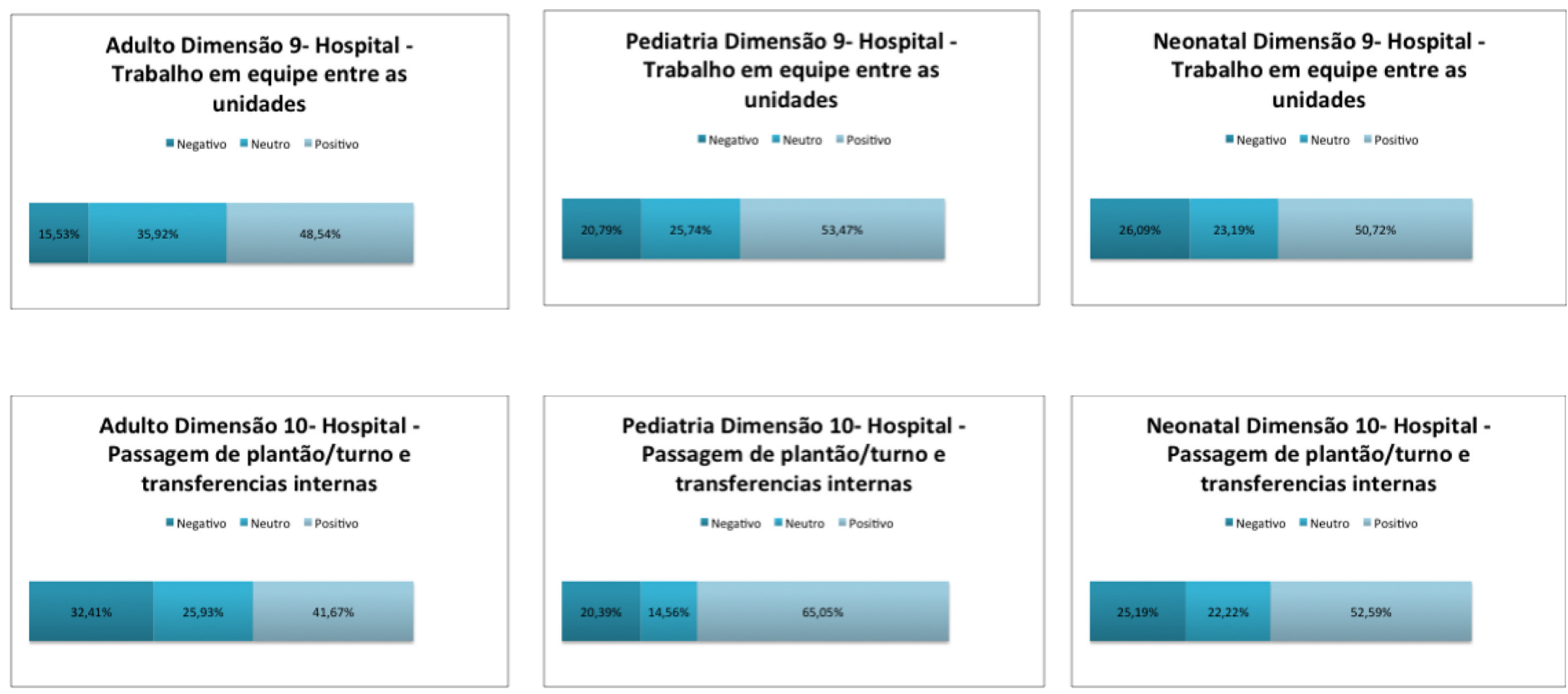

Figura 12 -: Percentual de respostas positivas, neutras e negativas para as dimensões 9 e 10 da Unidade HSOPSC nas UTIs Adulto, Pediátrica e Neonatal. Sumaré, 2014. 

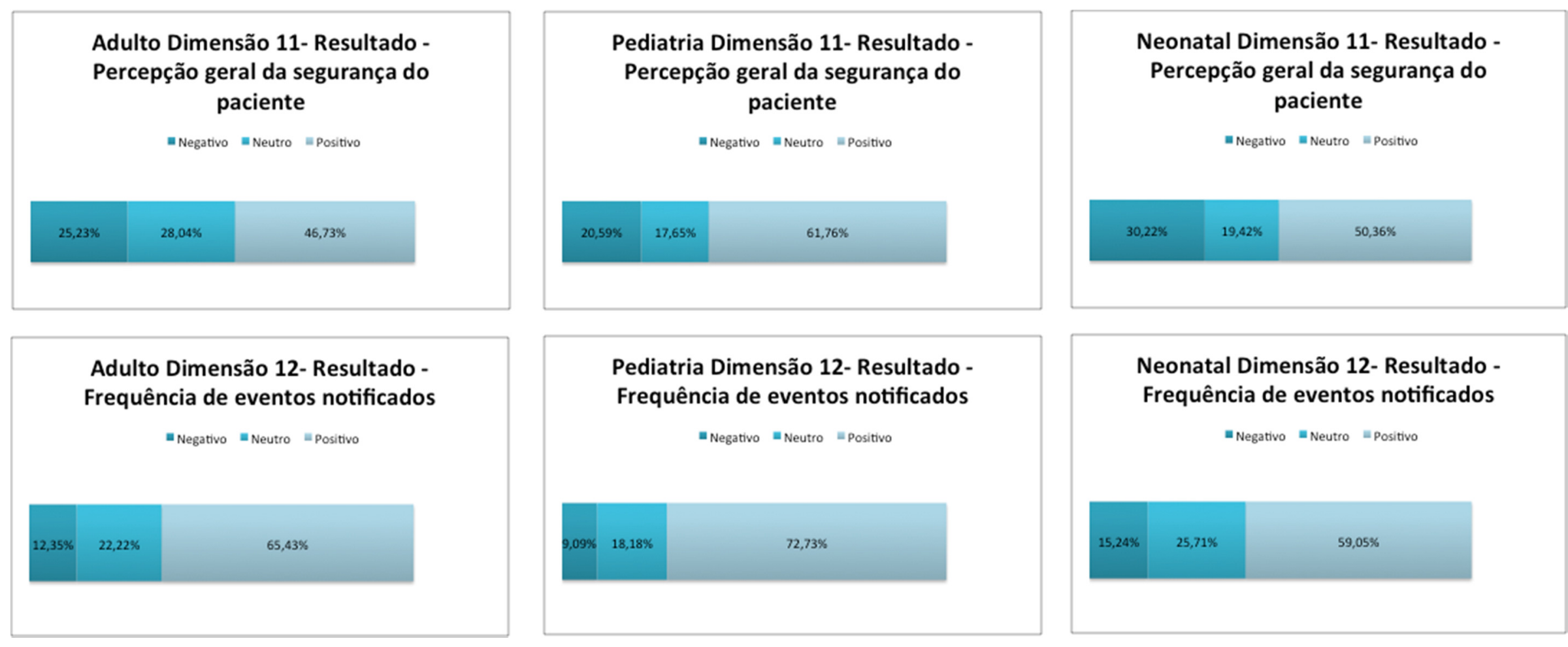

Figura 13 - Percentual de respostas positivas, neutras e negativas para as dimensões 11 e 12 da Unidade HSOPSC nas UTIs Adulto, Pediátrica e Neonatal. Sumaré, 2014. 
A "Nota de segurança do paciente" foi avaliada predominantemente como "excelente" ou "muito boa" nas três UTIs, sendo $77,8 \%$ na UTI - Adulto, $88,5 \%$ na UTI - Pediátrica e 85,7\% na UTI Neonatal. A UTI - Adulto apresentou maior percentual de respostas "regular" para esta avaliação. (Figura 14).
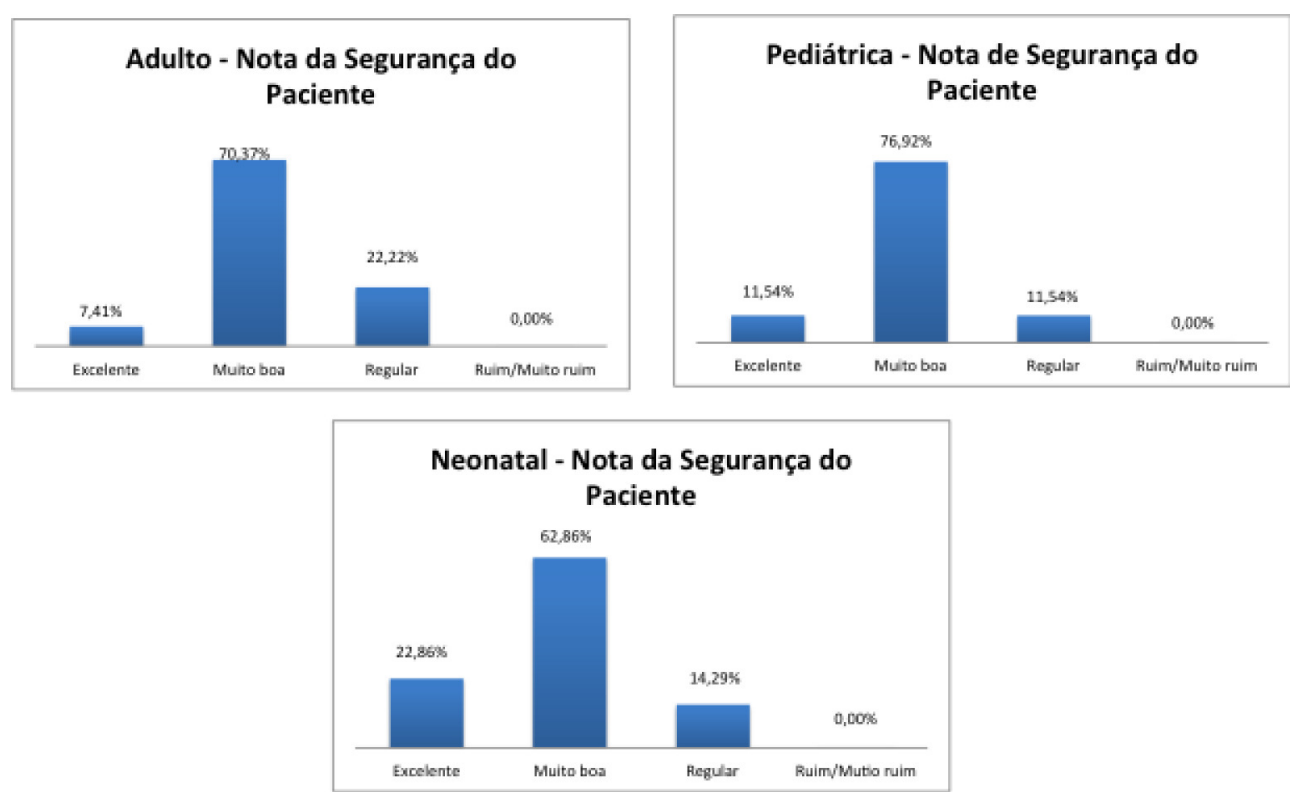

Figura 14 - Nota de segurança do paciente por UTI, Sumaré 2014

Nas três UTIs, a maioria dos participantes respondeu que não notificou nenhum evento de segurança nos últimos 12 meses. Apenas a UTI - Adulto declarou que notificou 21 ou mais; 14 participantes deixaram essa questão em branco, ou seja sem resposta. (Figura 15) 


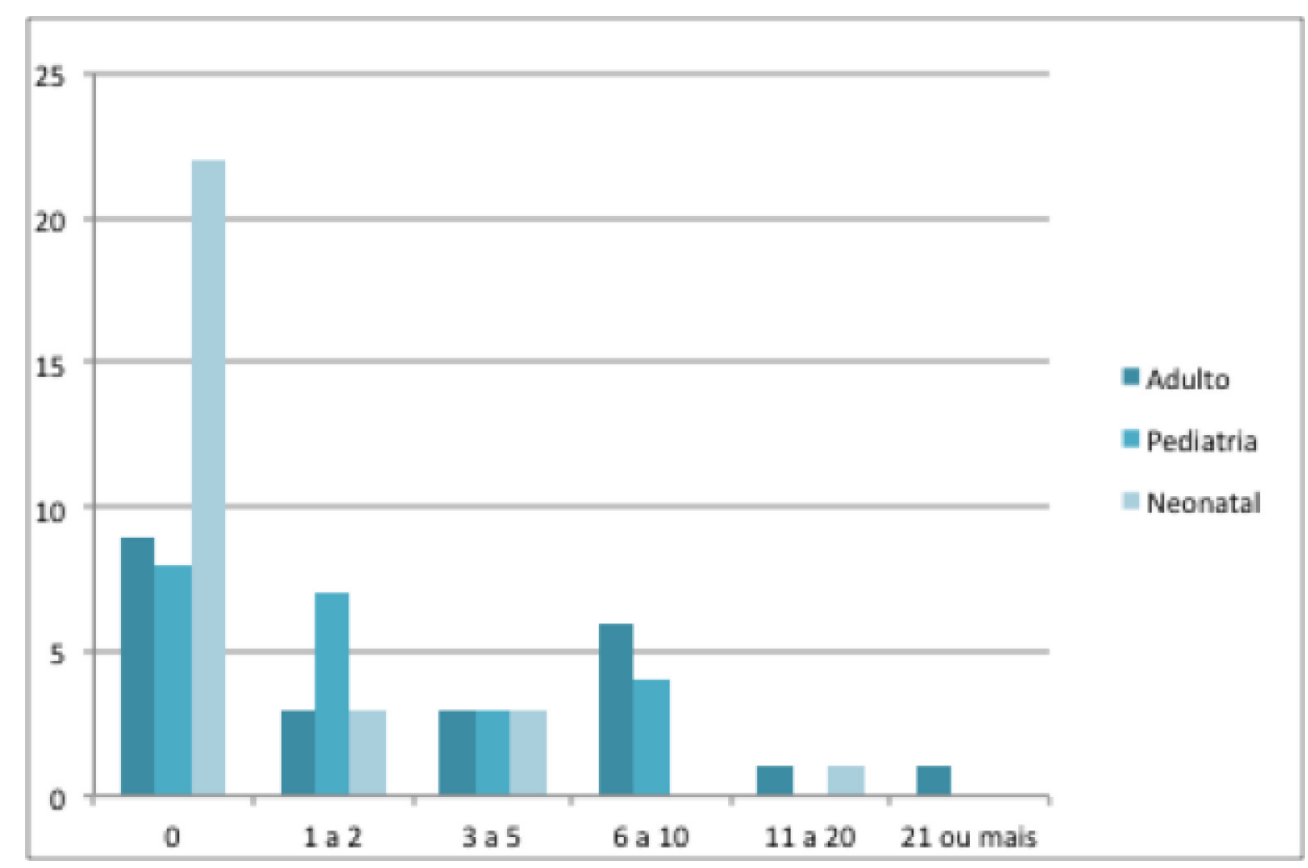

Figura 15 - Número de eventos modificados nos últimos 12 meses por UTI, Sumaré 2014.

\subsubsection{Associação entre as escalas e as variáveis sóciodemográfica e de caracterização profissional}

Foi realizado o teste de diferença de médias ou de variância para verificar se haveria alguma diferença nas pontuações obtidas nas escalas, domínios e variáveis de estudo

Comparando os domínios do SAQ e sexo (Apêndice D), houve significância estatística $(p=0,004)$ no domínio "Percepção do estresse", em que homens apresentaram maior percepção do estresse que as mulheres. Comparando os domínios das escalas com o tipo de UTI através do teste ANOVA, a UTI Neonatal tem melhor percepção do Domínio Satisfação no trabalho do que a UTI Adultos, com $\mathrm{p}=0,049$.

Houve correlação entre as variáveis quantitativas idade e o domínio "Percepção do estresse" da SAQ. Quanto maior a idade do respondente maior a percepção do estresse, $p=0,049$. 
Na comparação da escala HSOPSC (APÊNDICE D) entre as categorias profissionais, os "profissionais de enfermagem" mostraram melhor percepção nas dimensões do "Aprendizado Organizacional - Melhoria Continua" e "Adequação de Profissionais" do que "outros profissionais", respectivamente, $p=0,026$ e $p=0,019$. Comparando os cargos agrupados com os domínios através da ANOVA, "médicos" apresentaram melhor percepção sobre o domínio Clima de Trabalho em equipe do que "outros profissionais" $(p=0,034)$.

Entre o HSOPSC e as variáveis quantitativas houve correlação positiva entre "Grau de segurança do Paciente" e carga horária semanal, $p=0,020$, onde quanto maior a carga horaria semanal do respondente melhor a percepção do grau de segurança do paciente". Também foi observado correlação positiva entre a dimensão "Adequação de Profissionais" e carga horaria semanal $(p=0,011)$.

Houve correlação negativa entre a dimensão "Frequência de notificação de eventos" e tempo de trabalho no hospital, ou seja, quanto menor o tempo de trabalho no hospital, maior a frequência de notificação de eventos $(p=0,049)$.

\subsubsection{Correlação entre as escalas}

Diversos domínios da SAQ e dimensões do HSOPSC tiveram correlação estatisticamente significativa, porém com valores moderados de correlação.

Os maiores valores de correlação de Pearson ocorreram entre:

- HSOPSC Global e SAQ - Domínio Clima de Segurança: $r=$ 0,69 e $p=0,000$

- HSOPSC Global e SAQ Global: $r=0,66$ e $p<0,000$ 
- HSOPSC domínio "Retorno da informação e Comunicação sobre o Erro" e SAQ Total: $r=0,58$ e $p<0,000$.

- HSOPSC Domínio "Retorno da informação e Comunicação sobre o Erro" e SAQ Domínio Clima de Segurança: $r=0,57$ e $\mathrm{p}<0,000$

- HSOPSC Domínio "Retorno da informação e Comunicação sobre o Erro" e SAQ domínio Condições de Trabalho: $r=0,52$ e $p<0,000$

5.2.7 Análise de conteúdo da questão aberta - Seção H "Sinta-se a vontade para escrever qualquer comentário sobre segurança do paciente, erros ou relatos de evento no seu hospital

Através da análise de conteúdo, os conteúdos das respostas foram agrupados em quatro categorias: Reconhecimento da Preocupação com a Segurança do Paciente, Comunicação Interna e Gestão de Pessoas, Cultura da Culpa e Medo de Punição e Críticas, Sugestões e relatos de erros.

- Reconhecimento da Preocupação com a Segurança do Paciente

Nesta categoria os conteúdos de maior significado foram observados nas UTIs que envolvem a assistência de neonatos e crianças. Um profissional da UTI Pediátrica reconhece as mudanças ocorridas no hospital em decorrência dos processos de acreditação, com maior preocupação voltada para a segurança do paciente:

"[...] acredito que por parte do mesmo se preocupem muito com a segurança do paciente, neste tempo em que trabalho aqui .. 5 anos, muita coisa mudou nessa questão, até porque o hospital 
passou por 3 tipos de acreditação"- (Enfermagem UTI Pediátrica).

Outro profissional também da UTI Pediátrica relata a importância da notificação de eventos e o desfio para a mudança do paradigma que envolve o erro e a punição:

"[...]incentivar os colaboradores a notificar os eventos, trabalhar com as questões preventivas e mitigar os danos é fundamental. Mudar o paradigma do erro como punitivo para um olhar construtivo, favorecendo mais qualidade na assistência foi um desafio para a instituição [...]" (Enfermagem UTI Pediátrica).

Uma visão compartilhada da segurança do paciente se evidencia na fala a seguir:

\footnotetext{
"Por ser hospital modelo, a segurança do paciente, os cuidados e o comprometimento com os mesmos, são de responsabilidade de todos, $e$ creio que todos se comprometem neste sentido, pois ninguém sabe o que pode ocorrer no momento seguinte, pois de funcionário você pode ser paciente."(Enfermagem - UTI Neonatal).
}

\section{- Comunicação Interna e Gestão de Pessoas}

Em duas respostas da UTI - Adulto e uma da UTI - Pediátrica os profissionais demonstraram a percepção e preocupação quanto a política de gestão de pessoas e treinamento e o impacto na segurança do paciente:

"Má remuneração acarreta perda de ótimos profissionais que aqui estiveram. Nós somos os últimos, a saber, da s mudanças devido o noturno ser esquecido dos outros horários [...]"-

Enfermagem UTI Adulto 
"Não há plano de carreira para a área médica, o que dificulta a permanência de profissionais mais experientes e melhor qualificados, o que tem relação direta com a segurança do paciente (qualidade e quantidade) os profissionais que só trabalham de fim de semana são mal informados sobre mudanças de processos"- Médico UTI Adulto

"[...] não me sinto preparado com relação aos pacientes críticos [....] - Enfermagem UTI

Pediátrica

As dificuldades de comunicação interna com o turno de trabalho noturno e com o plantonista dos finais de semana também foram evidenciadas.

\section{- Cultura da Culpa e Medo de Punição}

O receio de que haja sanções aos profissionais diante de erros na assistência ao paciente também se revelou na resposta de um dos respondentes:

"[...] Observo que alguns colaboradores acreditam em ações punitivas, o que não é verdade, pois quando acontece o erro, buscamos rever 0 processo de trabalho... Talvez esse medo das notificações colabore com o aumento das subnotificações. "Enfermagem UTI Pediátrica.

"Não me sinto preparada em relação aos pacientes críticos, porém, se não existe preparação e houver erros somos repreendidas e apontadas"- Enfermagem UTI Pediátrica. 


\title{
- Críticas, sugestões e relatos de erros
}

Alguns dos participantes expressaram sugestões, como na questão de um respondente da UTI Neonatal sobre pulseiras de identificação adequadas a recém nascidos.

\begin{abstract}
"Poderia melhorar as pulseiras de identificação do $R N$ pois a atual causa lesão aos RN. Ter mais atenção na compra de material para que eles tenham mais qualidade. Ter cursos em horários que os profissionais da noite possam participar [...] - Enfermagem UTI Neonatal
\end{abstract}

$\mathrm{Na}$ resposta de um profissional da categoria "Outros profissionais" da UTI - Adulto aparece a crítica a um modelo burocrático na integração de novos profissionais em detrimento ao acompanhamento/supervisão direta.

"Hoje existe uma preocupação muito grande com a burocracia de se treinar funcionários, passar os protocolos existentes, mostrar dados e fluxogramas perfeitos, sendo que na prática não existe uma supervisão direta e específica para contabilizar os possíveis riscos que os pacientes estão expostos. Os objetivos se perderam ao longo do tempo, o paciente já não e mais o foco [...]"- Outros profissionais UTI-Adulto.

Também se expressou a diferença de comportamento em relação ao cumprimento de normas de acordo com a categoria profissional:

"Concordo com as regras, porém tem que ser para todos os funcionários, de medico e enfermeiro até o técnico [...]"- Enfermagem UTI Neonatal 


\section{DISCUSSÃO}

Este estudo selecionou unidades de terapia intensiva para pacientes adultos, pediátricos e neonatos, a fim de aplicar concomitantemente os instrumentos SAQ e HSOPSC, recentemente validados para o Brasil (Lima, 2011; Reis, 2013).

Outros trabalhos aplicando o instrumento HSOPSC, não mencionando validação do construto, foram realizados no país. (Batalha, 2012; Clinco, 2007)

Ambos os instrumentos, são largamente utilizados em outros países em unidades abertas (enfermaria) e fechadas como UTIs e centros cirúrgicos (Huag et al., 2011; Pronovost et al. 2008; Speroff et al., 2010).

Na validação para o Brasil, os instrumentos SAQ e HSOPSC foram aplicados em profissionais de unidades de internação. O presente estudo os aplicou, portanto, em população diferente da estudada no trabalho de adaptação transcultural e validação dos instrumentos.

Valores de alfa de Cronbach superiores a 0,70 indicam boa confiabilidade (Terwee et al., 2007). Como observado no presente estudo o alfa de Cronbach para o SAQ e HSOPSC foram elevados, assim como os obtidos nos estudos de validação para o português aplicado em profissionais de unidades de internação não críticas.

As autoras (Lima, 2011; Reis, 2013) dos estudos de validação do SAQ e HSOPSC sugerem que o alfa de Cronbach seja calculado em estudos futuros com os instrumentos no Brasil. Dessa maneira, as figuras 16 e 17 apresentam a comparação dos valores de alfa de Cronbach obtidos nos estudos de validação para o Brasil com os do presente estudo. 
Com exceção dos subdomínios supramencionados os demais valores de alfa de Cronbach foram semelhantes aos encontrados no estudo de validação do instrumento, sendo os mais elevados encontrados em "Percepção do estresse", "Satisfação no trabalho" e os mais baixos em "Clima de trabalho em equipe"," Clima de segurança" e "Condições de trabalho", como observado na figura 16.

Figura 16 - Comparação dos Alfas de Cronbach do SAQ obtido no estudo de validação de Lima (2011) com os do presente estudo.

\begin{tabular}{lcc}
\hline \multicolumn{1}{c}{ Domínios do SAQ } & \multicolumn{2}{c}{ alfa de Cronbach } \\
& UTIs Sumaré, 2014 & Lima (2011) \\
\hline $\begin{array}{l}\text { SAQ Total } \\
\text { Clima de trabalho em }\end{array}$ & 0,853 & 0,89 \\
equipe & 0,669 & 0,65 \\
Clima de Segurança & 0,604 & 0,67 \\
Satisfação trabalho & 0,729 & 0,77 \\
Condições de trabalho & 0,688 & 0,65 \\
Percepção do estresse & 0,743 & 0,78 \\
& & \\
Percepção da gerencia & 0,775 & $*$ \\
& & \\
Unidade & 0,629 & 0,79 \\
Hospital & 0,727 & 0,75 \\
\hline
\end{tabular}

* valor não informado

Os participantes desta pesquisa puderam preencher os instrumentos em momento posterior, caso desejassem. No momento da coleta dos envelopes preenchidos houve relatos por parte da equipe que o layout do $S A Q$ foi mais atrativo para preenchimento, por estar em página única e ser colorido.

Também existiram relatos, principalmente por profissionais de nível médio, que os itens reversos ofereceram maior dificuldade para compreensão, tanto no SAQ quanto no HSOPSC. Situação semelhante foi encontrada no estudo de validação do SAQ no Brasil. (Lima, 2011). 
Na comparação dos valores de alfa de Cronbach do HSOPSC do presente estudo (Figura 17) com os do estudo de validação por Reis (2013) observou-se a maior diferença para os domínios "Ações e expectativas sobre seu supervisor/chefe e ações promotoras da segurança do paciente" e "Aprendizado organizacional melhoria contínua".

Figura 17 - Comparação dos Alfas de Cronbach do HSOPSC validado por Reis (2013) e o do presente estudo.

\begin{tabular}{lcc}
\hline \multicolumn{1}{c}{ Dimensões HSOPSC } & \multicolumn{2}{c}{ alfa de Cronbach } \\
& UTIs Sumaré, 2014 & Reis (2013) \\
\hline HSOPSC Total & 0,899 & 0,91 \\
& & \\
Trabalho em equipe dentro das unidades & 0,668 & 0,66 \\
Ações e expectativas sobre seu supervisor /chefe & & \\
e açães promotoras da segurança do paciente & 0,55 & 0,76 \\
Aprendizado organizacional melhoria contínua & 0,712 & 0,56 \\
Apoio da gestão para segurança do paciente & 0,71 & 0,84 \\
Percepção geral da segurança do paciente & 0,437 & 0,52 \\
Retroalimentação da informação e comunicação & & \\
sobre o erro. & 0,674 & 0,72 \\
Abertura da comunicação & 0,487 & 0,69 \\
Frequência de notificação de eventos & 0,823 & 0,91 \\
Trabalho em equipe entre as unidades & 0,789 & 0,67 \\
Adequação de profissionais & 0,304 & 0,2 \\
Passagem de plantão ou de turno/transferências & 0,742 & 0,69 \\
Respostas não punitivas aos erros & 0,468 & 0,35 \\
\hline
\end{tabular}

Poderia se supor que o maior alfa para o domínio "Aprendizado organizacional melhoria contínua" nas UTIs do presente estudo estivesse relacionado ao fato do hospital ser acreditado, o que exige um processo de melhoria contínua para alcançar outros níveis de acreditação.

A possibilidade de utilizar instrumentos sobre clima e cultura de segurança adaptados e validados para a cultura local brasileira é de grande valor.

Diversos estudos vem mostrando o impacto do cuidado inseguro nos sistemas de saúde e na sociedade como um todo, tanto do ponto de vista social quanto financeiro (Jha, 2013; Khol, 1999; Vincent 2009; 
Wachter, 2013). Esta é, provavelmente, uma realidade também para o Brasil.

Pesquisas relacionando a percepção das equipes assistenciais sobre o clima/cultura de segurança do paciente e resultados assistenciais vem crescendo nos últimos anos. Há tentativas de avaliar se melhores percepções a cerca da segurança do paciente estariam relacionadas com melhores resultados assistenciais e menores taxas de eventos adversos.

Huang et al (2010) relatam em estudo em UTIs que a baixa percepção sobre a gerência estiveram moderadamente associados com maior mortalidade hospitalar e que baixos clima de segurança, satisfação no trabalho e percepção da gerência estiveram associados com aumento do tempo de permanência no hospital.

Em estudo em UTIs no Michigan Pronovost et al. (2008) observaram melhoria nas pontuações do SAQ após intervenções no ambiente de trabalho, o que demonstraria a sensibilidade do instrumento em refletir resultado de mudanças realizadas no contexto da unidade.

Como já mencionado a população alvo deste estudo foi a equipe multiprofissional das UTIs adulto, pediátrica e neonatal, compreendendo tanto profissionais ligados diretamente a assistência como médicos, enfermeiros, técnicos de enfermagem, fisioterapeutas, entre outros e profissionais de serviços de apoio e administrativo, numa tentativa de compreender as percepções da unidade como um todo, não exclusivamente de uma categoria profissional.

As três UTls apresentaram distribuição homogênea quanto a categoria profissional, sexo, predominando profissionais de enfermagem e do sexo feminino. Cargos de chefias das UTIs médico coordenador e enfermeiro supervisor - foram convidados a participar da pesquisa e foram agrupados com os demais participantes nos grupos "Profissionais médicos" e "Profissionais de 
enfermagem". Nestas unidades esses profissionais, com exceção da coordenação médica da UTI Pediátrica, desempenham função de liderança, concomitante com atividades assistenciais diretas ao paciente em alguns momentos.

$\mathrm{Na}$ avaliação pelo SAQ nenhuma das três UTls obteve pontuação inferior a 50, o que sinalizaria áreas frágeis para segurança do paciente. A maioria dos domínios permaneceu em faixa intermediária entre 50 e 75 pontos. Segundo os autores do instrumento pontuações iguais ou superiores a 75 indicam áreas fortes quanto a segurança do paciente.

Portanto, na avaliação do SAQ houve predomínio de nível intermediário de pontuação, sem apontamento de áreas francamente frágeis (pontuação abaixo de 50).

Quanto ao HSOPSC, alguns domínios obtiveram percentuais de respostas positivas inferiores a $50 \%$, o que, segundo os autores do instrumento, demonstra a sinalização de áreas de fragilidade (Sorra, Nieva, 2004). Apesar de, na avaliação geral, também haver predomínio de percentual de respostas positivas em faixas intermediárias, entre 50 e $75 \%$.

Para o SAQ, o domínio de mais baixa pontuação no agrupamento das três UTIs foi "Percepção da gerência" tanto da unidade $(61,2 \%)$ como do hospital $(55,3 \%)$.

Há relatos na literatura de que é frequente que a percepção dos profissionais da operação seja diferente da percepção da liderança sobre as questões de segurança (Wachter, 2013).

Aspectos relacionados a treinamento, capacitação e carreira estiveram presentes nas respostas dos profissionais da questão aberta do HSOPSC. A capacitação de recursos humanos em saúde é um desafio em nosso país. É frequente a contratação de profissionais sem adequada avaliação de conhecimento, com 
formação de qualidade prejudicada e que acumulem mais de uma jornada de trabalho devido aos baixos salários.

A liderança desempenha um papel importante no desenvolvimento de sua equipe (Limongi-França, Arellano, 2002; Schein, 2009). Pontuações baixas na avaliação deste quesito podem estar relacionadas a percepção do desenvolvimento profissional do indivíduo dentro da organização.

Os modelos de educação permanente dentro dos hospitais estão estruturados, com frequência, para atender necessidades técnicas pontuais, específicas, principalmente da equipe de enfermagem. A noção de integralidade na saúde, do processo de saúde doença e da coordenação de ações da equipe multiprofissional é pouco abordada.

Tronchin et al. (2009) relata o foco no aspecto técnico pontual, em estudo a cerca da educação permanente de três hospitais em São Paulo.

No presente estudo a dimensão "Aprendizado organizacionalmelhoria continua" foi melhor avaliada pela categoria "profissionais de enfermagem" do que pela categoria "outros profissionais".

Apesar das baixas pontuações quanto a percepção da gerência, o domínio "Satisfação no trabalho" do SAQ na UTI Neonatal apresentou diferença estatisticamente significativa quando comparada a UTI de adultos. Outros aspectos relacionados a satisfação no trabalho apresentaram-se maiores nas UTIs infantis (pediátrica e neonatal) do que na UTI Adulto. "Adequação de profissionais" do HSOPSC obteve o menor percentual de respostas positivas na UTI adulto. Não foram encontrados relatos na literatura que expliquem os dados encontrados.

A UTI neonatal concentrou também profissionais com mais tempo de experiência, quando comparada às demais UTIs estudadas. Este 
fato pode ser reflexo da melhor satisfação no trabalho onde, portanto, a rotatividade de profissionais seria menor.

O domínio "Percepção do estresse" do SAQ aborda o quanto o profissional consegue perceber que a carga de estresse favorece situações de risco para segurança do paciente. Neste quesito, a UTI Neonatal apresentou melhor percepção de estresse que as demais unidades.

Há estudos que relatam que, quanto maior a idade e a experiência dos profissionais, melhor a forma de lidar com estresse (Cavalheiro, 2008; Ferreira,1998). Talvez o aspecto tempo na especialidade, explique a superior pontuação da UTI Neonatal no domínio "Percepção do estresse", no presente estudo.

Uma investigação sobre estresse em enfermeiros de UTIs pediátrica, neonatal e adulto encontrou resultados que corroboram com a hipótese de que a experiência profissional parece estar inversamente relacionada com o estresse, como se o tempo de trabalho oferecesse suporte a mediação dos estressores no trabalho (Cavalheiro, 2008; Ferreira,1998).

Para Taylor (2013), o domínio "Percepção do estresse", que compõe a escala SAQ destoa dos demais domínios. Diferentemente dos outros cinco, que tratam a respeito da percepção do respondente sobre seu ambiente de trabalho, sua relação com a equipe e com seus superiores, o domínio "percepção do estresse" tem entonação de auto avaliação, sobre como o respondente se percebe frente as situações de estresse e relaciona isso com situações de vulnerabilidade à segurança do paciente em seu trabalho. Para os autores a percepção do estresse é uma medida distinta do clima de segurança e mais estudos devem ser produzidos para avaliar a separação deste domínio do restante da escala.

Profit et al. (2014) utilizou o SAQ em estudo em 44 UTIs neonatais nos Estados Unidos e seu estudo revelou que profissionais que 
sofriam de burnout tendiam a ter pior percepção da cultura de segurança, o que estabeleceria uma relação entre estresse e cultura de segurança.

A dimensão "Trabalho em equipe dentro das unidades" apresentou percentual de resposta positiva expressivamente maior na UTI Pediátrica do que na UTI Adulto e Neonatal. A UTI Pediátrica integra o grupo das Unidades pediátricas deste hospital, formada também pela Emergência Referenciada Pediátrica e pela Enfermaria de Pediatria. As lideranças médica e de enfermagem são comuns às três áreas. Provavelmente isso tenha colaborado para que a percepção do trabalho em equipe dentro das unidades fosse melhor.

$\mathrm{Na}$ dimensão "Trabalho em equipe entre as unidades", que compreende questões sobre a cooperação e a noção de impacto do trabalho de outros setores na sua unidade, as três UTIs obtiveram percentuais de repostas positivas semelhantes, em torno de $50 \%$, demonstrando que a interação intersetorial do hospital pode apresentar algumas fragilidades.

A importância da comunicação e seu impacto na segurança do serviços de saúde é amplamente reconhecida nos dias atuais.

A UTI adulto apresentou percentual de respostas positivas inferior a $50 \%$ na dimensão "Passagem de plantão ou turno". Essa dimensão obteve melhor a avaliação na unidade de terapia intensiva pediátrica, do que nas outras duas UTIs. Por outro lado, na dimensão "Abertura da comunicação" as UTIs pediátrica e neonatal apresentaram percentuais de respostas positivas inferior a $50 \%$.

Outro aspecto relevante ligado a comunicação é a dimensão "retorno da informação" e comunicação sobre o erro que apresentou percentuais de respostas positivas em torno de $50 \%$ nas UTIs.

O percentual de respostas positivas mais baixo, para todas as UTIs, foi na dimensão "Resposta não punitiva aos erros". Esse aspecto 
levanta a temática sobre a cultura justa e a cultura da não culpabilidade e a avaliação das dimensões relacionadas a comunicação e relato de erro pode sugerir a necessidade de maiores investimentos nesses quesitos.

O hospital que comporta as três UTIs participantes desse estudo é acreditado, pela metodologia nacional da Organização Nacional de Acreditação e pelo Accreditation Canada. O trabalho de melhoria da qualidade e segurança da assistência nesta instituição é de longa data e sua importância é reconhecida tanto pelos programas de acreditação quanto por outras instituições de saúde da região.

A preocupação com a qualidade e a segurança da assistência a saúde é percebida pelos profissionais tanto na atribuição da "Nota para segurança do paciente", dimensão do HSOPSC, onde predomina a avaliação excelente ou muito boa nas três UTIs, e também expressa na questão aberta de um dos respondentes.

Mesmo possuindo reconhecimento na área da qualidade dos serviços os instrumentos demonstraram áreas com oportunidades de melhoria.

Numa contextualização de cenário, a discussão sobre o erro no serviço de saúde é relativamente recente no Brasil e a imputação de culpa aos profissionais que erram é fortemente arraigada e está presente desde a formação desses profissionais.

Algumas matrizes de decisão, como, por exemplo, a apresentada na figura 18 , tem sido utilizada a fim de subsidiar a tomada de decisão e evitar posturas mais extremistas de culpar sempre ou nunca responsabilizar os profissionais envolvidos em incidentes que afetem a segurança do paciente. 


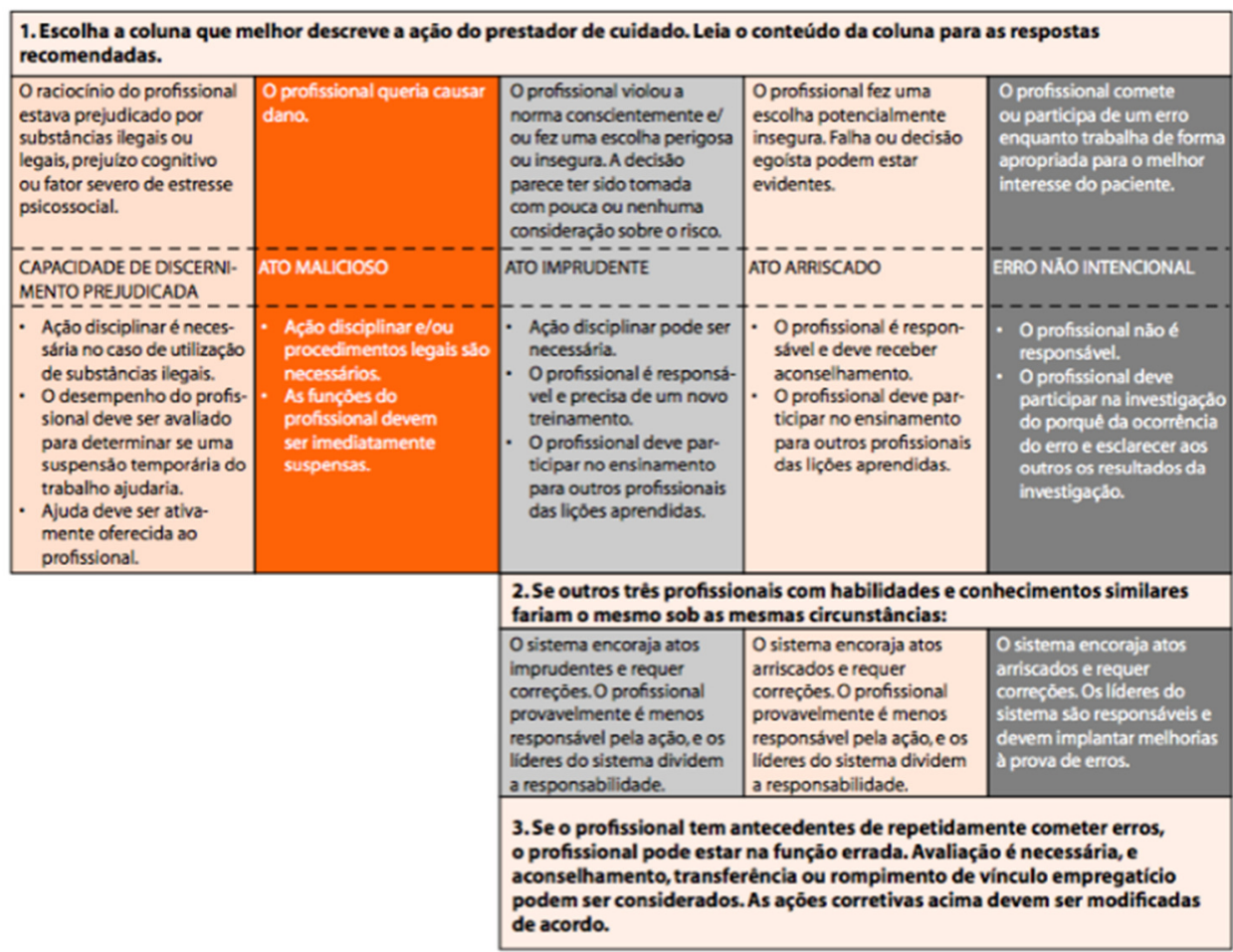

Figura 18 - Algoritmo de Frankel, Wachter, 2013, p 346.

Durante muitos anos o foco da "cultura da não culpabilidade" teve seu espaço, mas vem sendo recentemente confrontada com o conceito de "cultura justa".

Em entrevista a publicada no site Proqualis, os especialistas Sidney Dekker e Robert Wachter discutiram a responsabilização dos profissionais envolvidos em incidentes. Sidney Dekker aponta um fato curioso e ainda bastante presente no setor saúde: a soberania do senso de autonomia dos profissionais. O autor relata também que outras indústrias de alta confiabilidade, como a aviação, enfrentaram situações semelhantes no passado. (Proqualis, 2014)

É frequente no cotidiano dos hospitais que este "senso de autonomia" prevaleça em detrimento a questões já bem estabelecidas pela ciência, através de saúde baseada em evidência ou mesmo regulamentada por protocolos institucionais. Há uma relutância dos indivíduos em abandonar esse papel. Corroborando 
com isto, Gawande (2011) aponta que estamos vivendo um momento de transição cultural na saúde. A crença ainda vigente é que atividades complexas e de alto risco, como cirurgias, exigem profissionais arrojados e corajosos. O estímulo a adoção de protocolos ou ferramentas como checklist de segurança cirúrgica são iniciativas que consideram a falibilidade humana e vão na contramão da crença relatada.

A imprevisibilidade dentro dos serviços de saúde, a variabilidade clínica e outras características frequentemente reportadas como empecilho para adoção de ferramentas de qualidade e padronização estão presentes e precisam ser reconhecidas, mas há muitos aspectos previsíveis, onde esses instrumentos seriam aplicáveis e provavelmente benéficos. (Vincent, 2009; Gawande, 2011).

Em 2013 através da RDC 36, o Brasil estabelece em território nacional a obrigatoriedade das instituições de saúde adotarem um plano para segurança do paciente. A legislação estabelece a formação de núcleos de segurança do paciente dentro dos serviços de saúde e a necessidade de criar fluxo de notificação e tratamento dos incidentes relacionados a segurança do paciente, incluindo a notificação obrigatória a Agência Nacional de Vigilância Sanitária. (Brasil, 2013). Trata-se de um importante passo para ampliação da discussão sobre o assunto segurança do paciente em âmbito nacional.

Concomitantemente a publicação da RDC 36/2013, a Agência Nacional de Vigilância Sanitária publicou uma série de manuais para apoio e instrução das organizações de saúde sobre o assunto.

As relações de poder dentro do serviço de saúde também são observadas, entre categorias profissionais como médicos e enfermeiros e na própria estrutura hierárquica da organização entre liderança e subordinados. 
Speroff et al. (2010) aponta que culturas organizacionais mais burocráticas são menos propensas ao desenvolvimento da qualidade do que as organizações com maior equilíbrio de trabalho em grupo.

Em estudo comparando a aplicação do HSOPSC em diferentes países, Japão, Taiwan e estados Unidos da América, os autores encontraram baixos percentuais de respostas positivas quanto a dimensão "Abertura da Comunicação" em Taiwan (Fujita et al, 2013). No presente estudo esta foi uma dimensão de baixas respostas positivas em todas as UTIs.

Para os autores do estudo comparativo (Fujita et al, 2013) entre os três países, a cultura chinesa tem como característica lideranças bastante autoritárias, o que poderia implicar em receio por parte dos colaboradores em manifestar suas preocupações e problemas com relação a segurança do paciente. Apesar de ser um país asiático, o Japão tem uma política nacional para reportar erros e problemas na segurança do paciente desde 2002.

Apesar da obtenção de resultados estatisticamente significativos na correlação entre HSOPSC e SAQ, os valores de correlação mais elevados encontrados se enquadram em força de correlação moderada.

Etchegaray (2012) em estudo de comparação entre os dois instrumentos também encontrou força de correlação moderada entre algumas dimensões.

O autor também obteve boa confiabilidade em ambos os instrumentos e valores preditivos de algumas dimensões do SAQ e do HSOPSC relacionados as dimensões de resultado do HSOPSC. Concluíram, portanto, que as instituições poderiam escolher entre um ou outro para aplicação em seu contexto. 


\section{CONCLUSÃo}

As UTIs neonatal, pediátrica e adulto, mesmo lotadas dentro de um mesmo hospital, apresentaram percepções distintas em alguns aspectos da cultura e clima de segurança do paciente, o que reforça a presença de microculturas locais dentro das organizações.

Em consonância com a literatura mundial sobre segurança do paciente, os aspectos relacionados a comunicação dentro dos serviços de saúde precisam ser desenvolvidos. Foram evidenciadas oportunidades de melhoria nesse quesito na avaliação por ambos os instrumentos, SAQ e HSOPSC. Esforços nesse sentido provavelmente facilitarão 0 relato de informações importantes para melhoria da segurança dentro do sistema. Estratégias que favoreçam a transferência segura de informações nas trocas de plantões e no manejo de pacientes entre as unidades também se mostraram necessárias.

Esse estudo não demonstra que os instrumentos sejam equivalentes, apesar de ambos avaliarem fenômenos semelhantes e possuírem correlação moderada entre as escalas num todo e entre alguns domínios.

O impasse sobre a denominação clima e cultura de segurança do paciente não foi elucidado neste estudo. Provavelmente a área da saúde se beneficiaria do apoio de antropólogos e sociólogos para a maior delimitação desses conceitos.

Sugere-se, para pesquisas futuras amostras populacionais maiores para o estudo de correlação entre os instrumentos SAQ e HSOPSC.

Por fim, sugere-se também que amplas discussões sobre os problemas de segurança nos serviços de saúde precisam ser estimuladas, tanto na esfera das organizações de saúde e centros formadores, quanto na sociedade. 


\section{REFERÊNCIA}

Bardin L. Análise de conteúdo. Lisboa: Edições 70; 2007.

Brasil. ANVISA. Agência Nacional de Vigilância Sanitária. Série Segurança do Paciente e Qualidade em Serviços de Saúde. Assistência segura: uma reflexão teórica aplicada a prática. Brasília; 2013.

Brasil. ANVISA. Agência Nacional de Vigilância Sanitária. RDC 36/2013 que institui ações para a segurança do paciente em serviços de saúde e dá outras providências. Diário Oficial da União, 25 de julho de 2013.

Carneiro VA. O erro clínico, os efeitos adversos terapêuticos e a segurança dos doentes: uma análise baseada na evidência científica. Rev Port Saúde Pública 2010; 10: 3-10.

Cavalheiro AM, Moura Junior DF, Lopes AC. Estresse de enfermeiros com atuação em unidade de terapia intensiva. Rev. Latino-am Enfermagem 2008 jan-fev; 16(1): 29-35.

Colla JB, Bracken AC, Kinney LM, Weeks WB. Measuring patient safety climate: a review of surveys. Qual Saf Health Care 2005, 14: 364-366.

Dicionário eletrônico Michaelis de língua portuguesa. [Internet]. [Citado 2014 ago. 18]. Disponível em: http://michaelis.uol.com.br/moderno/portugues/index.php?lingua=por tugues-portugues\&palavra=atitude.

Etchegaray JM, Thomas EJ. Comparing two safety surveys: Safety Attitudes Questionnaire and Hospital Survey on Patient Safety. BMJ Qual Saf 2012; 21:490-98. 
Ferreira FG. Desvendando o stress da equipe de enfermagem em terapia intensiva. [dissertação]. São Paulo: Escola de Enfermagem/USP; 1998.

Fisher RM. Mudança e transformação organizacional. In: Fleury MTL, organizadora. As pessoas na organização. São Paulo: Editora Gente; 2002. p.147-64

Fleury MTL, Sampaio JR. Uma discussão sobre cultura organizacional. In: Fleury MTL, organizadora. As pessoas na organização. São Paulo: Editora Gente; 2002. p.283 -94

Gawande A. Checklist como fazer as coisas bem feitas. Rio de Janeiro: Sextante; 2011.

Griffin FA, Resar RK.IHI Global Trigger Tool for Measuring Adverse Events (Second Edition).IHI Innovation Series white paper. Cambridge, MA: Institute for Healthcare Improvement; 2009. [Cited 2013 set 09] Available from http://www.ihi.org/resources/Pages/Tools/IntrotoTriggerToolsforldenti fyingAEs.aspx

Halligan M, Zecevic A. Safety Culture in health care: a review of concepts, dimension, measures and progress. BMJ Qual Saf, 2011; 20: 338-343.

Huang DT, Clermont G, Sexton JB, Karlo CA, Miller RG, Weissfeld LA et al. perceptions of safety culture vary across the intensive care units of a single institution. Crit Care Med 2007; 35(1): 165-76.

Huang DT, Clermont G, Kong L, Weissfeld LA, Sexton B, Rowan KM, et al. Intensive care unit safety culture and outcomes: a US multicenter study. Int J Qual Health Care 2010; 22 (3): 151-61 
Health and Safety Executive. HSE Human Factors Briefing Note No. 7 Safety Culture [Cited 2013 set 09] Available from http://www.hse.gov.uk/humanfactors/topics/07culture.pdf

Jha, A.K.; Larizgoitia, I.; Audera-Lopez , C.; Prasopa-Plaizier, N.; Waters, H.; Bates , D.W. The global burden of unsafe medical care: analytic modelling of observational studies BMJ Qual Saf 2013; 22(10): 809-815.

Kohn L, Corringan J, Donaldson M, editors. Institute of Medicine Report. To err is human: building a safer health system. Washington, DC: Institute of Medicine; 2000.

Lima, REF. Adaptação transcultural do Safety Attitudes Questionnaire para o Brasil - Questionário de Atitudes de Segurança [tese]. Ribeirão Preto: Escola de Enfermagem de Ribeirão Preto USP; 2011.

Limongi-França AC, Arellano EB. Liderança, poder e comportamento organizacional. In: Fleury MTL, organizadora. As pessoas na organização. São Paulo: Editora Gente; 2002. p 259-70

Menezes IG, Gomes ACP. Clima organizacional: uma revisão histórica do construto. Psicologia em Revista 2010; 16 (1): 158-79.

Morello RT, Lowthian JA, Barker AL, McGinnes R, Dunt D, Brand C. Strategies for improving patient safety culture in hospitals: a systematic review. Quality and Safety Health Care 2013; 22: 11-18.

National Patient Safety Foundation. Patient Safety Dictionary. [Cited 2013 set 09] Available from http://www.npsf.org/for-healthcare- 
professionals/resource-center/definitions-and-hot-topics/patientsafety-dictionary-n-z/

Puente-Palacios KE. Abordagens teóricas e dimensões empíricas do conceito de clima organizacional. RAUSP. 2002; n 37(3): 96-104

Proqualis [internet]. Rio de Janeiro; [2013?] Disponível em: http://proqualis.net/sites/proqualis.net/files/Uma\%20conversa\%20co m\%20Sidney\%20Dekker.pdf

Pronovost PJ, Berenholtz SM, Goeschel C, Thom I, Watson SR, Holzmueller CG, et al. Improving patient safety in intensive care units in Michigan. J Crit Care. 2008 Jun;23(2):207-21. doi: 10.1016/j.jcrc.2007.09.002.

Reason J. Human error: models and management. BMJ. 2000; 320: 768-70

Reichers AE, Schneider B. Climate and culture: An evolution of constructs. In: SCHNEIDER, Benjamin (ed.). Organizational Climate and Culture. San Francisco: Jossey-Bass, 1990. p. 5-39

Reis CT. A cultura de segurança do paciente: validação de um instrumento de mensuração para o contexto hospitalar brasileiro [tese]. Rio de Janeiro: Escola Nacional de Saúde pública Sérgio Arouca; 2013

Schein EH. Cultura organizacional e liderança. São Paulo: Atlas; 2009

Schneider B, Ehrhart MG, Macey WH. Organizational climate and culture. Online Annu. Rev. Psychol. 2013. 64:361-88. Available from: 
http://www.annualreviews.org/doi/pdf/10.1146/annurev-psych$\underline{113011-143809}$

Sexton JB, Helmreich RL, Neilands TB, Rowan K, Vella K, Boyden J, Roberts PR, Thomas EJ: The safety attitudes questionnaire: Psychometric properties, benchmarking data, and emerging research. BMC Health Serv Res 2006, 6:44 [http://www.biomedcentral.com/1472-6963/6/44]

Sorra JS, Nieva VF. Hospital survey on patient safety culture. Rockville, MD: Agency for Healthcare Research and Quality, 2004

Speroff T, Nwosu S, Greevy R, Weiger MB, Talbot TR, Wall RJ, et al. Organizational culture: variation across hospitals and connection to patient safety climate. Qual Saf Heatth Care 2010: 19:592-596. DOI: 10.1136/qshc 2009039511

Taylor JA, Pandian R. A dissonant scale: stress recognition in the SAQ. BMC Research Notes 2013, 6: 302 DOI: 10.1186/1756-0500-6302

Terwee CB, Bot SDM, Boer MR, Van der Windt DAWM, Knol DL, Dekker J, Bouter LM, de Vet HCW. Quality criteria were proposed for measurement properties of health status questionnaires. J Clin Epidemiol, v. 60, n.1, p.34-42, 2007.

Tronchin DMR, , et al. "Educação permanente de profissionais de saúde em instituições públicas hospitalares." Revista da Escola de Enfermagem da USP 43.spe2 (2009): 1210 -15

Vicent C. Segurança do paciente: orientações para evitar eventos adversos. São Caetano do Sul: Yendis; 2009. 
Watcher RM. Compreendendo a segurança do paciente. Porto Alegre: Artmed; 2010.

Watcher RM Compreendendo a Segurança do paciente. Porto Alegre: AMGH; 2013.

World Health Organization. Conceptual Framework for the Internaional Classification for Patient Safety, 2009. [Cited 2013 set 09]. (Available from http://www.who.int/patientsafety/implementation/taxonomy/icps te chnical report en.pdf) 


\title{
APÊNDICE A - Termo de Consentimento Livre e Esclarecido
}

\author{
Termo de Consentimento Livre e Esclarecido
}

I. Registro dos esclarecimentos da pesquisadora aos participantes da pesquisa

Eu, Thaiana Helena Roma Santiago, mestranda da Escola de Enfermagem da Universidade de São Paulo, sob orientação da Prof. Dra. Ruth Natalia Teresa Turrini, venho convidá-lo (a) participar da pesquisa intitulada "Cultura Organizacional para segurança do paciente em terapia intensiva: comparação de dois instrumentos Hospital Survey on Patient Safety Culture e Safety Attitudes Questionnaire". Esta pesquisa tem por objetivo avaliar a percepção dos profissionais de saúde sobre o clima de segurança do paciente em unidades de terapia intensiva em hospital de ensino do município de Sumaré.

Os questionários serão distribuido na sua unidade de trabalho e o preeenchimento leva em torno de 15 minutos cada instrumento. O conteúdo do instrumento será utilizado apenas para a realização do estudo, podendo os resultados serem apresentados em eventos e publicados em revistas cientificas, sem a identificação dos participantes.

O estudo não acarretará em despesas financeiras, danos ou risco previsível ao participante, garantindo-se o sigilo das informações e o anonimato. $\mathrm{O}$ estudo também não acarretará benefício direto ao participante da pesquisa, o benefício indireto será a geração de conhecimento na área de cultura e clima de segurança do paciente. Será entregue uma cópia do termo de Consentimento Livre e Esclarecido ao participante da pesquisa. A sua participação no estudo será voluntária, podendo deixá-la a qualquer momento. Caso aceite participar solicito sua assinatura no item II deste documento.

A pesquisadora estará a disposição para esclarecer dúvidas no preenchimento do questionário e desde já agradece pela sua atenção e coloca-se à disposição para quaisquer esclarecimentos sobre a pesquisa.

O enfereço do CEP da Escola de Enfermagem da USP é: Avenida Dr. Enéas de Carvalho Aguiar, 419. Email: edipesq@usp.br. Fone: 30617548; o do CEP da UNICAMP é e-mail: cep@f́cm.unicamp.br Fone (19) 3521-8936 e o da pesquisadoraEmail: thaianasantiago@gmail.com ou thaianasantiago@usp.br, fone (19) 992944140, (19) 3381-7772.

São instituições co-participantes neste projeto de pesquisa: Universidade Estadual de Campinas (UNICAMP) e Hospital Estadual Sumaré (HES).

II.

Registro e assinatura do participante da pesquisa

Eu, RG:

compreendo os objetivos desta pesquisa e concordo em participar de forma livre da mesma, entendendo que as informações serão utilizadas apenas para realização do estudo, que não sofrerei qualquer tipo de sanção ou prejuízo, caso desista de participar deste estudo.

Declaro ainda que ao ser convidado a participar desta pesquisa, todos os esclarecimentos foram prestados pela pesquisadora.

Sumaré, de de 2014 


\section{APÊNDICE B - Informações Sócio-Demográficas}

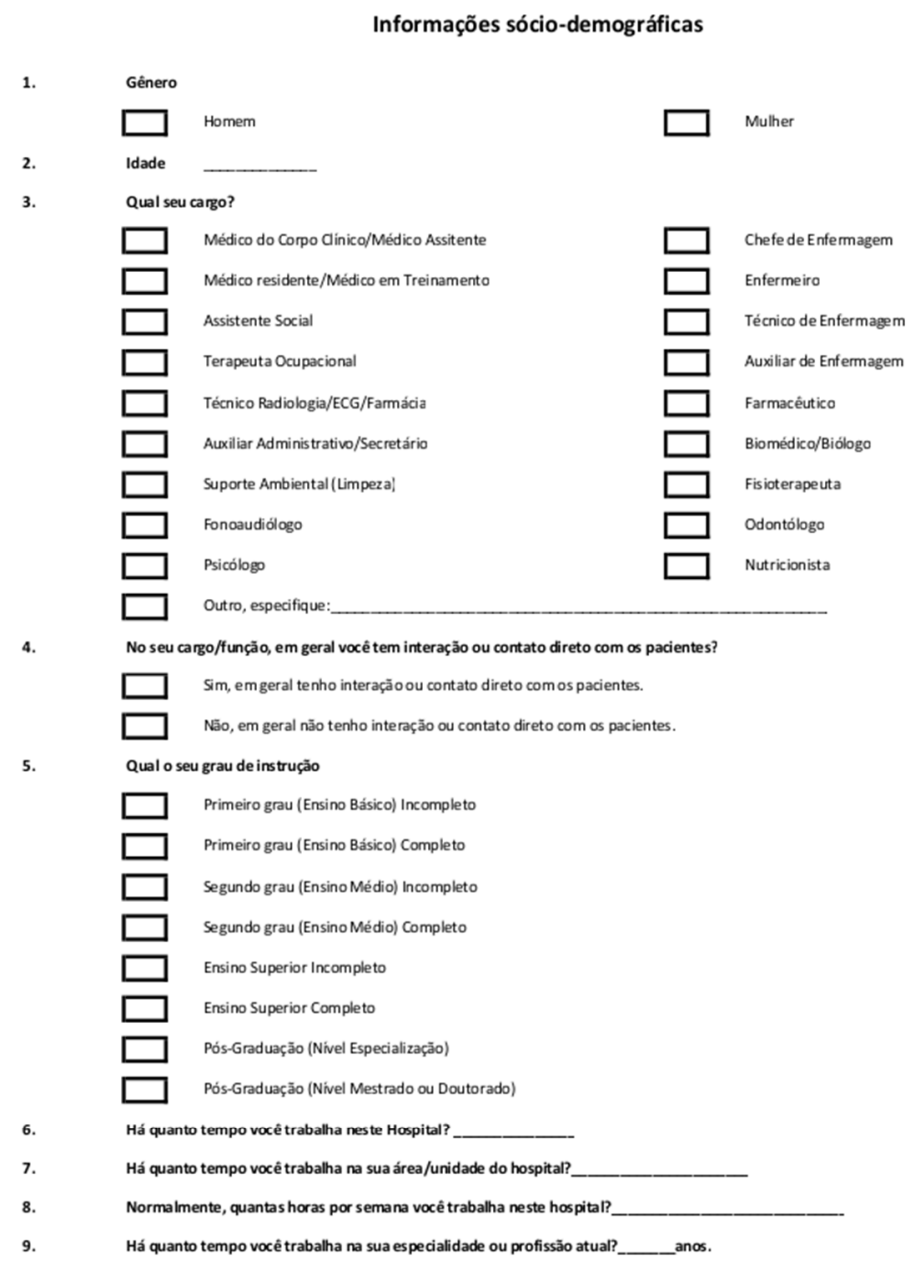




\section{APÊNDICE C - HSOPSC layout alterado}

Pesquisa sobre Segurança do Paciente em Hospitais (HSOPSC)

Instruçōes

Esta pesquisa solicita sua opiniáo sobre segurança do paciente, erros associados ao cuidado de saúde e notificaçắ

Se não quiser responder uma questâo, ou se uma pergunta năo se aplicar a você, pode deixá-la em branco.

Um "Evento" é definido como qualquer tipo de erro, engano, falha, incidente,
acidente ou desvio, independente se resultou ou ná em dano 80 paciente.

"Seguranca do paciente" $\theta$ definida como evitar e prevenir danos ou eventos

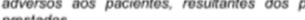

SECĀO A: Sua árealunidade de trabalho

Nesta pesquisa, pense em sua "unidade" como a área de trabalho, departamento ou área clinica do hospital onde vocé passe am

Qual 6 a sua principal area ou unidade neste hospital? Selecione UMA resposta.

\begin{tabular}{|c|c|}
\hline 口a. Diversas unidades do hospital/Nenhuma unidade especifica & $\square$ h. Psiquiatria/saúde mental \\
\hline 口 ๖. Clinica (nâo cirürgica) & 口 i. Reabilitaçâo \\
\hline$\square$ c. Cirurgia & 口j. Farmácia \\
\hline$\square$ d. Obstetricia & $\square$ k. Laboratorio \\
\hline 口 e. Pediatria & 口 L. Radiologia \\
\hline$\square$ f. Setor de Emergencia & $\square \mathrm{m}$. Anestesiologia \\
\hline$\square$ g. Unidade de terapia intensiva (qualquer tipo) & $\square$ n. Outra, por favor, especifique: \\
\hline
\end{tabular}

Por favor, indique a sua concordancia ou discordancia com relaçào às seguintes afirmaçoes sobre a sua área/unidade

\begin{tabular}{|c|c|c|c|c|c|}
\hline $\begin{array}{l}\text { Pense na sua area/unidade de trabalho no } \\
\text { hospital... }\end{array}$ & \begin{tabular}{|l|} 
Discordo \\
totalmente
\end{tabular} & Discordo & $\begin{array}{l}\text { Nab Concordo } \\
\text { nem Discordo }\end{array}$ & Concordo & $\begin{array}{l}\text { Concordo } \\
\text { totalmente }\end{array}$ \\
\hline $\begin{array}{l}\text { 1. Nesta unidade, as pessoas apoliam umas ats } \\
\text { outras }\end{array}$ & $\square 1$ & $\square 2$ & ㅁ 3 & $\square 4$ & 口 5 \\
\hline $\begin{array}{l}\text { 2. Temos pessoal suficiente para dar conta da } \\
\text { carga de trabalho }\end{array}$ & $\square 1$ & 口 2 & ㅁ 3 & $\square 4$ & 口 5 \\
\hline $\begin{array}{l}\text { 3. Quando há muito trabalho a ser feito } \\
\text { rapidamente, trabalhamos juntos em equipe para } \\
\text { concluvilo devidamente }\end{array}$ & $\square 1$ & $\square 2$ & ㅁ 3 & $\square 4$ & 口 5 \\
\hline $\begin{array}{l}\text { 4. Nesta unidade, as pessoas se tratam com } \\
\text { respeito }\end{array}$ & $\square 1$ & ㄴ 2 & ㅁ 3 & $\square 4$ & 口 5 \\
\hline $\begin{array}{l}\text { 5. Os profissionais desta unidade trabalham mais } \\
\text { horas do que seria o melthor para o cuidado do } \\
\text { paciente }\end{array}$ & $\square 1$ & ㅁ 2 & ㅁ 3 & $\square 4$ & 口 5 \\
\hline
\end{tabular}




\section{SEÇÃO A: Sua área/unidado de trabalho (continuaçăo}

\begin{tabular}{|c|c|c|c|c|c|}
\hline $\begin{array}{l}\text { Pense na sua área/unidade de trabalho no } \\
\text { hospital... }\end{array}$ & \begin{tabular}{|l}
$\begin{array}{l}\text { Discordo } \\
\text { totalmente }\end{array}$ \\
\end{tabular} & \begin{tabular}{|l} 
Discordo \\
\end{tabular} & $\begin{array}{l}\text { Nảo Concordo } \\
\text { nem Discordo }\end{array}$ & Concordo & $\begin{array}{l}\text { Concordo } \\
\text { totalmente }\end{array}$ \\
\hline $\begin{array}{l}\text { 6. Estamos atvamente lazendo coisas para } \\
\text { melhorar a seguranca do paciente }\end{array}$ & $\square 1$ & $\square 2$ & $\square 3$ & $\square 4$ & ㄴ 5 \\
\hline $\begin{array}{l}\text { 7. Utilizamos mais profissionais temporários } \\
\text { herceirizados do que seria desejável para o } \\
\text { culdado do paciente }\end{array}$ & $\square 1$ & ㄴ 2 & ㄱ 3 & $\square 4$ & ㄷ 5 \\
\hline $\begin{array}{l}\text { 8. Os profissionais consideram que seus erros } \\
\text { podem ser usados contra eles }\end{array}$ & $\square 1$ & $\square 2$ & $\square 3$ & $\square 4$ & 5 \\
\hline $\begin{array}{l}\text { 9. Erros têm levado a mudancas positivas por } \\
\text { aqui }\end{array}$ & $\square 1$ & $\square 2$ & $\square 3$ & $\square 4$ & $\square 5$ \\
\hline $\begin{array}{l}\text { 10. É apenas por acaso, que erros mais graves } \\
\text { nâo acontecem por aqui }\end{array}$ & $\square 1$ & $\square 2$ & ㄱ 3 & $\square 4$ & 口 5 \\
\hline $\begin{array}{l}\text { 11. Quando uma área desta unidade fica } \\
\text { sobrecarregada, os outros profissionais desta } \\
\text { unidade ajudam. }\end{array}$ & $\square 1$ & $\square 2$ & $\square 3$ & $\square 4$ & $\square 5$ \\
\hline $\begin{array}{l}\text { 12. Quando um evento é notficicado, parece que o } \\
\text { foco recai sobre a pessoa e não sobre o problema }\end{array}$ & $\square 1$ & $\square 2$ & $\square 3$ & $\square 4$ & $\square 5$ \\
\hline $\begin{array}{l}\text { 13. Após implementarmos mudancas para } \\
\text { mellhorar a seguranca do paciente, avaliamos a } \\
\text { efotividade }\end{array}$ & $\square 1$ & $\square 2$ & $\square 3$ & $\square 4$ & $\square 5$ \\
\hline $\begin{array}{l}\text { 14. Nós trabalhamos em "situaça de crise", } \\
\text { tentando fazer muito e multo rapido }\end{array}$ & $\square 1$ & $\square 2$ & $\square 3$ & $\square 4$ & $\square 5$ \\
\hline $\begin{array}{l}\text { 15. A segurança do paciente jamais é } \\
\text { comprometida em funcâa de maior quantidade de } \\
\text { trabaliho a ser concluida }\end{array}$ & $\square 1$ & $\square 2$ & $\square 3$ & $\square 4$ & $\square 5$ \\
\hline $\begin{array}{l}\text { 16. Os profissionais se proocupam que sous erros } \\
\text { sejam registrados em suas fichas funcionais }\end{array}$ & $\square 1$ & $\square 2$ & $\square 3$ & $\square 4$ & $\square 5$ \\
\hline $\begin{array}{l}\begin{array}{l}\text { 17. Nesta unidade temos problemas de } \\
\text { segurança do paciente }\end{array} \\
\end{array}$ & $\square 1$ & $\square 2$ & $\square 3$ & $\square 4$ & $\square 5$ \\
\hline $\begin{array}{l}\text { 18. Os nossos procedimentos e sistemas sáo } \\
\text { adequados para prevenir a ocorerencia de erros }\end{array}$ & $\square 1$ & $\square 2$ & $\square 3$ & $\square 4$ & $\square 5$ \\
\hline
\end{tabular}

SECÃO B: O seu supervisorichote

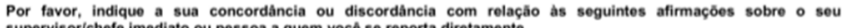

\begin{tabular}{|c|c|c|c|c|c|}
\hline $\begin{array}{l}\text { Pense na sua área/unidade de trabalho no } \\
\text { hospital ... }\end{array}$ & $\begin{array}{l}\text { Discordo } \\
\text { totalmente }\end{array}$ & Discordo & $\begin{array}{l}\text { Näo } \\
\text { Concordo } \\
\text { nem } \\
\text { Discordo }\end{array}$ & Concordo & $\begin{array}{l}\text { Concordo } \\
\text { totaimente }\end{array}$ \\
\hline $\begin{array}{l}\text { 1. O meu supervisorichefe elogia quando ve um } \\
\text { trabalho realizado de acordo com os } \\
\text { procedimentos estabelecidos de segurancha do } \\
\text { paciente }\end{array}$ & $\square 1$ & $\square 2$ & 口 3 & $\square 4$ & 口 5 \\
\hline $\begin{array}{l}\text { 2. O mou supervisorichefe reaimente leva em } \\
\text { consideraçao as sugestios dos profissionais para } \\
\text { a melhoria da seguranca do paciente }\end{array}$ & $\square 1$ & $\square 2$ & $\square 3$ & $\square 4$ & ㄷ 5 \\
\hline $\begin{array}{l}\text { 3. Sempre que a prossá aumenta, meu } \\
\text { supenisorichefe quer que trabalhemos mais } \\
\text { rapido, mesmo que isso signifique "pular etapas" }\end{array}$ & $\square 1$ & $\square 2$ & ㄱ 3 & $\square 4$ & 口 5 \\
\hline 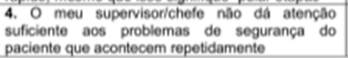 & 口 1 & ㄴ & ㄴ 3 & $\square 4$ & ㅁ 5 \\
\hline
\end{tabular}


SECÁO C: Comunicaç̃o

Com que frequência as situaçōes abaixo ocorrem na sua área/unidade de trabalho?

\begin{tabular}{|c|c|c|c|c|c|}
\hline $\begin{array}{l}\text { Pense na sua área/unidade de trabalho no } \\
\text { hospital ... }\end{array}$ & Nunca & Raramente & As vezes & $\begin{array}{l}\text { Quase } \\
\text { sempre }\end{array}$ & Sempre \\
\hline $\begin{array}{l}\text { 1. Nos recebemos informaçáo sobre mudancas } \\
\text { implementadas a partir dos relatórios de eventos }\end{array}$ & 口 1 & $\square 2$ & $\square 3$ & $\square 4$ & $\square 5$ \\
\hline $\begin{array}{l}\text { 2. Os profissionais têm liberdade para dizer ao ver } \\
\text { algo que pode afetar negativamente o cuidado do } \\
\text { paciente }\end{array}$ & 口 1 & ㅁ 2 & $\square 3$ & $\square 4$ & $\square 5$ \\
\hline $\begin{array}{l}\text { 3. Nos somos informados sobre os efrros que } \\
\text { acontecerm nosta unidado }\end{array}$ & 口 1 & $\square 2$ & $\square \mathbf{3}$ & $\square 4$ & $\square 5$ \\
\hline $\begin{array}{l}\text { 4. Os profissionais sentem-se â vontade para } \\
\text { questionar as decisóes ou açoes dos seus } \\
\text { superiores }\end{array}$ & 口 1 & $\square 2$ & $\square 3$ & $\square 4$ & 5 \\
\hline $\begin{array}{l}\text { 5. Nesta unidade, discutimos meios de prevenir } \\
\text { erros evitando que eles acontecam novamente }\end{array}$ & $\square 1$ & $\square 2$ & $\square 3$ & $\square 4$ & $\square 5$ \\
\hline $\begin{array}{l}\text { 6. Os profissionais têm receio de perguntar, } \\
\text { quando algo parece nåo estar certo }\end{array}$ & $\square 1$ & $\square 2$ & $\square 3$ & $\square 4$ & $\square 5$ \\
\hline
\end{tabular}

SECÃO Di Frequéncia de eventos relatados

Na sua área/unidade de trabalho no hospital, quando ocorrem os erros seguintes, com que frequência eles sảo

\begin{tabular}{|c|c|c|c|c|c|}
\hline & Nunca & Raramente & As Vezes & $\begin{array}{l}\text { Quase } \\
\text { sempre }\end{array}$ & Sempre \\
\hline $\begin{array}{l}\text { 1. Quando ocorre um erro, mas ele é percebidoe } \\
\text { corrigido antes de afetar o paciente com que } \\
\text { frequência ele é notificado? }\end{array}$ & $\square 1$ & ㄴ 2 & $\square 3$ & $\square 4$ & 口 5 \\
\hline $\begin{array}{l}\text { 2. Quando ocorre um erro, mas náo há risco do } \\
\text { dano ao paciente com que froquência elo ó } \\
\text { notificado? }\end{array}$ & 口 1 & ㄴ 2 & $\square 3$ & $\square 4$ & 口 5 \\
\hline $\begin{array}{l}\text { 3. Quando ocotre um erro, que poderia causar } \\
\text { danos ao paciente. mas nâo causa. com que } \\
\text { frequência ele é notficado? }\end{array}$ & 口 1 & $\square 2$ & $\square \mathbf{3}$ & $\square 4$ & $\square 5$ \\
\hline
\end{tabular}

SECÁO E: Nota da seguranca do paciente

Por favor, avalie a segurança do paciente na sua ârea/unidade de trabatho no hospitô. $\begin{array}{ccccc}\square & \square & \square & \square & \square \\ \begin{array}{c}A \\ \text { Excolente }\end{array} & \begin{array}{c}\square \\ \text { Muito boa }\end{array} & \begin{array}{c}C \\ \text { Regular }\end{array} & \begin{array}{c}\square \\ \text { Ruim }\end{array} & \begin{array}{c}\text { E } \\ \text { Muito Ruim }\end{array}\end{array}$

SECAAOF: O sou hospital

Por favor, indique a sua concordáncia ou discordância com as seguintos afirmaçóes sobre o seu hospital.

\begin{tabular}{|c|c|c|c|c|c|}
\hline Pense no seu hospital... & \begin{tabular}{|l|} 
Discordo \\
totalmente
\end{tabular} & Discordo & \begin{tabular}{|l|} 
Nao Concordo \\
nem Discordo
\end{tabular} & Concordo & $\begin{array}{l}\text { Concordo } \\
\text { totaimente }\end{array}$ \\
\hline $\begin{array}{l}\text { 1. A direçào do hospital propicia um clima de } \\
\text { trabalho que promove a seguranca do paciente }\end{array}$ & $\square 1$ & $\square 2$ & $\square 3$ & $\square 4$ & $\square 5$ \\
\hline $\begin{array}{l}\text { 2. As unidades do hospital nâo ostâ bem } \\
\text { coordenadas entre si }\end{array}$ & $\square 1$ & $\square 2$ & $\square 3$ & $\square 4$ & $\square 5$ \\
\hline $\begin{array}{l}\text { 3. O processo de cuidado do comprometido } \\
\text { quando um paciente o transterido de uma unidade } \\
\text { para outra }\end{array}$ & $\square 1$ & $\square 2$ & $\square 3$ & $\square 4$ & $\square 5$ \\
\hline $\begin{array}{l}\text { 4. Ha uma boa cooperacho entre as unidades do } \\
\text { hospital que precisam trabalhar em conjunto }\end{array}$ & $\square 1$ & $\square 2$ & $\square 3$ & $\square 4$ & $\square 5$ \\
\hline
\end{tabular}


SECĀO F: O sou hospital (continuaç̊)

\begin{tabular}{|c|c|c|c|c|c|}
\hline Pense no seu hospital... & \begin{tabular}{|l}
$\begin{array}{l}\text { Discordo } \\
\text { totalmente }\end{array}$ \\
\end{tabular} & Discordo & $\begin{array}{l}\text { Nāo Concordo } \\
\text { nem Discordo }\end{array}$ & Concordo & $\begin{array}{l}\text { Concordo } \\
\text { totalmente }\end{array}$ \\
\hline $\begin{array}{l}5 \text { E comum a perda de informaçōes importantes } \\
\text { sobre o cuidado do paciente durante as } \\
\text { mudanças de plantâo ou de turno }\end{array}$ & $\square 1$ & $\square 2$ & $\square 3$ & $\square 4$ & ㄷ 5 \\
\hline $\begin{array}{l}\text { 6. Muitas vezes } \dot{e} \text { desagraddável trabalhar com } \\
\text { profissionais de outras unidades do hospital }\end{array}$ & $\square 1$ & $\square 2$ & $\square 3$ & $\square 4$ & $\square 5$ \\
\hline $\begin{array}{l}\text { 7. Com frequência ocorrem problemas na troca de } \\
\text { informacóes entre as unidades do hospital }\end{array}$ & $\square 1$ & $\square 2$ & $\square 3$ & $\square 4$ & $\square 5$ \\
\hline $\begin{array}{l}\text { 8. As acbes da direçà do hospital demonstram } \\
\text { que a segurança do paciente e uma prioridade } \\
\text { principal }\end{array}$ & $\square 1$ & $\square 2$ & $\square 3$ & $\square 4$ & $\square 5$ \\
\hline $\begin{array}{l}\text { 9. A direçáo do hospital so parece interessada na } \\
\text { segurança do paciente quando ocorre algum } \\
\text { evento adverso }\end{array}$ & $\square 1$ & $\square 2$ & $\square 3$ & $\square 4$ & $\square 5$ \\
\hline $\begin{array}{l}\text { 10. As unidades do hospital trabalham bem em } \\
\text { conjunto para prostar o melhor cuidado aos } \\
\text { pacientes }\end{array}$ & $\square 1$ & $\square 2$ & $\square 3$ & $\square 4$ & 口 5 \\
\hline $\begin{array}{l}\text { 11. Neste hospital, as mudanças de plantâo ou de } \\
\text { turno sâo problemáticas para os pacientes }\end{array}$ & $\square 1$ & $\square 2$ & $\square 3$ & $\square 4$ & $\square 5$ \\
\hline
\end{tabular}

SECÃO G: Número de eventos notificados

Nos últimos 12 meses, quantas notificaçø̄es de eventos vocé preencheu e apresentou?

\section{SECĀOH: Seus comentários}

Por favor, sinta-so à vontade para escrever qualquer comentário sobre segurança de paciente, erro ou relato de Pentos no seu hospital. 


\section{APÊNDICE D - Dimensões HSOPSC Categorias profissionais}

\begin{tabular}{|c|c|c|c|c|c|}
\hline Dimensōes HSOPSC & Categoria Profissional & $\mathrm{N}$ & Média & $\begin{array}{l}\text { Desvio } \\
\text { Padrăo }\end{array}$ & $\mathrm{p}$ \\
\hline \multirow[t]{4}{*}{ HSOPS global } & Médico & 11 & 61,9 & 7,9 & 0,491 \\
\hline & Profissional de enfermagem & 63 & 63,3 & 11,2 & \\
\hline & Outros & 14 & 59,5 & 12,4 & \\
\hline & Total & 88 & 62,5 & 11,0 & \\
\hline \multirow[t]{4}{*}{ Trabalho em equipe dentro das unidades } & Médico & 11 & 72,2 & 7,1 & 0,408 \\
\hline & Profissional de enfermagem & 63 & 65,1 & 18,1 & \\
\hline & Outros & 14 & 67,6 & 12,5 & \\
\hline & Total & 88 & 66,4 & 16,4 & \\
\hline \multirow{4}{*}{$\begin{array}{l}\text { Açōes e expectativas sobre seu supervisor/chefe e } \\
\text { açōes promotoras da segurança do padiente }\end{array}$} & Médico & 11 & 72,2 & 12,0 & 0,084 \\
\hline & Profissional de enfermagem & 63 & 67,4 & 13,7 & \\
\hline & Outros & 14 & 77,1 & 21,9 & \\
\hline & Total & 88 & 69,5 & 15,3 & \\
\hline \multirow[t]{4}{*}{ Aprendizado organizacional - melhoria contínua } & Médico & 11 & 65,2 & 15,3 & 0,026 \\
\hline & Profissional de enfermagem & 63 & 72,0 & 14,5 & \\
\hline & Outros & 14 & 60,7 & 15,7 & \\
\hline & Total & 88 & 69,3 & 15,2 & \\
\hline \multirow[t]{4}{*}{ Apoio da gestão para segurança do paciente } & Médico & 11 & 60,6 & 15,9 & 0,919 \\
\hline & Profissional de enfermagem & 63 & 62,5 & 19,1 & \\
\hline & Outros & 14 & 60,7 & 17,7 & \\
\hline & Total & 88 & 62.0 & 18.3 & \\
\hline \multirow[t]{4}{*}{ Percepção geral da segurança do paciente } & Médico & 11 & 52,3 & 8,5 & 0,326 \\
\hline & Profissional de enfermagem & 63 & 53,1 & 11,2 & \\
\hline & Outros & 14 & 58,5 & 19,4 & \\
\hline & Total & 88 & 53.9 & 12,6 & \\
\hline \multirow{4}{*}{$\begin{array}{l}\text { Retroalimentaçăo da informaçăo e comunicaçăo sobre } \\
\text { erro }\end{array}$} & Médico & 11 & 62,1 & 13,1 & 0,313 \\
\hline & Profissional de enfermagem & 63 & 68,5 & 21,6 & \\
\hline & Outros & 14 & 60,7 & 15,8 & \\
\hline & Total & 88 & 66,5 & 20,0 & \\
\hline \multirow[t]{4}{*}{ Abertura da comunicaçāo } & Médico & 11 & 66,7 & 15,4 & 0,413 \\
\hline & Profissional de enfermagem & 63 & 62,6 & 18,9 & \\
\hline & Outros & 14 & 57,1 & 16,3 & \\
\hline & Total & 88 & 62,2 & 18,1 & \\
\hline \multirow[t]{4}{*}{ Frequência de notificaçāo de eventos } & Médico & 11 & 63,6 & 19,5 & 0,058 \\
\hline & Profissional de enfermagem & 63 & 75,4 & 26,4 & \\
\hline & Outros & 14 & 59,5 & 20,6 & \\
\hline & Total & 88 & 71,4 & 25,4 & \\
\hline \multirow[t]{4}{*}{ Trabalho em equipe entre as unidades } & Médico & 11 & 57,4 & 8,3 & 0,966 \\
\hline & Profissional de enfermagem & 63 & 58.5 & 19,3 & \\
\hline & Outros & 14 & 59.4 & 21,3 & \\
\hline & Total & 88 & 58,5 & 18,5 & \\
\hline \multirow[t]{4}{*}{ Adequação de profissionais } & Médico & 11 & 55,7 & 17,3 & 0,019 \\
\hline & Profissional de enfermagem & 63 & 61,9 & 12,6 & \\
\hline & Outros & 14 & 51.3 & 13,0 & \\
\hline & Total & 88 & 59,5 & 13,8 & \\
\hline \multirow[t]{4}{*}{ Passagem de plantão ou tumo/transferências } & Médico & 11 & 59,1 & 15,7 & 0,241 \\
\hline & Profissional de enfermagem & 63 & 59,1 & 19,2 & \\
\hline & Outros & 14 & 49,6 & 21,6 & \\
\hline & Total & 88 & 57,6 & 19,3 & \\
\hline \multirow[t]{4}{*}{ Resposta não punitiva aos erros } & Médico & 11 & 41,7 & 13,9 & 0,903 \\
\hline & Profissional de enfermagem & 63 & 43,9 & 18,9 & \\
\hline & Outros & 14 & 44,9 & 18,9 & \\
\hline & Total & 88 & 43,8 & 18.2 & \\
\hline \multirow[t]{4}{*}{ Grau de segurança do paciente } & Médico & 11 & 72,7 & 7,5 & 0,510 \\
\hline & Profissional de enfermagem & 62 & 75,8 & 13,6 & \\
\hline & Outros & 14 & 71,4 & 19,3 & \\
\hline & Total & 87 & 74,7 & 14,0 & \\
\hline \multirow[t]{4}{*}{ Frequeência de incidentes relatados } & Médico & 11 & 1,0 & 1,8 & 0,695 \\
\hline & Profissional de enfermagem & 52 & 4,8 & 16,8 & \\
\hline & Outros & 11 & 2,6 & 3,7 & \\
\hline & Total & 74 & 3,9 & 14,2 & \\
\hline
\end{tabular}




\section{ANEXO 1 - SAQ Short Form Validado Brasil}

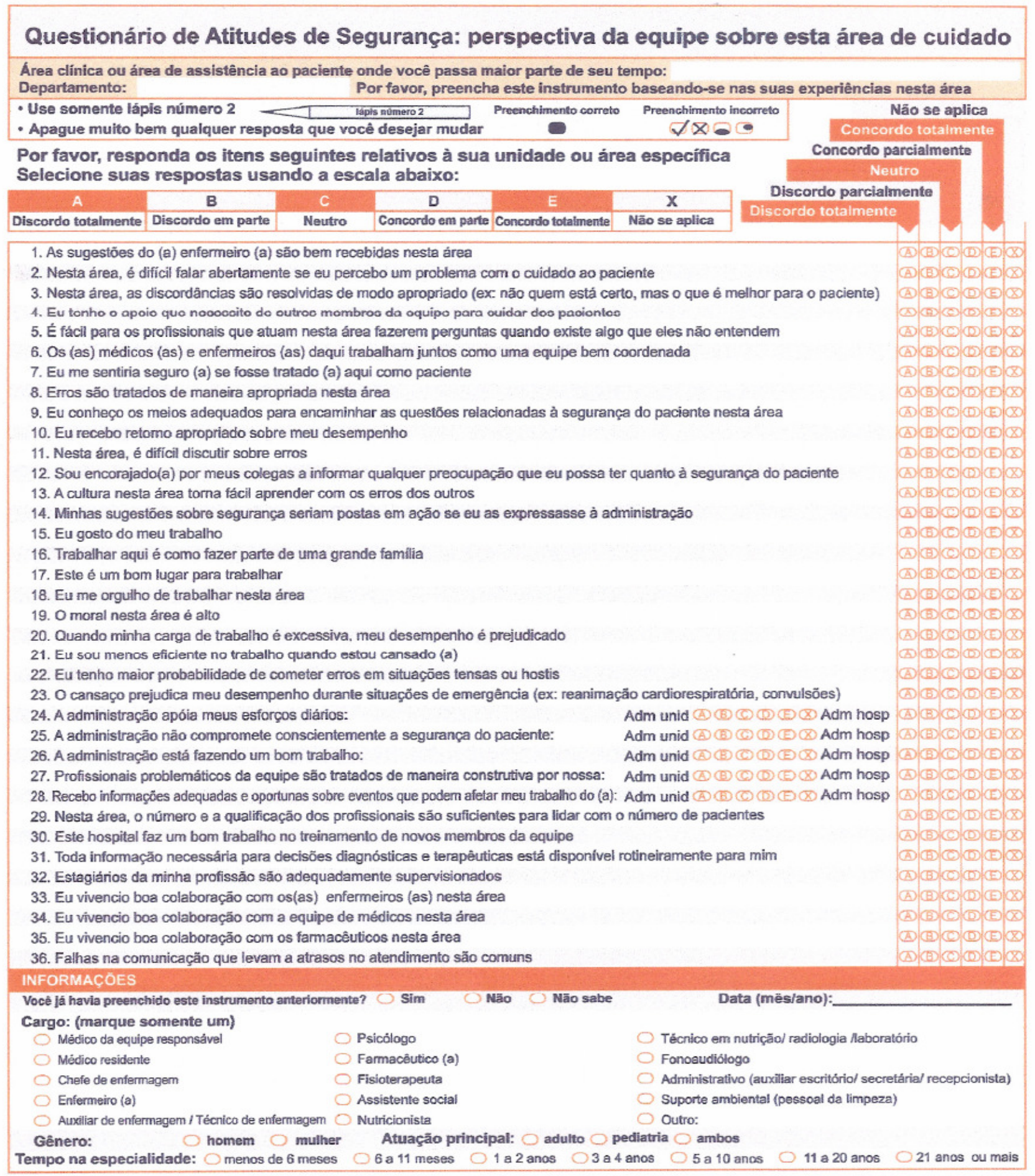

Obrigado por responder este instrumento. seu tempo e sua participação são muito importantes. 
ANEXO 2 - HSOPSC Validado Brasil

APENNICE G- VERSÃO FINAL
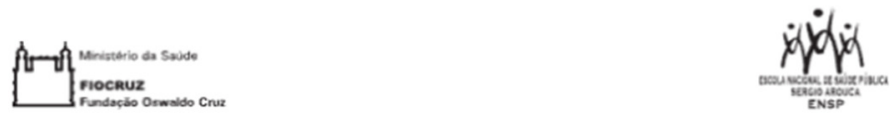

Pesquisa sobre Segurança do Paciente em Hospitais (HSOPSC)

Instruções

Esta pesquisa solicita sua opinião sobre segur ança do paciente, erros associados ao cuidado de saúde e relato de

areenchid.

Se não quiser responder uma questão, ou se uma pergunta não se aplicar a você, pode deixá-la em branco.

Um "Evento" é de bnido como qualquer tipo de erro, engano, falha, incidente,

"Sequranca do paciente" è definida como evitar e prevenir danos ou eventos

Seguranca do paciente E definida como evitar e prevenir danos ou eventos

SECĀO A: Sua árealunidade de trabalho

Nesta pesquisa, pense em sua "unidade" como a área de trabalho, departamento ou área clínica do hospital onde você passa a maior parte do seu tempo de trabalho ou na qual presta a maior parte dos seus serviços clinicos.

Qual é a sua principal área ou unidade neste hospital? Selecione UMA resposta.

\begin{tabular}{|l|l|}
\hline$\square$ a. Divers as unidades do hospitalNenhuma unidade especifica & $\square$ h. Psiquiatria/saúde mental \\
\hline$\square$ b. Clinica (não cirürgica) & $\square$ i. Reabiiitaçăa \\
\hline$\square$ c. Cirurgia & $\square$ j. Farmácia \\
\hline$\square$ d. Obs lettricia & $\square$ k. Laboratório \\
\hline$\square$ e. Pediatria & $\square$ i. Radiologia \\
\hline$\square$ f. Setor de Emergẻncia & $\square$ m. Anestesiologia \\
\hline$\square$ g. Unidade de terapia intensiva (qualquer tipo) & $\square$ n. Outra, por favor, especifique:................................ \\
\hline
\end{tabular}

Por favor, indique a sua concordảncia ou discordảncia com relação às seguintes afir maçōes sobre a sua área/unidade de

\begin{tabular}{|l|l|l|l|l|l|}
\hline $\begin{array}{l}\text { Pense na sua área/unidade de trabalho no } \\
\text { hospital... }\end{array}$ & $\begin{array}{l}\text { Discordo } \\
\text { totalmente }\end{array}$ & Discordo & $\begin{array}{l}\text { Năo Concordo } \\
\text { nem Discordo }\end{array}$ & Concordo & $\begin{array}{l}\text { Concordo } \\
\text { totalmente }\end{array}$ \\
\hline 1. Nesta unidade, as pessoas apóiam umas às & $\square 1$ & $\square 2$ & $\square 3$ & $\square 4$ & $\square 5$ \\
\hline
\end{tabular}




\begin{tabular}{|c|c|c|c|c|c|}
\hline outras & & & & & \\
\hline $\begin{array}{l}\text { Continuaçăo } \\
\text { Pense na sua área/unidade de trabalho no } \\
\text { hospital... }\end{array}$ & $\begin{array}{l}\text { Discordo } \\
\text { totalmente }\end{array}$ & Discordo & $\begin{array}{l}\text { Nảo Concordo } \\
\text { nem Discordo }\end{array}$ & Concordo & $\begin{array}{l}\text { Concordo } \\
\text { totalmente }\end{array}$ \\
\hline $\begin{array}{l}\text { 2. Temos profiss ionais (independente do vinculo } \\
\text { empregaticio) suficientes para dar conta da carga } \\
\text { de trabalho }\end{array}$ & $\square 1$ & $\square 2$ & $\square 3$ & $\square 4$ & $\square 5$ \\
\hline $\begin{array}{l}\text { 3. Quando há muito trabalho a ser feito } \\
\text { rapidamente, trabalhamos juntos em equipe para } \\
\text { concluito devidamente }\end{array}$ & $\square 1$ & $\square 2$ & $\square 3$ & $\square 4$ & $\square 5$ \\
\hline $\begin{array}{l}\text { 4. Nesta unidade, as pessoas se tratam com } \\
\text { respeito }\end{array}$ & ㅁ 1 & $\square 2$ & $\square 3$ & $\square 4$ & $\square 5$ \\
\hline $\begin{array}{l}\text { 5. Nesta unidade, os profissionais (independente } \\
\text { do vinculo empregaticio) trabalham mais horas do } \\
\text { que seria o melhor para o cuidado do paciente }\end{array}$ & $\square 1$ & $\square 2$ & $\square 3$ & $\square 4$ & $\square 5$ \\
\hline $\begin{array}{l}\text { 6. Estamos ativamente fazendo coisas para } \\
\text { mehorar a segurança do paciente }\end{array}$ & 口 1 & $\square 2$ & $\square 3$ & $\square 4$ & 口 5 \\
\hline $\begin{array}{l}\text { 7.Utiinzamos mais profis sionais temporários } \\
\text { therceirizados do que seria desejével para } \\
\text { cuidado do paciente }\end{array}$ & $\square 1$ & $\square 2$ & $\square 3$ & $\square 4$ & $\square 5$ \\
\hline $\begin{array}{l}\text { 8. Os profissionais consideram que seus erros, } \\
\text { enganos ou falhas podem ser usados contra eles }\end{array}$ & $\square 1$ & $\square 2$ & $\square 3$ & $\square 4$ & $\square 5$ \\
\hline $\begin{array}{l}\text { 9. Erros, enganos ou falhas têm levado a } \\
\text { mudanças positivas por aqui }\end{array}$ & $\square 1$ & $\square 2$ & $\square 3$ & $\square 4$ & $\square 5$ \\
\hline $\begin{array}{l}\text { 10. É apenas por acaso, que erros, enganos ou } \\
\text { falhas mais graves nâo acontecem por aqui }\end{array}$ & $\square 1$ & $\square 2$ & $\square 3$ & $\square 4$ & 口 5 \\
\hline $\begin{array}{l}\text { 11. Quando uma área/unidade de trabaltho fica } \\
\text { sobrecarregada, as outras ajudam }\end{array}$ & $\square 1$ & $\square 2$ & $\square 3$ & $\square 4$ & 口 5 \\
\hline $\begin{array}{l}\text { 12. Quando um evento é relatado, parece que o } \\
\text { foco recai sobre a pessoae nấ sobre o problema }\end{array}$ & $\square 1$ & $\square 2$ & $\square 3$ & $\square 4$ & $\square 5$ \\
\hline $\begin{array}{l}\text { 13. Após implementarmos mudancas para } \\
\text { melhorar a segurança do paciente, avaliamos a } \\
\text { efetividade }\end{array}$ & ㅁ 1 & $\square 2$ & $\square 3$ & $\square 4$ & $\square 5$ \\
\hline $\begin{array}{l}14 . \quad \text { Nós trabalhamos em "situação de crise", } \\
\text { tentando fazer muito e muito rápido }\end{array}$ & ㅁ 1 & $\square 2$ & $\square 3$ & $\square 4$ & $\square 5$ \\
\hline $\begin{array}{l}\text { 15. A segurança do paciente jamais í } \\
\text { comprometida em funçăo de maior quantidade de } \\
\text { trabalho a ser concluida }\end{array}$ & $\square 1$ & $\square 2$ & $\square 3$ & $\square 4$ & 口 5 \\
\hline $\begin{array}{l}\text { 16. Os profissionais (independente do vinculo } \\
\text { empregaticio) se preocupam que seus erros, } \\
\text { enganos ou falhas sejam registrados em suas } \\
\text { fichas funcionais }\end{array}$ & $\square 1$ & $\square 2$ & $\square 3$ & $\square 4$ & $\square 5$ \\
\hline $\begin{array}{l}\text { 17. Nesta unidade temos problemas de } \\
\text { segurança do paciente }\end{array}$ & $\square 1$ & $\square 2$ & $\square 3$ & $\square 4$ & $\square 5$ \\
\hline
\end{tabular}




\begin{tabular}{|l|l|l|l|l|l|}
\hline $\begin{array}{l}\text { 18. Os nossos procedimentos e sistemas são } \\
\text { adequados para prevenir a ocorrência de erros }\end{array}$ & $\square 1$ & $\square 2$ & $\square 3$ & $\square 4$ & $\square 5$ \\
\hline
\end{tabular}

SECĀOB: O seu supervisor/chefe

Por favor, indique a sua concordảncia ou discordảncia com relação às seguintes afirmaçōes sobre o seu supervisor/chefe imediato ou pessoa a quem você se reporta diretamente.

\begin{tabular}{|c|c|c|c|c|c|}
\hline Pense na sua área/unidade de trabalho no hospital .. & $\begin{array}{c}\text { Discordo } \\
\text { totalmente }\end{array}$ & Discordo & $\begin{array}{l}\text { Não Concordo } \\
\text { nem Discordo }\end{array}$ & Concordo & $\begin{array}{l}\text { Concordo } \\
\text { totalmente }\end{array}$ \\
\hline $\begin{array}{l}\text { 1. O meu supervis orichefe elogia quando vê um trabalho } \\
\text { realizado de acordo com os procedimentos } \\
\text { estabelecidos de segurança do paciente }\end{array}$ & $\square 1$ & $\square 2$ & $\square 3$ & $\square 4$ & $\square 5$ \\
\hline $\begin{array}{l}\text { 2. O meu supervisorkhefe realmente leva em } \\
\text { consideraçāo as sugestōes dos profissionais } \\
\text { (independente do vinculo empregaticio) para a melhoria } \\
\text { da segurança do paciente }\end{array}$ & $\square 1$ & $\square 2$ & $\square 3$ & $\square 4$ & $\square 5$ \\
\hline $\begin{array}{l}\text { 3. Sempre que a pressão aumenta, meu } \\
\text { supervisor/khefe quer que trabalhemos mais rapido, } \\
\text { mesmo que isso signifique "pular etapas" }\end{array}$ & $\square 1$ & $\square 2$ & $\square 3$ & $\square 4$ & $\square 5$ \\
\hline $\begin{array}{l}\text { 4. O meu supervisorichefe náo dá atençăo suf ciente aos } \\
\text { problemas de segurança do pacienta que acontecem } \\
\text { repefidamente }\end{array}$ & $\square 1$ & $\square 2$ & $\square 3$ & $\square 4$ & $\square 5$ \\
\hline
\end{tabular}

SECGĀOC: Comunicaçāo

Com que frequência as situaçōes abaixo ocorrem na sua área/unidade de trabalho?

\begin{tabular}{|c|c|c|c|c|c|}
\hline $\begin{array}{l}\text { Pense na sua área/unidade de trabalho no } \\
\text { hospital... }\end{array}$ & Nunca & Raramente & As Vezes & $\begin{array}{l}\text { Quase } \\
\text { sempre }\end{array}$ & Sempre \\
\hline $\begin{array}{l}\text { 1. Nós recebemos informação sobre mudanças } \\
\text { implementadas a partir dos relatótios de eventos }\end{array}$ & ㄴ 1 & $\square 2$ & $\square 3$ & $\square 4$ & $\square 5$ \\
\hline $\begin{array}{l}\text { 2. Os profissionais (independente do vinculo } \\
\text { empregaticio) têm liberdade para dizer ao ver } \\
\text { algo que pode afetar negativamente o cuidado do } \\
\text { paciente }\end{array}$ & ㅁ 1 & $\square 2$ & $\square 3$ & $\square 4$ & 5 \\
\hline $\begin{array}{l}\text { 3. Nós somos informados sobre os erros que } \\
\text { acontecem nesta unidade }\end{array}$ & ㄴ & $\square 2$ & $\square 3$ & $\square 4$ & $\square 5$ \\
\hline $\begin{array}{l}\text { 4. Os profissionais (independente do vinculo } \\
\text { empregaticio) sentem-se à vontade para } \\
\text { questionar as decisōes ou aços dos seus } \\
\text { superiores }\end{array}$ & ㅁ 1 & $\square 2$ & $\square 3$ & $\square 4$ & ㄷ 5 \\
\hline $\begin{array}{l}\text { 5. Nesta unidade, discutimos meios de prevenir } \\
\text { erros eviando que eles acontecam novamente }\end{array}$ & ㅁ 1 & $\square 2$ & $\square 3$ & $\square 4$ & $\square 5$ \\
\hline $\begin{array}{l}\text { 6. Os profissionais (independente do vinculo } \\
\text { empregatício) têm receio de perguntar, quando }\end{array}$ & 口 1 & $\square 2$ & $\square 3$ & $\square 4$ & 口 5 \\
\hline
\end{tabular}




\begin{tabular}{|l|l|l|l|l|l|}
\hline algo parece nåo estar certo & & & & & \\
\hline
\end{tabular}

SEÇÁO D: F requência de eventos relatados

Na sua área/unidade de trabalho no hospital, quando ocorrem os erros, enganos ou falhas seguintes, com que frequência

\begin{tabular}{|l|l|l|l|l|l|}
\hline Pense na sua área/unidade no hospital & Nunca & Raramente & As Vezes & $\begin{array}{c}\text { Quase } \\
\text { sempre }\end{array}$ & Sempre \\
\hline $\begin{array}{l}\text { 1. Quando ocorre erro, engano ou falha, mas ele } \\
\text { percebido e corrigido antes de afetar o } \\
\text { paciente. com que frequência ele è relatado? }\end{array}$ & $\square 1$ & $\square 2$ & $\square 3$ & $\square 4$ & $\square 5$ \\
\hline $\begin{array}{l}\text { 2. Quando ocorre erro, engano ou talha, mas năo } \\
\text { há risco de dano ao paciente. com que } \\
\text { frequência ele è relatado? }\end{array}$ & $\square 1$ & $\square 2$ & $\square 3$ & $\square 4$ & $\square 5$ \\
\hline $\begin{array}{l}\text { 3. Quando ocorre erro, engano ou falha que } \\
\text { poderia causar danos ao paciente. mas nâo } \\
\text { causa, com que frequência ele é relatado? }\end{array}$ & $\square 1$ & $\square 2$ & $\square 3$ & $\square 4$ & $\square 5$ \\
\hline
\end{tabular}

SEÇĀOE: Nota da segurança do paciente

Por favor, avalie a segurança do paciente na sua área/unidade de trabalho no hospital.

$$
\begin{array}{ccccc}
\square & \square & \square & \square & \square \\
\begin{array}{c}
\text { A } \\
\text { Excelente }
\end{array} & \begin{array}{c}
\square \\
\text { Muito boa }
\end{array} & \begin{array}{c}
\mathrm{C} \\
\text { Regular }
\end{array} & \begin{array}{c}
D \\
\text { Ruim }
\end{array} & \begin{array}{c}
\text { E } \\
\text { Muito Ruim }
\end{array}
\end{array}
$$

SEÇÃO F: O seu hospital

Por favor, indique a sua concordảncia ou discordảncia com as seguintes afirmações sobre o seu hospital.

\begin{tabular}{|c|c|c|c|c|c|}
\hline Pense no seu hospital... & $\begin{array}{l}\text { Discordo } \\
\text { totalmente }\end{array}$ & \begin{tabular}{|l|} 
Discardo \\
\end{tabular} & $\begin{array}{l}\text { Nāo Concordo } \\
\text { nem Discordo }\end{array}$ & Concordo & $\begin{array}{l}\text { Concordo } \\
\text { totalmente }\end{array}$ \\
\hline $\begin{array}{l}\text { 1. A direçăo do hospital propicia um clima de } \\
\text { trabalho que promove a segurança do paciente }\end{array}$ & $\square 1$ & $\square 2$ & $\square 3$ & $\square 4$ & $\square 5$ \\
\hline $\begin{array}{l}\text { 2. As unidades do hospital năo estão bem } \\
\text { coordenadas entre si }\end{array}$ & $\square 1$ & $\square 2$ & $\square 3$ & $\square 4$ & $\square 5$ \\
\hline $\begin{array}{l}\text { 3. O processo de cuidado é compromefido } \\
\text { quando um paciente é transferido de uma unidade } \\
\text { para outra }\end{array}$ & $\square 1$ & $\square 2$ & $\square 3$ & $\square 4$ & $\square 5$ \\
\hline $\begin{array}{l}\text { 4. Há uma boa cooperaçao entre as unidades do } \\
\text { hospital que precisam trabalhar em conjunto }\end{array}$ & $\square 1$ & $\square 2$ & $\square 3$ & $\square 4$ & $\square 5$ \\
\hline $\begin{array}{l}5 \text { É comum a perda de informaçōes importantes } \\
\text { sobre o cuidado do paciente durante as } \\
\text { mudanças de plantâo ou de turmo }\end{array}$ & $\square 1$ & $\square 2$ & $\square 3$ & $\square 4$ & $\square 5$ \\
\hline $\begin{array}{l}\text { 6. Muitas vezes é desagradável trabalhar com } \\
\text { profissionais (independente do vinculo }\end{array}$ & $\square 1$ & $\square 2$ & $\square 3$ & $\square 4$ & $\square 5$ \\
\hline
\end{tabular}




\begin{tabular}{|l|l|l|l|l|l|}
\hline empregaticio) de outras unidades do hospital & & & & & \\
\hline
\end{tabular}

\begin{tabular}{|c|c|c|c|c|c|}
\hline $\begin{array}{l}\text { Continuaçăo } \\
\text { Pense no seu hospital... }\end{array}$ & $\begin{array}{l}\text { Discordo } \\
\text { totalmento }\end{array}$ & Discordo & $\begin{array}{l}\text { Năo Concordo } \\
\text { nem Discordo }\end{array}$ & Concordo & $\begin{array}{l}\text { Concordo } \\
\text { totalmente }\end{array}$ \\
\hline $\begin{array}{l}\text { 7. Com frequência oc orrem problemas na troca de } \\
\text { informaçōes entre as unidades do hospital }\end{array}$ & $\square 1$ & $\square 2$ & $\square 3$ & $\square 4$ & $\square 5$ \\
\hline $\begin{array}{l}\text { 8. As açäes da direção do hospital demonstram } \\
\text { que a segurança do paciente é a principal } \\
\text { prioridade }\end{array}$ & 口 1 & $\square 2$ & $\square 3$ & $\square 4$ & ㄷ 5 \\
\hline $\begin{array}{l}\text { 9. A direção do hospital só parece interessada na } \\
\text { segurança do paciente quando ocorre algum } \\
\text { evento adverso }\end{array}$ & ㄴ 1 & $\square 2$ & ㄱ 3 & $\square 4$ & 口 5 \\
\hline $\begin{array}{l}\text { 10. As unidades do hospital trabaham bem em } \\
\text { conjunto para prestar o melhor cuidado aos } \\
\text { pacientes }\end{array}$ & ㄱ 1 & $\square 2$ & 口 3 & $\square 4$ & 口 5 \\
\hline $\begin{array}{l}\text { 11. Neste hospital, as mudanças de plantão ou de } \\
\text { turno são problemáticas para os pacientes }\end{array}$ & ㄴ 1 & $\square 2$ & ㄱ 3 & $\square 4$ & 5 \\
\hline
\end{tabular}

SECCĀO G: Número de eventos relatados

Nos últimos 12 meses, quantos relatórios de eventos vocé preencheu e apresentou?
$\square$ a. Nenhum relatório
$\square$ d. 6 a 10 relatários
$\square$ b. 1 a 2 relatorios
$\square$ e.11 a 20 relatórios
$\square$ c. 3 a 5 relatónios
$\square$ f. 21 relabrios ou mais

SECCĀOH: Informaçōes gerais

As informaçōes a seguir contribuirão para a análise dos resultados da pesquisa.

1. Há quanto tempo vocẻ trabalha ne ste hospital?
$\square$ a. Menos de 1 ano
$\square$ d. 11 a 15 anos
$\square$ b. 1 a 5 anos
$\square$ e. 16 a 20 anos
ㄷ. 6 a 10 anos

2. Há quanto tempo você trabalha na sua atual área/unidade do hospital?
$\square$ a. Menos de 1 ano
$\square$ d. 11 a 15 anos
$\square$ b. 1 a 5 anos
๑e. 16 a 20 anos
$\square$ c. 6 a 10 anos
$\square$ f. 21 anos ou mais

3. Normalmente, quantas horas por semana vocẻ trabalha neste hos pital? 


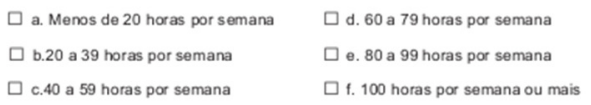

4. Qual é o seu cargolfunção neste hos pital? Selecione UMA resposta que melhor descreva a sua posiçăo pessoal.

$\square$ a. Médico do Corpo Clinico/Médico Assistente

$\square$ b. Médico Residente/ Médico em Treinamento

$\square$ c. Enfermeiro

$\square$ d. Técnico de Enfermagem

$\square$ e. Auxiliar de Enfermagem

$\square$ f. Farmacéutico/Bioquímico/Biólogo/Biomédico

$\square$ g. Odontólogo

$\square$ h. Nutricionista

$\square$ i. Fisioterapeuta, Terapeuta Respiratónio, Terapeuta Ocupacional ou Fonoaudiólogo

$\square$ j. Psióólogo

$\square$ k. Assistente Social

ㄴ. Técnico (por exemplo, ECG, Laboratório, Radiologia, Farmácia)

$\square$ m. Adminis traçăo/Direçăo

$\square$ n. Auxiliar Administrativo/Secretário

$\square$ o. Outro, es pecifique

5. No seu cargo/funçẫo, em geral você tem interação ou contato direto com os pacientes?
a. SIM, em geral tentro interação ou contato dreto com os pacientes.
$\square$ b. NĀO, em geral NĀO tenho interação ou contab direto com os pacientes.

6. Há quanto tempo você trabalha na sua especialidade ou profissão atual? _____ anos

7. Qual o seu grau de instrução:

$\square$ a. Primeiro grau (Ensino Básico) Incompleto $\square$ e. Ensino Superior Incompleto 
$\square$ b. Primeiro grau (Ensino Básico) Completo

$\square$ f. Ensino Superior Completo

$\square$ c. Segundo grau (Ensino Médio) Incompleb

$\square$ g. Pós-graduaçăo (Nivel Especializaçẳ)

$\square$ d. Segundo grau (Ensino Médio) Completo

h. Pós-graduaçăo (Nivel Mestrado ou Doutorado)

8. Qual a sua idade? ___ anos

9. Indique o seu sexo:

$\square$ a. Feminino $\square$ b. Masculino

SEÇĀOI: Seus comentários

Por favor, sinta-se à vontade para escrever qualquer comentário sobre segurança de paciente, erro ou relato de eventos no seu hospital. (Por favor, utilize o verso)

Obrigado por você completar este questionário e participar desta pesquisa. 


\section{ANEXO 3 - CAAE Parecer consubstanciado CEP UNICAMP}

FACULDADE DE CIENCIAS

MEDICAS - UNICAMP

(CAMPUS CAMPINAS)

\section{PARECER CONSUBSTANCIADO DO CEP}

Elaborado pela Instituição Coparticipante

\section{DADOS DO PROJETO DE PESQUISA}

Título da Pesquisa: Cultura Organizacional para Segurança do Paciente em Terapia Intensiva: comparação (HSOPSC) e Safety Attidudes Questionnaire (SAQ)

Pesquisador: thaiana helena roma santiago

Área Temática:

Versão: 1

CAAE: 24166713.0 .3001 .5404

Instituição Proponente: Escola de Enfermagem da Universidade de São Paulo - EEUSP

Patrocinador Principal: Financiamento Próprio

\section{DADOS DO PARECER}

Número do Parecer: 604.961-0

Data da Relatoria: 25/02/2014

Apresentação do Projeto:

O termo segurança do paciente vem sendo frequentemente utilizado nos dias atuais e é bastante recorrente nas discussões sobre qualidade nos serviços de saúde. Sua definição tem focado principalmente os danos decorrentes da assistência prestada. O impacto dos desfechos assistenciais é refletido tanto na esfera pessoal, por pacientes e familiares, quanto no âmbito coletivo; oneram o sistema de saúde, elevam o tempo de internação e

causam prejuizos sociais, de modo geral. Intervir no funcionamento das organizações e, portanto, na cultura organizacional de serviços de saúde,tornando-os mais seguros para os pacientes e trabalhadores demonstra-se como uma tarefa bastante complexa, que envolve esforços da sociedade, do governo,dos profissionais de saúde e engajamento dos pacientes.

Objetivo da Pesquisa:

Objetivo Primário:

Avaliar a percepção dos profissionais de saúde sobre a cultura de segurança do paciente em unidades de terapia intensiva em hospital de ensino do município de Sumaré, estado de São Paulo, por meio do Hospital Survey on Patient Safety Culture (HSOPSC) e Safety Attidudes Questionnaire.

Objetivo Secundário:

Objetivos especificos

Endereço: Rua Tessália Vieira de Camargo, 126

UF: SP Municipio: CAMPINAS

Telefone: (19)3521-8936 Fax: (19)3521-7187 E-mail: cep@fcm.unicamp.br 


\section{FACULDADE DE CIENCIAS \\ MEDICAS - UNICAMP \\ (CAMPUS CAMPINAS)}

Confnuaçấo do Parecer: 604.961-0

- Identificar a percepção de cultura de segurança dos profissionais que atuam em unidades de terapia intensiva adulto, pediátrica e neonatal.

- Identificar a percepção sobre atitudes de segurança dos profissionais que atuam em unidades de terapia intensiva adulto, pediátrica e neonatal.

- Verificar a correlação entre cultura de segurança do paciente e atitudes de segurança

Avaliação dos Riscos e Benefícios:

Riscos:

A pesquisa não oferece riscos previsiveis, mas é possivel algum desconforto ao responder aos questionários.

Benefícios:

Benefícios: não haverá benefícios diretos aos participantes. Academicamente, o estudo busca compreender a relação entre clima de segurança dos pacientes e as atitudes de segurança dos funcionários para melhor direcionar ações de segurança do paciente.

Comentários e Considerações sobre a Pesquisa:

Pesquisa relevante, que contribuirá para avaliar a segurança do paciente. $O$ projeto está bem descrito, metodologia adequada e objetivos bem definidos.

Considerações sobre os Termos de apresentação obrigatória:

Foram apresentados o projeto original, o formulário gerado pela Plataforma Brasil, Autorização do Hospital Estadual de Sumaré e do superintendente do hospital de Clínicas da Unicamp (locais onde se realizará a coleta de dados), Folha de Rosto devidamente assinada e TCLE.

Recomendações:

Quanto aos Riscos e desconfortos com a pesquisa: Em vez de informar -não há riscos- corrigir para -não há riscos previsíveis-.

TCLE deve contemplar os nomes das instituições $\infty$-participantes.

Conclusões ou Pendências e Lista de Inadequações:

Projeto aprovado com recomendações, cujo atendimento deverá ser feito mediante apresentação de emenda ao projeto original (Correção dos TCLEs).

Situação do Parecer:

Aprovado

Necessita A preciação da CONEP:

Não

Endereço: Rua Tessália Vieira de Camargo, 126

Bairro: Barāo Gerald

UF: SP Municipio: CAMPINAS

Telefone: (19)3521-8936 Fax: (19)3521-7187 E-mail: cep@fcm.unicamp.br 


\section{FACULDADE DE CIENCIAS \\ MEDICAS - UNICAMP \\ (CAMPUS CAMPINAS)}

Confnuaçấo do Parecer: 604.961-0

Considerações Finais a critério do CEP:

Aprovado em reunião do colegiado dia 25/02/2014.

CAMPINAS, 12 de Abril de 2014

Assinador por:

Fátima Aparecida Bottcher Luiz

(Coordenador)

Este parecer reemitido substitui o parecer número 604961 gerado na data 06/03/2014 17:48:01, onde o número CAAE foi alterado de 24166713.0.0000.5392 para 24166713.0.3001.5404.

Endereço: Rua Tessália Vieira de Camargo, 126

Bairro: Barāo Geraldo

UF: SP Municipio: CAMPINAS

Telefone: (19)3521-8936

Fax: (19)3521-7187

E-mail: cep@fcm.unicamp.br 


\section{ANEXO 4 - CAAE Parecer CEP USP}

\section{EE . एSTP ESCOLA DE ENFERMAGEM DA

1 \\ UNIVERSIDADE DE SÃO \\ PAULO - EEUSP}

\section{PARECER CONSUBSTANCIADO DO CEP}

\section{DADOS DO PROJETO DE PESQUISA}

Título da Pesquisa: Cultura Organizacional para Segurança do Paciente em Terapia Intensiva: comparação de dois instrumentos Hospital Survey on Patient Safety Culture (HSOPSC) e Safety Attidudes Questionnaire (SAQ)

Pesquisador: thaiana helena roma santiago

Área Temática:

Versão: 2

CAAE: 24166713.0 .0000 .5392

Instituição Proponente: Escola de Enfermagem da Universidade de São Paulo - EEUSP

Patrocinador Principal: Financiamento Próprio

\section{DADOS DO PARECER}

Número do Parecer: 612.365

Data da Relatoria: 08/04/2014

Apresentação do Projeto:

Este projeto foi aprovado pelo CEP da EEUSP em 12/12/2013. Trata-se de emenda, incluida pela pesquisadora por solicitação do CEP da Faculdade de Ciências Médicas da UNICAMP, instituição coparticipante da pesquisa.

Objetivo da Pesquisa:

O objetivo geral da pesquisa é avaliar a percepc $\_a_{i}$ o dos profissionais de sau $¿$ de sobre a cultura de seguranc $_{i}$ a do paciente em unidades de terapia intensiva em hospital de ensino do munici $i p i o$ de Sumare $i$, estado de Sa ¿o Paulo, por meio do Hospital Survey on Patient Safety Culture (HSOPSC) e Safety Attidudes Questionnaire.

Avaliação dos Riscos e Benefícios:

os riscos na coleta de dados são mínimos, trata-se de entrevistas com enfermeiros hospitalares, foram contornados por prever autorização da instituição e consentimento dos sujeitos de pesquisa.

Comentários e Considerações sobre a Pesquisa:

O CEP da instituição co-participante fezas seguintes solicitaçöes: 1) em vez de informar que na¿०

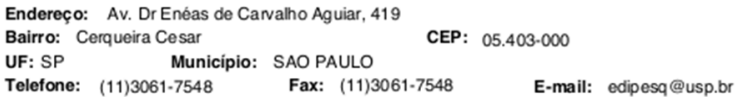




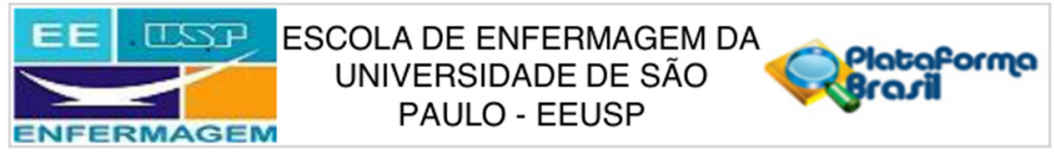

Contnuą̧ăo do Parecer: 612.365

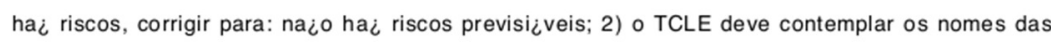
instituicioies co-participantes.

Considerações sobre os Termos de apresentação obrigatória:

Este CEP avaliou anteriormente e aprovou o projeto, em todas as suas partes.

Recomendações:

não há.

Conclusões ou Pendências e Lista de Inadequações:

A pesquisadora incluiu emenda ao projeto, para que o CEP da instituição co-participante pudesse ter acesso e dar vistas às respostas das pendências sinalizadas.

Situação do Parecer:

Aprovado

Necessita A preciação da CONEP:

Não

Considerações Finais a critério do CEP:

Esta aprovação não substitui a autorização da instituição co-participante, antes do início da coleta de dados. Os resultados da pesquisa deverão ser registrados na Plataforma Brasil.

SAO PAULO, 10 de Abril de 2014

Assinador por:

Celia Maria Sivalli Campos

(Coordenador)

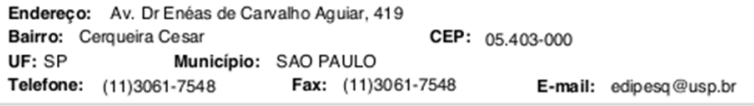




\section{ANEXO 5 - Carta de autorização hospital}
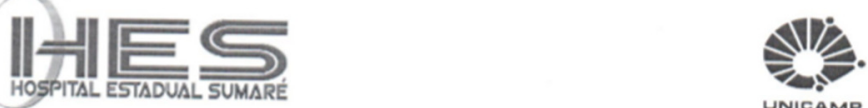

DECLARAÇÃO

Pelo presente instrumento declaramos que foi aprovada pela Comissão de Ensino e Pesquisa do Hospital Estadual Sumaré o desenvolvimento do projeto mestrado intitulado "Cultura Organizacional para segurança do paciente em terapia intensiva: comparação de dois instrumentos Hospital Survey on Patient Safety Culture e Safety Attitudes Questionnaire ", sob responsabilidade de THAIANA HELENA ROMA SANTIAGO, porém sendo autorizado o inicio da pesquisa nesta instituição a partir da aprovação do Comitê de Ética em Pesquisa da UNICAMP.

Na oportunidade, renovamos nossos laços de elevada estima e consideração.

Sumaré, 26 de novembro de 2013.

Cordialmente,

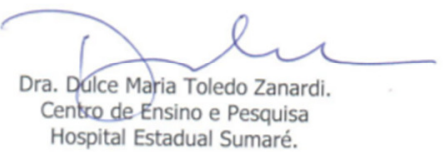

